\title{
Where States Lie: A Historical Sociological Investigation into the Art of Cover Storying in a Secret Cold War Intelligence Operation
}

\author{
by
}

\author{
Alexander Luscombe
}

A thesis submitted to the Faculty of Graduate and Postdoctoral Affairs in partial fulfillment of the requirements for the degree of

Master of Arts

in

Sociology

Carleton University

Ottawa, Ontario

(C) 2015, Alexander J. Luscombe 


\begin{abstract}
Secrecy and deception are integral components of ruling, yet remain under-researched and under-theorized sociologically. This thesis draws on two complimentary literatures with the goal of advancing a conceptual framework and agenda for the study of secrecy and deception in government: governmentality studies and dramaturgy. The usefulness of this framework is demonstrated by analyzing the cover storying practices of military officials in Cobra Mist, a secret radar intelligence station built in England in the late 1960s. Based on a theoretical understanding of cover storying, six interrelated themes are developed and substantiated empirically: i) scripting and rehearsing a suitable cover narrative; ii) going public via press release; iii) backstage struggles over cover storying and information leaks; iv) strategies for managing information leakage; v) secret site closure; and vi) the production of mystery. In conclusion this thesis reflects on the methodological limitations of research on government secrecy and offers four possible avenues for future research on cover storying.
\end{abstract}




\section{Acknowledgements}

To all those who have made an immense difference in my thinking over the years: Dr. Bruce Curtis, Dr. Aaron Doyle, Jacob Forrest, Dr. Daniel Fridman, Dr. Neil Gerlach, Michael-Anthony Lutfy, Dr. Janet Siltanen, Dr. Justin Piché, Jordan Todd, Jordon Tomblin, Dr. Kevin Walby, Dr. John Walsh, and Dr. William Walters. This project would never have been possible in the absence of your sharp wits, criticisms, feedback, and support. Special thanks to my longtime friend, colleague, and co-author, Kevin Walby for voluntarily suffering through a lengthy, half-baked version of my thesis sometime in early May. Daniel Fridman taught me to always second guess my conclusions and to ask myself: 'but what is this really a case of?' William Walters (supervisor) and Neil Gerlach (second reader) provided me with some of the hardest feedback I've ever received on anything I've written.

To William, my supervisor and mentor: I cannot even begin to express my level of gratitude for everything you have done for me. I can still remember the day you invited me to help you think through the political sociology of secrecy during my visit to Ottawa in July 2013. Were it not for you, secrecy and Cobra Mist would have never entered upon my intellectual radar. Nor would I have had to the opportunity to spend 10 days in England in July 2014, fearfully driving a standard transmission rental car on the left side of the road. I can only hope that what I have come up with here leaves a positive impression upon your own thinking on the subject.

An earlier version of this thesis was presented on the Society \& Security panel at the 2015 Canadian Sociological Association annual meeting held at the University of Ottawa. I am grateful to the organizers of this panel, Dr. Philip Boyle and Shannon Speed, for commenting on a condensed version which they were kind enough to read.

Mom, Dad, Robyn, Molly, the guinea pig that recently passed, and my loving partner and best friend, Melissa: it goes without saying that I could never have done any of this without your unwavering support for 'whatever it is he does.' The past two years have involved far more than completing a Master's. From scuba diving in the Pacific to an impromptu snowshoeing trip in Charlevoix, they have been jam packed with adventure, spontaneity, and excitement. If nothing else, it was our countless escapades that kept me sane during my studies at Carleton, and for that I am forever grateful.

I dedicate this thesis to all of you. 


\section{Table of Contents}

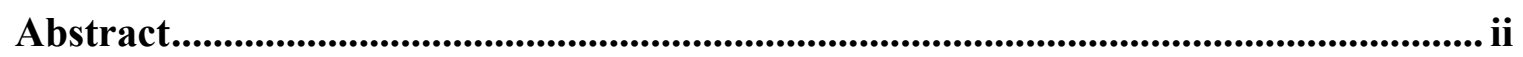

Acknowledgements .................................................................................................................... iii

List of Figures.................................................................................................................... v

List of Appendices................................................................................................................. vi

1 Chapter: Introduction .................................................................................................... 1

2 Chapter: Conceptualizing State Secrecy ............................................................. 12

2.1 The State, Government, and Official Secrecy …………................................ 15

2.2 Governmentality Studies and Secrecy …………........................................... 19

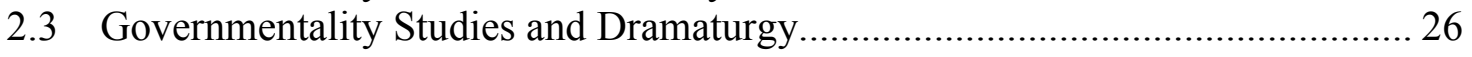

2.4 Cover Storying, State Secrecy, and the Art of Deception..................................... 34

3 Chapter: Research Design and Method ..................................................................4

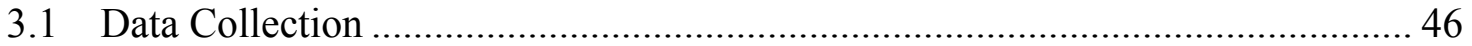

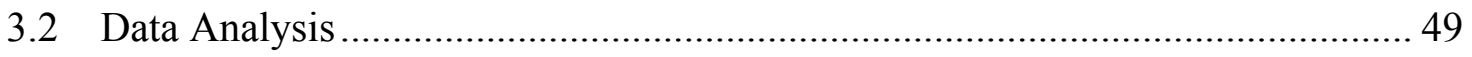

4 Chapter: State Secrecy and Cover Storying in Cobra Mist...................................... 59

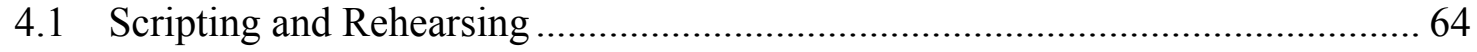

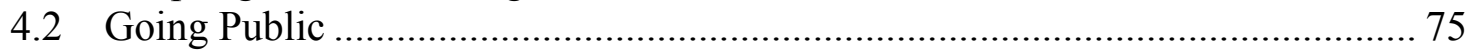

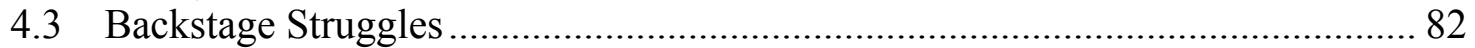

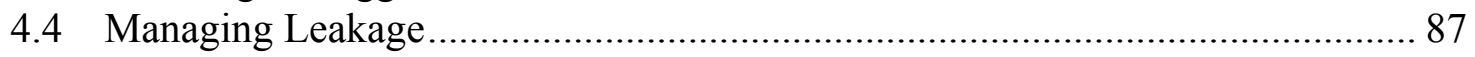

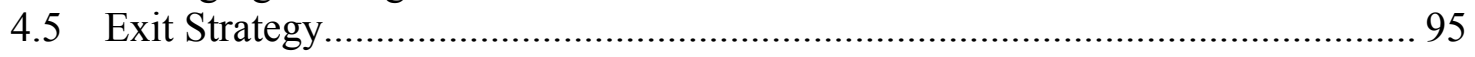

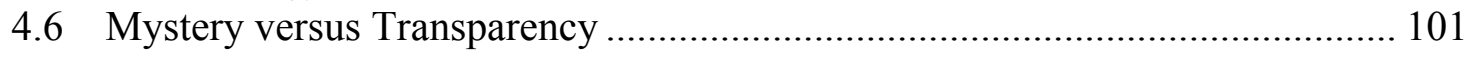

5 Chapter: Discussion and Conclusion ............................................................................ 112

5.1 Dramaturgy and the Governmentality of Secrecy ........................................... 113

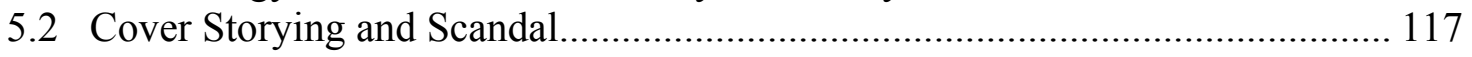

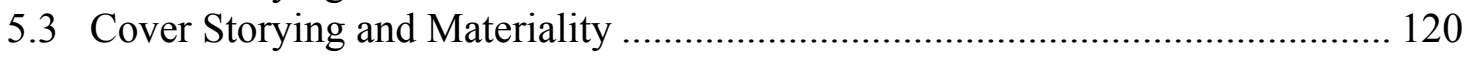

5.4 Cover Storying and Conflict ....................................................................... 121

5.5 Cover Storying and Mystery ………………….......................................... 122

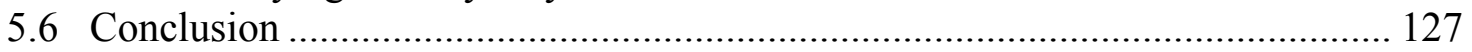

Appendices.................................................................................................................... 129

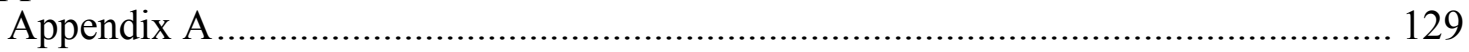

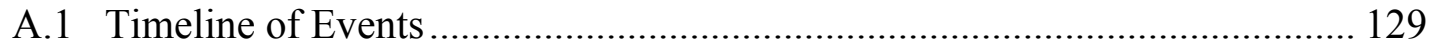

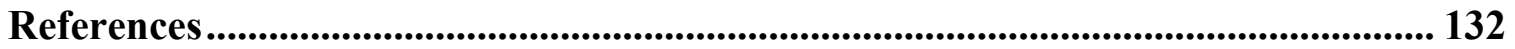




\section{List of Figures}

Figure 1 Orfordness, River Alde, and Cobra Mist from Aerial View ......................... 67

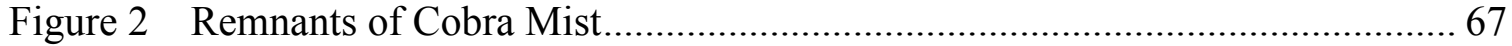




\section{List of Appendices}

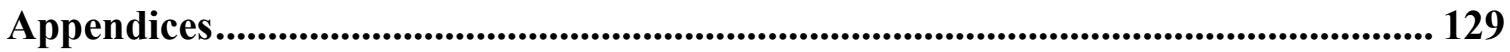

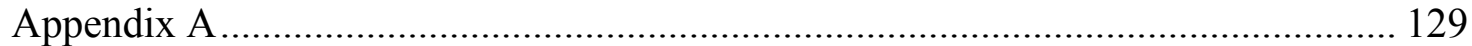

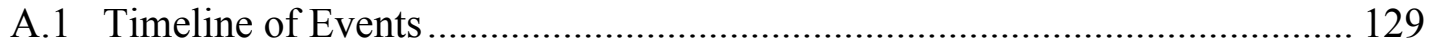




\section{Chapter: Introduction}

'[S]ecrets and lies are central to all manner of frauds, plots, cabals, cover-ups, black markets, man-made disasters, clandestine projects, and espionage operations. With the occasional exception, we as sociologists have not made a practice of studying such things, which means we have turned away from society's darker regions in order to search for what-ever may be conveniently discovered under the light'

(Gibson 2014:303)

On 6 August 2010, TIME magazine published an online article titled 'Top 10 Weird Government Secrets' (Silver et al. 2010). As the article is described: 'It's not just military secrets that governments keep close. And some information, like the recently revealed allegation that Winston Churchill ordered a cover-up of a UFO sighting, seems more amusing than disturbing. TIME takes a look at odd hush-hush moments' (Silver et al. 2010). Reading the article one is informed of Churchill's alleged cover-up a UFO sighting; controversial CIA mind-control experiments during the Cold War; Area 51 and secret alien experiments; the Soviet government's 1978 investigation into paranormal activity; police protection of the Loch Ness Monster; the CIA's contemplation of an explosive seashell as a means of assassinating Fidel Castro in the 1960s; Julia Child's early intelligence career; secret bunkers in New York City's Grand Central Terminal; the FBI's secret investigation of John Lennon; and the origins of the term 'Potemkin village.' The TIME article stands out to me not just for its immediate content, but for its underpinning assumptions about the nature of government secrecy.

First, we find at work in this article the normative assumption that governments keep secrets based on strategic necessity, always in the best interests of civil society, making these secrets 'weird' rather than normal. But who is to say that these types of government secrets are the exception rather than the rule? Could it not be that the 
majority of government secrets are unusual in this sense? What evidence, beyond official rhetoric, do we have to the contrary? Second, in the account of each of the ten secrets, we find a curious yet typical mix of intrigue, speculation, and mystery. The title of the article alone is enough to lure us in; the very notion of peering into a secret world intrigues us. Moreover, the narratives provided do not aim to settle these secrets once and for all, but rather, through speculation, they reproduce their mystery as secrets still not yet fully understood. We know there are bunkers below Grand Central Terminal. We know that 'It's rumored that during World War II, the bunker had guards with shoot-to-kill orders, for fear of sabotage while the station's trains were being used to ferry troops into and out of New York' (Silver et al. 2010). But what were they really used for...?

The social organization of secrecy and deception, in its various shapes and forms, is something that sociologists ought to take more seriously in their studies of political power and organizational dynamics more generally. Until recently, as noted by Gibson, sociologists have taken little to no interest in theorizing the social dynamics of secrecy and deception. Georg Simmel (1906) was the first to do so in his essay 'The Sociology of Secrecy and Secret Societies,' but few followed in his footsteps. In the discipline of psychology, research dedicated to the subject of secrecy and deception is more commonplace. The work of behavioural psychologists like Paul Ekman, for example, has examined extensively the dynamics of secrecy and deception at the interpersonal level. Ekman's (e.g., 2009) research focuses at length on the importance of nonverbal clues of deception that deceivers give off when lying: odd facial expressions, forced hand gestures, and inconsistent emotional responses are among the obvious giveaways to the experienced lie detector. One finds an even greater interest in secrecy and deception in 
the discipline of anthropology. As Jones (2014:54) writes, reviewing most major works on the anthropology of secrecy to date, 'Secrecy ripples through anthropology, as both an explicitly thematized topic and an implicitly realized motif.' The analyses of symbolic interactive sociologists like Erving Goffman on the performative dynamics of secrecy and deception in everyday life brings us closer to a more sociological treatment of the phenomenon, but still falls short given Goffman's principal interest in brief and ephemeral transactions between people in spaces like the restaurant or home. A sociological framework for the study of the more long-term and socially organized forms of secrecy and deception in liberal-democratic regimes, as when an office within government dupes a large national public using a cover story, although underway (Baker and Faulkner 1993; Bail 2015; Costas and Grey 2014; Gibson 2014; Ku 1998), is still in need of much sociological concept development and substantive research.

Secrecy and deception are vital albeit widely under-examined elements of past and contemporary societies. Secrecy and deception are everywhere. Together they comprise a vibrant force embedded in the relational fabric of human life. Just think of the many available words in the English language: lies, deceits, mendacities, dishonesties, trickeries, deceptions, elusions, omissions, disclosures, confessions, fabrications, falsehoods, silences, hushes, evasions, the list goes on. Secrecy and deception are things we are each familiar with and experience everyday. In the formal political realm, secrecy and deception are conceived as lively strategic tools in the achievement of inter-State comparative advantage and reasoned decision-making. As Niccolò Machiavelli (1998) makes clear to readers of The Prince, the infamous 16th-century political treatise on sovereignty, secrecy and deception are tantamount to effective political rule, for the best 
of princes must recognize that total virtue and truth telling comes with its negative consequences. Deception, or the indispensible art of illusory appearances as Machiavelli describes it, has long been an integral component of ruling (Bachrach and Baratz 1962; Bail 2015; Foucault 2009; Horn 2011; Lukes 1974; Shils 1996).

Together secrecy and deception form a rich nexus for sociological analysis, a matter simultaneously interpersonal and institutional. What originates as an interpersonal secret can easily become the domain of a broader network of institutional actors, interests, and strategies. The opposite is also true, as when institutions fall and the last remaining trace of its secrets and deceptions lay in the imperfect memories (and memoires) of former employees. Secrecy and deception at the interpersonal level is very different than at the institutional level. In the former, secrets are kept at the disciplined will of the speaking subject, sometimes under explicit or implicit oath not to tell, maybe even under threat of retaliation. At the institutional level, one happens upon a far more formal and elaborate set of mechanisms put in place for the maintenance of secrecy and the production of lies, from official secrecy laws to the expert cover storying capabilities of top military officials. While the interpersonal is significant, a matter best examined ethnographically from the perspective of the participant observer in the midst of unfolding interactions, this thesis investigates the latter, the institutional, with the goal of advancing a theoretical framework for the study of the social organization of secrecy and deception in society rooted in the analytic ethos of Foucaultian governmentality studies and the early dramaturgical perspective of Erving Goffman.

Although one could hardly argue the world is more secret than it used to be, it is evident today that the form secrecy takes in Western social and political relations is 
qualitatively different than in the past. Secrecy, once the respected domain of rightful political rulers, is becoming more and more open and publicly contested (Bratich 2006). State secrets are made known to publics in limited form - the secrets of Guantanamo, the torture photographs from Abu Ghraib, the extensive powers of national security agencies - indeed, sometimes by governments themselves who wish to make their secret powers vaguely known; and are at the same increasingly challenged and called into question by publics on the assumption that secrecy marks the closure of something worth knowing, often something scandalous and illegal (Abrams 1988; Horn 2011).

Yet within a more limited historical time frame, perhaps it can be said that world is becoming more secretive. As Galison (2004:233) has calculated regarding government information in the United States: 'Secret information is accumulating, at a rate that itself is accelerating, far quicker than it is being declassified.' As such, Galison (2004:231) calls for a revision of our understanding of the realm of public information:

The closed world is not a small strongbox in the corner of our collective house of codified and stored knowledge. It is we in the open world-we who study the world lodged in our libraries, from aardvarks to zymurgy, we who are living in a modest information booth facing outwards, our unseeing backs to a vast and classified empire we barely know. ${ }^{1}$

The study of this 'vast and classified empire' is no easy task. For the most part, sociologists are limited to researching it after the fact and through heavily redacted and incomplete datasets garnered through leaks, newspaper articles, archives, access to information requests, or some combination. The project is thus by definition a historical one. This incompleteness of available data does not make the task of researching secret

\footnotetext{
${ }^{1}$ Unless otherwise noted, emphasis is as found in original.
} 
and deceptive sites futile, but calls upon historical sociologists to be more tolerant of gaps and ambiguity in research results.

Building on recent sociological studies of secrecy and deception (e.g., Bail 2015; Costas and Grey 2014; Gibson 2014; Ku 1998; Zerubavel 2006), I examine in this thesis the secretive and deceptive practices of military officials in a top secret military programme known as Operation Cobra Mist, built in the late 1960s, and their relationship to publics, journalists, and politicians mediated through the art of cover storying. (Readers unfamiliar with Cobra Mist can consult the timeline of events in Appendix A for a brief chronology of the programme.) Cobra Mist was a joint Anglo-American overthe-horizon radar (OTHR) station built on Orfordness, Suffolk, UK in 1967 in the latter half of the Cold War. It was financed and operated by the US Air Force (USAF) and UK Ministry of Defence (MoD). Pentagon papers label Cobra Mist the most powerful radar station of its time. Its mission was to generate intelligence on the movement of Soviet and Soviet allied aircraft, missile and satellite launchings, and to serve as an experimental proving ground in further refining existing OTHR techniques. In June 1973, the operation was terminated due to the inability to reach desired operational capacity. One explanation for this failure posits that the station was secretly jammed by pro-Soviet forces from distant ships anchored in the North Sea. However, the exact reasons for its failure remain unclear. Where this thesis takes primary interest in Cobra Mist is with its strategic use of cover storying in order to inhibit publics, journalists, politicians (and presumably Soviet and Soviet-bloc forces, although surprisingly these are never mentioned in the texts analyzed) from learning its operational military function. The cover story chosen was one of 'radio research station.' 
Two general arguments are made. First, by cover storying the operation behind the guise of radio research, Cobra Mist officials reconfigured their front and backstage institutional practices in ways that the study of secrecy, deception, and cover storying brings to light. Through Cobra Mist, I show how scripting a suitable cover narrative, careful and consistent press releases, internal struggles around and the need to manage inconsistent leaks, and an opaque and uncontroversial site closure are among the core concerns of any military operation caught up in the use of cover storying. This thesis explores these practices through an analysis of declassified texts from Britain's National Archives in Surrey, newspaper articles collected from the Suffolk Public Records Office in Ipswich and the British Library in London, and materials available online, including the results of Freedom of Information Act requests from the US Pentagon. To help guide and contextualize the analysis of archival documents, I attended a public tour of the site and conducted informal conversations with locals on the topic of Cobra Mist.

Second, while the programme ended in June 1973, I argue that its cultural significance lives on today in the form of a vibrant mystery. Speaking of mystery, I suggest, is a useful means of complicating the now overly simplistic relationship between organizational secrecy and transparency. Greater disclosure does not necessarily equate to greater transparency, but can just as easily enhance a public's sense of mystery. Regarding Cobra Mist, many publics continue to believe that gaps in the historical record (e.g., reasons the station failed to reach the sought operational capacity) point to a larger and still secret ultimate truth, from Orford locals through to the authoritative historical account of Orfordness historian Paddy Heazell (2011), whose discussion of the living 'mysteries' of Cobra Mist only seems to intensify the intrigue of the site's remaining 
sources of uncertainty. It is argued that this mysterious aura surrounding Cobra Mist is not independent of, but an unintended effect, a byproduct, of the use of cover storying. Simply put, cover storying arouses speculation which, when left unchecked by government officials, can coalesce yielding a powerful assemblage of conflicting ideas and hypotheses that constrain actors' ability to know a secret site except in terms of mystery, which differs from transparency. The concept of mystery is developed in the Discussion and Conclusion (Chapter 4).

There are four parts to this thesis. Chapter 1 is about theory and concept development. It begins by conveying an overview of the theoretical problem in general, which I use as an arbitrary entrance point into the larger 'rhizome' (Deleuze and Guattari 1988) of government secrecy. This is the problem of the relationship between the State, that unified and coherent entity that dominates lay and academic discussions of politics; government, the State in its dispersed and heterogeneous form, understood as a less coherent assemblage of conflicting agencies, actors, and ideas; and secrecy, a polysemous concept denoting a broad range of strategies used in the figuration of mutable and differentiated epistemic boundaries between actors. I argue that it is in large part through strategies of official secrecy and deception, cover storying included, that governments are able to appear as unified and orderly actors - as States. The title of this project, Where States Lie, thus holds a double meaning: The State, as a performed identity, lies (in the sense of occupying a place in relation to something else) within the disjointed network of actors and institutions otherwise known as government. The State is an ideological effect of government practice and official discourse. Yet it is also this same network, generally inaccessible to civil society, which affords States the capacity to lie in the first place (in 
the sense of feeding others disinformation with the intention of deceiving), both about its State identity and its backstage governmental practices in general.

I argue that this State-government-secrecy problematic, most clearly expressed by Abrams (1988), can be empirically researched using two distinct theoretical frameworks: Foucaultian governmentality studies and Goffman's early dramaturgical perspective. Following Hacking (2004), it is argued that when combined, these two analytic approaches, the first more an analytic 'ethos' than a conceptual framework per se, yield a more complete theoretical toolkit for the examination of the sociological dynamics of secrecy and deception in government. The final section of this chapter specifies this general theoretical argument by advancing a theory of cover storying, proposed as a guiding conceptual lens for the study of the governmental processes of secrecy and deception rooted in the work of Arendt (2001) and Canetti (1978), among others. Influenced by the relational sociology of Elias (1978), the -ing is affixed to cover story in order to highlight its ontological status as a mutable social process in constant flux. From this perspective, there is no fixed and static cover story, only an array of shifting and contingent practices and 'discursive frames' (Goffman 1986). Cover storying is the focus of the analysis of Cobra Mist in Chapter 3.

Chapter 2 discusses research design and method. Using a case study research design, data were collected from four archives in Britain, including the National Archives in London. Online searches, ethnographic observation, and informal conversations with locals helped guide and contextualize the archival dataset and analysis. To analyze these data, I use a method of analysis which is simultaneously open, theoretically informed, and based in techniques of discourse analysis. The unlikelihood of achieving classical 
positivist objectivity is also considered, promoting in its place a post-positivist reconceptualization the term that embraces messiness and individual difference without devaluing the project of a quasi-cumulative social science.

Chapter 3 presents the case study of cover storying in Cobra Mist. The results of the analysis are organized according to six themes: i) the making up of a cover story (scripting and rehearsing); ii) publicizing a cover narrative through the news media (going public); iii) performance disruption and breakdowns in dramaturgical cooperation around cover storying and information leaks (backstage struggles); iv) defending the cover story in light of unwanted information leakage (managing leakage); v) shutting down a secretive and deceptive site without undermining the commitment to cover storying (exit strategy); and vi) the unintentional production of mystery (mystery versus transparency)

In Chapter 4, the Discussion and Conclusion, I reflect on the significance of future studies of cover storying for the governmentality of secrecy, as well as the limits of studying secret sites through the imperfect methodological means available to most sociologists. I call on sociologists to invest greater analytic interest in socially organized forms of secrecy and deception in past and contemporary societies, and to adopt a heightened tolerance for, and awareness of, gaps and ambiguities in social research on organizational secrecy and deception. Today, themes of secrecy and transparency occupy an increasingly prominent place in politics and organizational practice in North America and across much of Europe. From political platforms built on promises of enhanced governmental transparency, to Wikileaks, to invasive surveillance technologies and the degradation of privacy, to the protection and leakage of trade secrets in business-each 
plays a significant role in the politics of government secrecy today. Through my historical investigation into the art of cover storying in Cobra Mist, the ultimate aim of this project is to help generate the analytic tools necessary to systematically engage processes of government secrecy from a sociological perspective. 


\section{Chapter: Conceptualizing State Secrecy}

'The state is, then, in every sense of the term a triumph of concealment. It conceals the real history and relations of subjection behind an a-historical mask of legitimating

illusion; contrives to deny the existence of connections and conflicts which would if recognised be incompatible with the claimed autonomy and integration of the state. The real official secret, however, is the secret of the non-existence of the state'

(Abrams 1988:77)

'If Falsehood, like truth, had only one face, we would be in better shape. For we would we take as certain the opposite of what the liar said. But the inverse of truth has a hundred thousand shapes and a limitless field'

(Michel de Montaigne)

In this chapter, I develop a conceptual framework for the study of the social organization of secrecy and deception in government and its connection to the exercise of State political power. I then use this general theoretical framework to develop the concept of cover storying. To do this I make use of two general literatures: governmentality studies and Goffman's dramaturgy. After a clarification of key terminology, I argue that the two literatures balance and extend one another yielding a conceptual framework for the study of secrecy and deception that neither literature on its own could achieve. Both literatures inform my understanding of processes of cover storying.

There are a handful terms running throughout the course of this thesis which, at the outset, should be clarified in order to minimize confusion. These are secrecy, deception, leakage, and disclosure. It is not my intention to forever fix and define these concepts, but to rather assert their meaning in a pragmatic and relational sense with respect to the specific theoretical interests and case study of this project.

At first glance, secrecy and deception may seem neatly conceptually apart from one another. But as Gibson (2014) points out, the inverse is true. Secrecy, the intentional withholding of information (Bok 1989), implies deception, the purposeful dissemination 
of a false truth, and vice versa. As Gibson (2014:286) writes, 'On the one hand, secrets often involve implicit lies, namely, that nothing important is being withheld. On the other, lies involve secrets, namely, that the assertion in question is a falsehood.' Unless otherwise specified, secrecy and deception are treated as inseparable in this thesis.

The notion of leakage also keeps with the work of Gibson (2014), who clarifies his own meaning of the word by referring analogously to the psychology of Ekman (2009) on 'leakage' and 'deception clues.' ${ }^{2}$ Whereas leakage denotes the deceivers disclosure of the secret truth, whether in part or whole, as by the intentional leaks of disgruntled insiders or whistleblowers (see Bail 2015; Ku 1998), deception clues refer to those cues which inform an audience of a deceiver's untruthful behavior without revealing the truth per se. Shadowing Gibson (2014:285), who rightfully points to analogous 'counterparts on the organizational level,' the term leakage is employed to mean both leakage and deception clues according to Ekman's meaning of the words, for in both cases what we are dealing with is the imminent failure of the institutional containment of the use of deception, which motivates a public audience's increasing drive to settle once and for all the hidden truth and the reasons for hiding it in the first place.

Disclosure, as I understand the term, describes an intentional act of information dissemination from inside to publics, but differs from leakage in that it is formally sanctioned according to inside organizational patterns of authority. The official press release, according this meaning, is an instance of disclosure. Such disclosures to the public, carefully scripted and rehearsed by public relations experts, are vital means of

\footnotetext{
${ }^{2}$ To clarify, what is taken from Ekman is his conceptual distinction, not his (controversial) findings concerning the determination of deception through presumptively universal expressions of emotion in the face and culturally-specific non-verbal cues. For criticisms of Ekman, see, e.g., Bond Jr and Uysal (2007), Lutz and White (1986), and Russell and Fernández-Dols (1997).
} 
secrecy and deception in politics. Disclosure also includes those many extraordinary and minor acts of formally authorized information dissemination that take place within and between bureaucratic organizations on a daily basis. Disclosure, in this sense, encompasses a far broader set of organizational practices than leakage.

Other terminology worth clarifying are the distinctions between insider/outsider and frontstage/backstage. I worry that readers will decode from these distinctions a fixity and simplicity of social relations, as if 'here are the insiders, they hold the secrets, and here is the backstage, this is where the insiders work' were the image such concepts were meant to convey. Rather, in the spirit of relational sociology, the connection between insider/outsider should be understood as highly contextual and in constant flux. Insiders become outsiders, frontstages become backstages, and vice versa. Moreover, to say that someone is an insider rather than an outsider does not refer simply to their position inside or outside an institutional network. It is common knowledge that many employees of secret organizations do not possess comprehensive access to its greatest secrets. The term is used instead to denote that category of actors that do possess access, as gradated and variable as it might be, not to all secrets, but to a specific one. This project traces the processes involved in the production, publicization, and maintenance of a cover story in a secret Cold War intelligence operation known as Cobra Mist. Therefore, terms like insiders and outsiders are meant to refer to those involved in the performance of the cover story on the one hand, and those on the receiving end on the other. Of course, whether the outsiders are effectively duped by the cover story or not is another question. 


\subsection{The State, Government, and Official Secrecy}

The relationship between the State, government, and official secrecy was first brought to my attention reading the work of Philip Abrams. In his article 'Notes on the Difficulty of Studying the State,' written and presented in 1977 but published posthumously, Abrams (1988) interrogates the ontological status of the State in relation to strategies of official secrecy. By many political sociologists at the time, it was assumed that the State was an essential entity distinct from Society, the latter being the home of the social, the economic, the religious, and other non-State 'domains' (Latour 2013). Today many political sociologists (although not all) would recognize an account of the State as a unified and substantial being as problematic (e.g., Bartelson 1995, 1998; Jessop 1990; Laclau and Mouffe 2001). The State, Abrams argues, is in reality a fluid and heterogeneous assemblage of actors and institutions.

Yet if the fixed and stable creature that is the State cannot pass the scholarly tests of theory and empiricism, why does commonsense tell us otherwise? Ironically, those political theorists that outright reject the existence of the State rarely succeed in erasing it entirely from their thought and writing (Bartelson 2001). As Abrams (1988:61) puts it,

The everyday life of politics suggests forcibly that the conception of the state offered in marxism and political sociology is - whatever the difficulties of operationalising it—well-founded. Commonsense impels us to the inference that there is a hidden reality in political life and that that reality is the state.

Although in relational social theory the State as a unified and essential ontological being is nonexistent, empirically the State can be said to exist as a lasting ideological construct 
with concrete effects. Thus, what we are left with according to Abrams' alternative view of the State is an analytical division that avoids essentializing the State, but without completely doing away with the lasting authority of a vast and fragmented governmental network to appear otherwise (see also Passoth and Rowland 2010).

On the one hand, there the State-idea, which I denote here simply 'the State,' an abstract concept with little basis in objective reality, but which has tangible effects on our understanding and experience nonetheless. On the other hand, there is the State as a dispersed system or assemblage, referred to here as 'government.' The State, which always appears to signify something intuitively more real than an ideological impression, is made possible through endless repetitions in government discourse and practice, continuously tailored to the reproduction of a self-image of order and unification, and works in large part through distorting strategies and effects of government secrecy, which render the State as much a public appearance as it is a secret and deceptive one (Bachrach and Baratz 1962; Bail 2015; Foucault 2009; Lukes 1974; Simmel 1906; Shils 1996). Through claims to secrecy, government agencies reserve as a central mechanism of selfstability the right 'to withhold information, deny observation and dictate the terms of knowledge' (Abrams 1988:62). Secrecy, in this sense, lies at the very basis of the ‘epistemic authority’ of the State (Glaeser 2011).

Another way to put this is by using Butler's language of performativity (Bialasiewicz et al. 2007; Campbell 1992; Weber 1998). Like the gendered body, the State is not pre-given, but continuously and creatively performed into existence. The State is 'an identity tenuously constituted in time, instituted in an exterior space through a stylized repetition of acts' (Butler 1990:140 as quoted in Campbell 1992:9). All identities 
are shaped by the strategic withholding and selective disclosure of information, whether true or false (Simmel 1906). Thus, as Campbell (1992:9) has argued, if 'the performative constitution of gender' is to seen as analogous to 'the performative constitution of the state,' it follows that tracing the role secrecy and deception in the constitution of the State-identity should be an integral component of this project.

Thus, situated and disjointed government agencies, through the selective control of access to material and informational infrastructure and the careful regulation of public discursive frames (making publics aware of certain things but not others), engage in a performative art of self-imaging that masks the disorder of government behind an aura of trustworthiness, consensus, and unification (Abrams 1988; Mitchell 1991). The State is therefore not only a political abstraction but also an inherently deceptive one, 'which prevents us from seeing more clearly the almost inevitable disparity between the idealized representation of the state in such terms and the practices authorized in the name of state' (Hay 2014:468). Abrams (1988:63) further suggests that the experience of frustrated publics and political sociologists only substantiates this image, for the resistance of the State to outside scrutiny is seen as evidence for the concealment of something significant, in this case proof of an otherwise unsupported essentialist theorization of the State posited by classical Marxism and other like-minded political sociologies (see also Horn 2011). Secrecy and the State come hand in hand, in much the same way as secrecy does with publicity (Birchall 2011; Dean 2001). Nevertheless, Abrams' discussion of the relationship between the State, government, and secrecy is not without its limits. One thing missing from Abrams' account is an engagement with the transnational. 
To 'transnationalize' Abrams' State-government-secrecy nexus, let us add that a crucial component of a government appearing like a State is the masking and management of a government's relationship to other governments. A government not only appears like a State, but a distinctively domestic State that can enter into formal relationships with other Westphalian States. Under such circumstances, domestic States, which in turn become complex transnational muddles of actors and institutions (Bigo 2002, 2006), strive to preserve all the while an image of independence and autonomy from those States it cooperates with. Thus, we hear narratives of States liaising, entering into this or that deal or partnership, but rarely if ever stories of States becoming multinational or global entities as a result of transnational relationships reconfiguring existing State boundaries. In tracing the distorting capacity of governments to perform State identities, it is necessary to acknowledge not only the domestic institutional connections that are being masked, the chief focus of Abrams, but also the international ones, the relations between States, and the effects of such relations on the backstage institutional arrangement of government despite frontstage claims to the contrary.

A second shortcoming of Abrams' (1988) essay is that it does not provide a clear means of empirically investigating this general theoretical problematic. To fill this void I turn to the work of Foucaultian governmentality studies. Governmentality studies complements Abrams' argument by resituating “"the state" within an investigation of problematics of government' (Rose and Miller 1992:174). The State, possessing 'neither the unity nor the functionality ascribed to it,' is a "'mythical abstraction" which has assumed a particular place within the field of government' (Rose and Miller 1992:175). The aim of governmentality studies is to trace the emergence of the State as an 
'historically variable linguistic device' and its inscription in shifting modes of government (Rose and Miller 1992:177).

\subsection{Governmentality Studies and Secrecy}

Although governmentality studies has only recently shown interest in questions about secrecy (e.g., Horn 2003, 2011; Masco 2002; Walters 2014a, 2014b; Weiskopf and Willmott 2013), the same cannot be said of some of the earliest works in sociology. In his essay 'The Sociology of Secrecy and Secret Societies,' Georg Simmel (1906) dubbed secrecy one of humanity's 'greatest achievements.' Secrecy adds further depth and complexity to social life by allowing 'the possibility of a second world alongside the manifest world,' the latter 'decisively influenced by the former' (Simmel 1906). Less extensive remarks on secrecy can be found in the canonical works of Emile Durkheim and Max Weber. In the Elementary Forms of Religious Life, Durkheim conferred the role of secrecy in the production of sacred meaning. Secretive rituals inject profane objects with an aura of sacredness. And it is in reading Weber's Economy and Society that we are informed of the constitutive role of secrecy in modern bureaucracy: 'Every bureaucracy strives to increase the superiority of its position by keeping its knowledge and intensions secret' (Weber 1946:233).

mid- to late-20th-century sociological literature on secrecy emphasizes the structural elements of secrecy in bureaucracy, from official secrecy laws to systems of classification (e.g., Coser 1963; Littrell 1973; Lowry 1971; Merton 1940; Rigney 1979; Rourke 1957; Sjoberg and Miller 1973; Tefft 1980; Wilsnack 1980). Such contributions highlight secrecy as a structural element bound to the bureaucratic impetus for 
'information control' (Wilsnack 1980), but which could in excess result in overclassification, unlawful organizational behavior, and injustice. One can also find in this earlier literature analyses of the structural dimensions of secrecy and deception under prebureaucratic forms of rule, albeit as a secondary rather than primary conceptual foci (e.g., Habermas 1991; Zaret 1996). More recently, scholars have expanded Weber's idea of bureaucratic secrecy to emphasize an informal organizational culture of secret-keepers, in addition to the formal rules and routines of information handling, authorization, and law (e.g., Ellsberg 2010; Moran 2012; Vincent 1998; Weiskopf and Willmott 2013). Shifting from a Weberian to a more Simmelian perspective on secrecy, at least two contributions have sought to conceptualize secrecy in the form of testable Simmelian propositions and hypotheses (Hazelrigg 1969; Marx and Muschert 2009), and a general framework for the study of barriers to undermining secrecy and deception in complex organizations (Gibson 2014). Still, others draw influence from Durkheim on secrecy, using his insights to guide analyses of ritual and symbolic secrecy in anthropology and cultural sociology (e.g., Alexander 1990; Ku 1998; Taussig 1999; Wagner 1984).

Yet a crucial weakness of this literature is the tendency to use the concept of secrecy as if it were a variable attribute mediating the relation between fixed and stable entities (with notable exceptions, e.g., Bail 2015; Best and Walters 2013; Birchall 2011; Bratich 2006; Costas and Grey 2014; Dean 2001; Gibson 2014; Ku 1998; Masco 2002; Paglen 2010a; Weiskopf and Willmott 2013). In a more contemporary and influential contribution on secrecy in government, Pozen (2009) suggests that secrecy can be indexed according to four interrelated continua: the number of people in the know; the kind of people in the know; how much of the secret they possess; and when they came to 
possess the secret. Based on these axes, some government secrets can be described as 'shallow,' others 'deep.' In general terms, Pozen's analysis introduces variability to an attribute (secrecy) that mediates the relation between two fixed categories: the knowing subject and the unknowing subject. Secrecy is of variant legal and political significance depending on the quantity and kinds of people in the know, the amount of information known, and when the information becomes known. But although in many ways useful, elaborating the concept of secrecy in this way is also limited. Pozen's framework is restrictive insofar as it leaves the entities whose relation is mediated by secrecy frozen in time and space. In reality, knowing and unknowing subjects are as variable as the secrecy between them (Gibson 2014; Goffman 1959; Ryan 2006). The point is to underscore the need for an additional conceptual language of secrecy that is attentive to the multiple layers of fluidity, contingency, and contestability at stake in secret regimes of truth and governance (Abbott 2001; Elias 1978; Latour 2005; Urry 2007; Valverde 2006).

The Foucaultian influenced shift from a fixed institutional to a more relational 'analytics of government' familiar in other sociological literatures has only begun for the study of secrecy (Walters 2014b). Recent examples include Galison (2010), who has analyzed changes in the 'ontology of secrets' from World War I through to the $21^{\text {st }}$ century with the proliferation of anti-terrorism discourse. Masco (2002), who has explored the Cold War foundations of a dynamic 'secret governmentality' enacted for the concealment of American nuclear secrets. And Horn (2011), who discusses three shifts in the overarching logic of political secrecy from the medieval era into the present. To approach the subject of secrecy and deception from the perspective of governmentality studies, as I understand it, means adopting the Foucaultian analytic ethos representative 
of his later genealogies into the State and government (Bevir 2010; Colwell 1997; Larner and Walters 2004; Saar 2002). In this sense, governmentality studies is not to be confused for a social scientific school or theory in the typical meaning of the words, but treated as a conceptual toolkit 'that can be used to enhance the think-ability and criticize-ability of past and present forms of government' (Walters 2012:2). As a toolkit, governmentality studies rejects the possibility of any grand, essentialist theorization of social and political phenomena, preferring to work at the level of situated empirical moments and ad hoc conceptual interventions. Such conceptual innovations are 'untimely' in the Nietzschean sense, intended for purposes of 'acting counter to our time, and thereby acting on our time, and let us hope, for the benefit of a time to come' (Nietzsche 1997:60). Sociologists, adopting this view, 'must no longer accept concepts as gifts, nor merely purify and polish them, but first make and create them, present them and make them convincing' (Nietzsche 2011:220). While a substantive array of contributions attests to the increasing significance, maturity, and complexity of the governmentality studies literature to date (e.g., Dean 2010; Garland 1997; Larner and Walters 2004; Rose 1999; Walters 2012), themes of secrecy and deception have been largely overlooked.

Since the early 1990s, governmentality scholars have set out to challenge the illusion of State order, turning their focus to the dispersion of heterogeneous governmental programmes and their situated rationalities and technologies of power. Yet in doing so, governmentality scholars seem to have at the same time managed to hypostasize State order to a degree by limiting their analytics of government to visible manifestations of governing at the expense of the invisible (see also Curtis 1995). Without accounting for this neighbouring secret and deceptive field of government, 
governmentality studies not only avoids a crucial element of the picture, but fails to take seriously its own agenda of studying of the State as "mythical abstraction" which has assumed a particular place within the field of government.' If we are to trace with any depth and clarity the conditions upon which specific articulations of the logic of the State emerge into the manifest field of governing, an entrance into the dark and hidden world of government's multiple and contested back regions is necessary.

Why this abandonment of the secret at the expense of the publicly visible? For all that it may have to offer, governmentality scholars have had surprisingly little to say on the subject of secrecy. As did Foucault himself, although scattered remarks on secrecy and in/visibility can be found in Birth of the Clinic (1994), History of Sexuality (2012) and Security, Territory, Population (2009). Perhaps one explanation for this omission stems from Foucault's account of philosophy as the description of the visible:

For a long time one has known that the role of philosophy is not to discover what is hidden, but to make visible precisely what is visible, that is to say, to make evident what is so close, so immediate, so intimately linked to us, that because of that we do not perceive it. Whereas the role of science is to reveal what we do not see, the role of philosophy is let us see what we see. (Foucault 1978 as quoted in Davidson 1997:2).

A similar disregard for the invisible is expressed by Rose and Miller (1992), who call for a descriptive account of government in terms of manifest rationalities and technologies in official discourse. Yet what appears largely overlooked, or misinterpreted, in the above arguments from Foucault and Rose and Miller is the intellectual context of their claims. 
What they are suggesting is not a wholesale disinterest in the secret and hidden forms of government. Their intention is to distinguish their work from conventional sociological approaches aimed at unearthing from below all institutional arrangements a hidden and unified ideological agenda a la classical Marxism. Rose and Miller (1992:177) express this clearly in stating that the objective of governmentality studies is

not to penetrate the surfaces of what people said to discover what they meant, what their real motives or interests were. Rather, we attend to the way in which authorities in the past have posed themselves these questions: what is our power; to what ends should it be exercised; what effects has it produced; how can we know what we need to know, and do what we need to do in order to govern?

The latter half of this passage opens much space in governmentality studies for questions about secrecy and deception. If the goal is to take seriously such questions about governing from the perspective of actors, one cannot limit their analysis to the immediate statements and practices of government actors in the public arena. Of equal analytic importance is what happens behind closed doors.

To further my case, this same publicity bias can be found in the notion of visibility: government is meant to convey an outward looking practice that performatively re/defines the 'field of visibility' through particular approaches to governing. As Dean (2010:41) suggests,

We might ask what the field of visibility is that characterizes a regime of government, by what kind of light it illuminates and defines certain objects and with what shadows and darkness it obscures and hides others. 
An architectural drawing, a management flow chart, a map, a pie chart, a set of graphs and tables, and so on, are all ways of visualizing fields to be governed. These all make it possible to 'picture' who and what is to be governed, how relations of authority and obedience are constituted in space, how different locales and agents are to be connected with one another, what problems are to be solved and what objectives are to be sought.

The meaning of visibility therefore lies in the partial and mutating capacities of government actors to visualize the world according to various diagrams, from the disciplinary gaze of the Panopticon (Foucault 1977) to the reductive and continuous powers of the 'societies of control' (Deleuze 1992). The obvious drawback of Dean's summary is the emphasis on how government's see without mention of how they wish to be seen. Here we can build on his conceptualization of the field of visibility by highlighting the ways in which government itself is a thing meant to be pictured in specific ways, most notably as a State, which various strategies of secrecy and deception aim to achieve. The art of cover storying is one such strategy worth exploring.

In the next section, I turn to the dramaturgical sociology of Erving Goffman. While Foucaultian governmentality studies has much to offer the study of State secrecy and deception, as theoretical perspective and a method it has its limitations. Insofar as the goal of this thesis is to trace the front and backstage work of cover storying in a secret military operation, I am in need of an framework that not only operates at the level of conceptual abstraction (thinking in terms of underpinning rationalities and technologies of power, for example), but one that is also sensitive to the nitty-gritty details of everyday 
interactions, deliberations, and decision-making. As Hacking (2004) argues, combining Goffman with Foucault is one way to achieve this more holistic approach (see also Fridman 2014; Walby 2012).

\subsection{Governmentality Studies and Dramaturgy}

Few classic texts in sociology have so directly engaged with subject of secrecy and deception than Goffman's The Presentation of Self in Everyday Life (1959). In the book, Goffman advances a metaphor for the study of social life as an ongoing theatrical performance, routinely commenting on the matter of secrecy and deception in everyday interaction (see also Goffman 1969, 1986). I argue that Goffman's dramaturgical perspective advances governmentality studies conceptually, in that the metaphor of theatrical performance provides an accompanying theoretical language to examine political relations of secrecy and deception. But also empirically, in that the metaphor of theatrical performance expands governmentality studies into a descriptive analytic terrain it is generally unacquainted with. A Goffmanian approach also has much to gain from governmentality studies, as Goffman's emphasis on the 'immediate situation' (Callero 2003:122) never quite approximated the analytical rigour of genealogy to abstract from the broader ecology of government the historically specific 'rationalities, programmes, techniques and subjectivities which underpin it and give it form and effect' (Walters 2012:2). This lack of abstraction of sorts might also stem from the fact that Goffman exclusively dealt with brief and momentary transactions between people, 'lasting a few minutes or, at most, an hour or two' (Gibson 2014:286). The Goffmanian metaphor of frontstage/backstage has long been recognized as a fruitful conceptual lens for the study 
of practices of government secrecy (e.g., Giddens 1981:41), but for the most part has yet to be developed into any in-depth sociological framework for doing so.

Hacking (2004), in an article titled 'Between Michel Foucault and Erving Goffman,' contends that the works of the French philosopher and American sociologist, respectively, complement and render one another more complete. While much of Hacking's analysis is limited to the more archaeological incarnation of Foucault, focusing on Foucault's earlier 'top-down' analyses of the production of 'discursive formations,' the general thrust of his argument is applicable to the genealogical adaptation of Foucault which came later, and by extension governmentality studies. As Hacking (2004) argues, 'Foucault's archaeologies established the preconditions for and the mutations between successive institutional forms. His later genealogies are closer to how the historical settings work on people to form their potentialities, but never indicate how this happens in daily life' (288). While the genealogical vein of Foucault's work and governmentality studies have been at pains to do away with the structuralist assumptions still lingering in his archaeological arguments (Sawyer 2002), Foucault avoiding in his later analyses references to things like the 'rules of formation' of discourse and placing far greater weight on power relations and practice, both still read quite abstract 'in the plain sense of being abstracted from those who speak' (Hacking 2004:278).

And for good reason. It is not a criticism of governmentality studies to label it abstract in this sense. Logics, technologies, subjectivities - each is necessarily abstracted, but never completely removed, from the particular words, practices, and power relations from which they were drawn. On the other hand, it is precisely this emphasis on 
conceptual abstraction that makes the Goffmanian privileging of the messy details of meaning-making and interaction a fruitful addition to governmentality studies.

Goffman's theory of dramaturgy is meant first and foremost to express an interactive dynamic between two or more parties, and includes consideration of discursive and non-discursive elements in a symbolic exchange. There are two sides to a performance: the intended meaning of the performance and the actual one. In the latter case, it is not about what an actor meant to convey to another party, but what was conveyed according to the counter-action of the audience. The meaning of a performance is thereby measured relationally at the moment when the audience counter-acts 'as if the individual had conveyed a particular impression' (Goffman 1959:6). For Goffman, the definition of the situation and the performative boundary between parties for the time being is therefore not necessarily the product of 'real agreement as to what exists' as much as it is 'a real agreement as to whose claims concerning what issues will be temporarily honored' (Goffman 1959:9-10).

Next, Goffman complicates his framework by further distinguishing between two major categories of 'stage' on which interaction takes place, each with their own constraining and enabling conditions of discourse and practice and 'barriers to perception' (Goffman 1959:106; see also Gibson 2014): frontstages and backstages. It is in the front regions that actors carry out their planned performances, the realm of official discourse, whereas backstage they are generally able to 'let loose' and act in a much more free and less calculated manner, 'where the impression fostered by the performance is knowingly contradicted as a matter of course' (Goffman 1959:112). 
Goffman's broader point is not that every backstage region necessarily contains certain universal characteristics, as if positing a back region to some moment of interaction meant first identifying the presence of specific traits. Simply put, the point is to draw a variable boundary between two interconnected empirical territories, each delineated by differing norms and conditions of performance talk and behaviour, but also access. In government, the backstage tends to be a restricted domain of talk and action, the reasons for this dating back to the earliest formulations of the need for secrecy in raison d'État (Chambers 2004; Foucault 2009; Horn 2011; Neocleous 2002). By contrast, we can understand the frontstage of government as the space of the symbolic public or civil society, where different arts of governing become openly intelligible and take form and effect. In the case of cover storying, we can think of the frontstage as the spectacular space of the calculated falsehood, the cover story, while backstage, actors who may be in on the use of deception can speak more truthfully about what is being carried out. The relationship between front and backstage is not causal in a linear sense, as if the backstage was the moment of creation and the frontstage the presentation, but back and forth, each shaping and informing the other in a continuous feedback loop.

Finally, in my analysis of cover storying and Cobra Mist, I make use of three additional concepts from Goffman's (1959) book. These are staging talk, performance disruption, and impression management. First, staging talk refers to the considerable time and energy spent backstage reflecting on how past performances were taken by audiences, on how future performances might be improved, on mistakes made by certain performers, on boundary changes, on the next strategic move in the performance. As Goffman (1959:176) writes, 
When team-mates are out of the presence of the audience, discussion often turns to problems of staging. Questions are raised about the condition of sign equipment; stands, lines, and positions are tentatively brought forth and 'cleared' by the assembled membership; the merits and demerits of available front regions are analyzed; the size and character of possible audiences for the performance are considered; past performance disruptions and likely disruptions are talked about; news about the teams of one's colleagues is transmitted; the reception given one's last performance is mulled over in what are sometimes called 'post mortems'; wounds are licked and morale is strengthened for the next performance. Staging talk is central to a group's ability to control the definition of the situation in that they must always be seeking ways to improve and recalibrate future performances on the basis of what has been done and said to audiences in the past. Without staging talk, future performances may lose their persuasiveness or be inconsistent with past performances provoking audience suspicion.

Second, performance disruption occurs when an act, mistake, outcome, or misbehaving artifact results in the performance not going as planned, when 'the reality sponsored by the performers is threatened' (Goffman 1959:212). While performance disruptions are imagined and simulated in rehearsal, contingency plans fail and certain sources of disruption will always be overlooked by actors backstage and in the midst of unfolding interactions. Performance disruption takes many forms. One source of performance disruption is the unwanted disclosure of secrets, or leaks, whether it be of classified information or the status of the performance as a deceptive one (Goffman 
1959:141). The inevitability of leaks in government is proof that States are not the unified actors they claim to be. The reality of the State as a jumbled network of actors and institutions guarantees a degree of competition and struggle between elites, as well as information mismanagement. Strategic and accidental leaks are thus commonplace, to the point where even 'the most authoritarian regimes cannot completely hide the political backstage' (Bail 2015:100; also see Gibson 2014; Ku 1998; Sagar 2013). Leaks undermine the self-image of the State because they expose 'discrepancies between the public and private behaviour of the state, that is, discrepancies between the public and discursive frames states use to sustain their epistemic authority over social problems and the clandestine activities they may use to redress them' (Bail 2015:101).

When a frontstage performance is successfully disrupted, performers may attempt to save the show. Here the group must adopt, modify, and improvise reactive strategies to either save the group's secrets or in turn alter the performance from one of deception to openness without provoking an unmanageable conflict and putting an end to the group and interaction once and for all. One strategy to this end is to multiply and reterritorizalize a backstage: 'By invoking a backstage style, individuals can transform any region into a backstage' (Goffman 1959:128-129). Paglen's (2010a) account of the reaction of US Air Force officials to the 1986 crash landing of a top secret stealth fighter jet in California, US exemplifies this strategy. The plane crashed on non-secret property and was thereby attended to by rural firefighters from the outside world. Rather than become witnesses of a now public US military innovation, the firefighters were made to swear a secret oath not to tell; they became unexpected members of a military backstage. 
Third, impression management strategies are used by actors striving to reduce the possibility of performance disruption by acting in a 'thoroughly calculating manner' (Goffman 1959:6), some preemptive, the result of planning through backstage talk, others reactive and improvised. This capacity to calculate and re/mould one's performance to manage impressions, Goffman (1959:9) argues, 'sets the stage for a kind of information game - a potentially infinite cycle of concealment, discovery, false revelation, and rediscovery.' Attempts to manipulate the definition of a situation through impression management are not always successful, as a certain 'shading of conduct' (Goffman 1959:7) or misplaced symbolic cue may have been overlooked by the performer. Two relevant strategies of impression management are discipline, the capacity of insiders to perform persuasively, without error, and without getting 'carried away' (Goffman 1959:216); and circumspection, the use of 'foresight and design in determining in advance how best to stage a show' before taking it frontstage (Goffman 1959:218).

Dramaturgical circumspection is in part realized in the capacity of insiders to prepare convincing scripts, in this thesis cover stories, which must be carefully written on the basis of the imagined reactions of an audience, as well as the audience's 'access to information sources external to the interaction' (Goffman 1959:222). Scripts must also be convincingly performed, which requires not just a good script, but use of the right actors and artifacts to do the job. Key to the design of an effective performance is the ability of insiders to decode one's own performance from the perspective of others. This is true both at the level of content, or how will audiences will react to what is being said, and at the level of 'meta-notification' (Ryan 2006). Meta-notification denotes the array additional 'relational information that can be extracted from, or inserted into, a 
notification' (Ryan 2006:245) or performance. Meta-notificational questions on behalf of recipients of information focus on the who, how, and when of notification, which allows them to 'make inferences about relationships and content' (Ryan 2006:246). Notifiers, or insiders to the performance of secrecy, tailor their frontstage performances to the expected meta-notificational expectations of audience members.

To summarize, it has been argued that combining governmentality studies with Goffman's dramaturgical perspective puts me a favourable position to systematically engage with Abrams' (1988) problematic of the State, government, and secrecy. Through strategies of secrecy and deception, government actors reserve the sovereign right to perfect, alter, and control their performative relationship to publics, maintaining the upper-hand through such arts of governing as statistics, police, and surveillance, always preferring an image of coherence and interconnection (i.e., the State) over that of disarrangement and dispersion (i.e., government). Such an approach begins by supplementing the diagnostic focus of governmentality studies on the abstraction of rationalities, technologies, and modes of subjectivity from frontstage and manifest government programmes with a turn to secret back regions. By documenting and describing the hidden and restricted realm of the backstage, one can expand the focus of governmentality studies to encompass a broader analytic terrain, making visible the ongoing processual nature of creating, contesting, adopting, and abandoning strategies of government rule before going public. As Bail (2015:98) reminds us, to date 'cultural and political sociologists have scarcely recognized that most discursive frames are created behind closed doors.' Here it is advantageous to consider what Goffman calls backstage talk, performance disruption, and impression management and how these backstage 
moments shape and influence the production of frontstage conceptualizations and re/articulations of (State) governance. In an effort to synthesize what has been thus argued, beginning with Abrams' (1988) 'Notes on the Difficulty of Studying the State' and through to governmentality studies and Goffman's dramaturgy, a turn is made to the more particular arrangement of institutional practices devised for the enactment of cover storying. The notion of cover storying is proposed as a general conceptual lens for the analysis of deceptive forms of government which operate behind false narratives. Questions about whether or not government actors should be allowed to use cover stories are not addressed by this framework, left instead to sociologists of ethics who take such issues as their central concern (e.g., Bok 1989, 1999; Barnes 1994). The focus is on how government cover stories are produced, maintained, and altered over time, the effects of cover storying on the backstage practices of government officials involved, and the role of cover storying in effecting a mysterious rather than transparent relationship between government and publics.

\subsection{Cover Storying, State Secrecy, and the Art of Deception}

In this final section, I want to develop the notion of 'cover storying' into a general concept that can supplement existing scholarship on the sociology of secrecy and deception in government and in organizations (e.g., Arendt 2001; Bail 2015; Becker 1996; Best and Walters 2014; Bratich 2006; Gibson 2014; Goffman 1969, 1986; Harrington 2009; Ku 1998; Mearsheimer 2011; Paglen 2010a; Piché 2012). Although I present this concept before the analysis of Cobra Mist, thereby following the standard formula of scientific argumentation, this is largely misleading. My understanding of 
cover storying and the literature I draw on to help develop it into a general concept, governmentality studies and dramaturgy included, arose alongside my data analysis in a messy and iterative cycle best described as 'abductive' (Timmermans and Tavory 2012). My conceptualization of cover storying involves thinking through eight interrelated processes. These are, for lack of better terms: secrecy, imagination, forms of deception, the concealment of contingency, performer-spectator distancing, journalistic reporting/denunciation, and context. I begin with secrecy and imagination.

It goes without saying that some degree of secrecy is necessary in order for cover storying to take place. Secrecy enables government officials the freedom to say one thing publicly, on the frontstage, while simultaneously doing another backstage and in secret. The study of cover storying in government thus requires some analysis of both front and back regions, paying particular attention to how officials navigate between the two worlds. Backstage is where possible cover narratives are deliberated (staging talk) and decided upon, a practice which requires government actors to acknowledge the inherent contingency of the social world, that things could and can always be different than they actually are. In other words, cover storying requires an imagination, the ability to construct and entertain alternative discursive frames for reality (Arendt 2001:5; Bail 2015). It is this fragility of the social world, as opposed to the natural one, Arendt (2001:6) argues, that makes deception a forever enticing strategy for politicians and military leaders in particular, who wish to hide certain things from publics or manage others' impressions through selective image-making. Cover narratives are convincing because things could have easily been exactly as the deceiver claims they are. In some cases, they may be more persuasive than the ultimate truths they suppress, 'since the liar 
has the great advantage of knowing before hand what the audience wishes or expects to hear' (Arendt 2001:6).

Although Arendt's (2001) essay is titled 'Lying in Politics: Reflections on the Pentagon Papers' (my emphasis), as Michel De Montaigne long ago observed, deception can take a multiplicity of forms. A useful distinction for thinking through processes of cover storying is drawn by Shauer and Zeckhauser (2009) between lying and paltering. Whereas lying involves the intentional communication to another of a narrative they know to be literally false with the goal of getting them to believe it, paltering refers to that much more capacious grey area between lying and truth-telling in the purest sense of the words. For example, when one friend asks another if they like their new hat, the friend being asked their opinion may choose to act offended and respond by repeating the question: 'do I like your hat? C'mon!' The intended effect of the statement being that the friend will assume the answer is yes when it is actually no. It is intentionally misleading, but still literally correct to say. In Shauer and Zeckhauser's (2009) terms, it is an example of paltering rather than lying. Obviously paltering in this sense is a routine and constitutive element of interpersonal relations, with both positive (e.g., the friend avoids hurting the other friend's feelings) and negative consequences (e.g., the friend with the new hat later finds out the friend's real opinion, weakening trust). Paltering, however, like deception, has many forms. At the institutional level, paltering can have far grander sociopolitical significance, as when government and corporate actors palter in a court of law to avoid or lessen fines for organizational misconduct.

The distinction between lying and paltering does two things for the analysis of cover storying. First, it expands the focus to include those hazier forms of deception that 
might not fit a conventional definition of lying. Second, at least in the case of Cobra Mist, paltering sheds light on a crucial tension in the art of cover storying in government: that the need to one day justify lies to publics - as no organizational secret is eternal (Gibson 2014) — can make paltering a more attractive deceptive strategy given its hazier moral and legal status in Western social and political relations (Shauer and Zeckhauser's 2009).

Tracing the art of deception through cover storying not only involves thinking through secrecy, imagination, and forms of deception, but should also be thought of in a more theoretically abstract sense as a unique governmental technology with an underpinning logic of power. Here I find it useful to turn to the work of Elias Canetti, who reflects on the art of 'masking' in his book Crowds and Power (1978). Cover storying is certainly a form of masking. Canetti (1978:374) begins his analysis with a luring account of the ancient conception of masking, very different from our modern one, which begins and ends with a transformation, the unmasked and masked subject blurring into one another to yield the 'figure,' which he sees exemplified in the human-animal hybrids of ancient mythology, from Sekhmet, the woman-lioness, to Anubis, the manjackal. More than just figures, these mythical characters are distinctively 'free' in that they are perfectly symmetrical. Both masked and unmasked states of being are 'equal in importance; neither is ranked higher than the other and neither is hidden behind the other' (Canetti 1978:374). And thus through this radical state of equivalence the distinction loses its meaning, a form which represents simultaneously 'the process of transformation and its result' (Canetti 1978:374).

Today the distinction between masked and unmasked is alive and well. The 'free figure' in this pure and ancient form is inconceivable. When it comes to the masking of 
government programmes under liberal-democracy, longstanding political procedures are in place which inhibit the two conditions of being from blurring into a unified state of equivalence (cf. Rosanvallon 2008). Behind every imagined cover story is always assumed to be concealed something worth knowing. Thus, liberal-democratic publics, journalists, and opposition parties expend considerable energy countering perceived uses of cover stories in government, blaming known or alleged deceptive government programmes for concealing their involvement in something unlawful or otherwise that 'the Public' has a fundamental right to know.

Canetti illuminates three additional features of masking that help think through cover storying as a governmental technology, and which feed into the broader deceptive performance of the self-image of the State. First, the rigidity of the mask erases the fluidity of local contingency, of governance in process, displaying in its place an image of 'perfect fixity and sameness' (Canetti 1978:374). Literal masking, to use Canetti's example, hides all or some of an actor's facial expressions, many of which may be necessary symbolic cues for communicating shared symbolic meanings to others. Simply put, the mobility of the face is frozen. In a figurative and governmental sense, what it is erased from view are not important facial expressions per se, although this is certainly part of it, but the actual meaning and content of a government programme, which, made up actors in a processual network, is also made to appear as a unified and orderly actor. Through the inaccessible fixity of different forms of masking, government appears as a singular and monolithic State. The internally delineated binary between the State and the Public comes to life (Mitchell 1991; Passoth and Rowland 2010). 
Second, masking 'sets a distance between itself and the spectator' (Canetti 1978:375), serving as a 'boundary object' (Star and Griesemer 1989) between between government programme and outside publics. The spectator 'may come nearer to him, as sometimes in a dance, but he must always stay where he is. To fixity of form is added fixity of distance' (Canetti 1978:375). Distance invites speculation and intrigue from those outside. As Canetti (1978:375-376) writes, 'Everything behind the mask is mysterious.... The mask facinates and, at the same time, enforces distance.' That which is unknown and mysterious is some how always worthy of our knowledge and attention (see also Simmel 1906 on this point).

Third, cover storying not only enables government actors, but constrains them in their capacity to do and say certain things publicly and backstage. As Canetti (1978:377) observes, masking not only radiates 'outwards, affecting those who do not know what it contains; a mask is something worn by a man and he is inside it.' The deceiver must publicly perform the mask to an audience, and therefore must act within defined limits at all times by 'corresponding to the nature of the mask' being performed (Canetti 1978:377). On the frontstage, for example, officials involved in the use of cover storying cannot simply say anything, but must stick to discursive frames that are consistent with their assembled cover narrative. Another source of contraint concerns the fear being discovery by outsiders (Canetti 1978:377). Like Bernie Madoff in the years leading up to the exposure of his Ponzi scheme, conveyors of a cover story must live out their days in perpetual apprehension of leakage and exposure (on Madoff's fear of discovery, see Gibson 2014). In government, the issue of discovery is complicated by the need to publicly justify after the fact any decisions or deliberations that publics were previously 
unaware of (Chambers 2004; Thompson 1999). The goal is not only to create plausible cover narratives that publics will accept, but ones that will hold up publicly should the truth ever become known.

When cover stories are blown, it is often thanks to the tireless work of investigative journalists in the news media. The news media have for centuries played a pivotal role in the management of government secrecy (Ku 1998; Rosanvallon 2008; Thompson 2000). At the same time, it would be naïve to suggest that the news media are solely there to challenge government secrecy; through the simple act of 'objective' reporting, as when newspapers reproduce press releases without adding significant detail or commentary, journalists unwittingly help constitute a cover narrative as an instance of truth-telling. Simply put, secrecy is either enacted and reproduced through the media, as journalists negotiate with political officials, engage in self-censorship, and uncritically report on alleged matters of fact, or it is challenged and undermined through the investigative art of 'denunciation' (Rosanvallon 2008).

When it comes to media reporting on military activities in the UK, journalists are in a uniquely sensitive position. Since 1912, they have been under the guidance (although non-legally binding) of Defence Advisory Notices (DA-Notices), which discourage journalists from publishing certain matters pertaining to national security (Moran 2012). DA-Notices are issued by the Defence, Press and Broadcasting Advisory Committee chaired by the Director General Security Policy of the Ministry of Defence and a representative of the Press Association. According to the online journal Defence Viewpoints, between 1997-2008 the committee issued 30 letters to news editors notifying them of their ostensible breach of the DA-Notice code and reminding them of the need to 
censor their reporting accordingly (Roberts 2008). Journalistic freedom to report is therefore is in part stymied by the need to act in congruence with State national security interests for fear of undoing rapport or worse, being accused of unprofessional practice resulting in scandal (on latter, for example, see discussion of 'D-Notice Affair' involving investigative journalist Chapman Pincher in Moran 2012:Ch.4). On the other hand, since the 1960s especially, one finds heightened journalistic cycnicism toward DA-Notices, resulting in an increased propensity to denounce national security programmes rather than respect them through cautious reporting and self-censorship (Aldrich 2003:607-608; Moran 2012:Ch.3).

First appearing during the French Revolution, the practice of denunciation 'was then simply, as the etymology would have it, to make known, to expose, to unveil, to reveal. Publicity was expected to restore order to the world' (Rosanvallon 2008:42). For Rosanvallon, denunciation achieves this publicity effect by first, shaping the political agenda and second, reinforcing the collective conscience. With the emergence of denunciatory logic during the French Revolution as an increasingly popular means of holding government democratically accountable comes a whole journalistic tradition of political muckraking and exposure (Rosanvallon 2008:43). By the $19^{\text {th }}$ century, denunciation as a general strategy of media oversight was reserved for those more rare events raised into scandals, whose framing today predominantly revolves around notions of transparency and office holder reputation rather than political ideology (see Rosanvallon 2008:46-51). In any case, the point being that is in large part through the denunciatory powers of the media that the openness/secrecy boundary between public and government is constituted and re/defined (Ku 1998). Access to secret information 
provides media and other non-State actors with an opportunity to undermine the basis of the self-image of the State "by amplifying contradictions between the public and secret behaviour' of government (Bail 2015:103). In addition to media self-censorship and the uncritical reporting of government press releases, the news media serve a denunciatory function aimed at challenging the art of cover storying through practices of investigation, speculation, and exposure (Clayman and Reisner 1998; Flynn 2006; Ku 1998; Moran 2012; Negrine 2008; Reich 2008; Schudson 1993).

Finally, the foregoing characteristics of cover storying are not universal, but context specific. It matters not only how and why, but which institutional network is doing the deception and when. It has always been easier for certain institutionallyauthorized actors to get away with deceiving publics than others, actors involved in military and security programmes chiefly among them. Thus, US Naval military expert and practitioner, William Glenney IV (2009:254) can declare in a recent edited volume on political deception that 'Military deception is fundamentally different from deception in any other context and different from what is normally understood when talking about deceiving or lying.' It also matters when political secrets are held and deceptions presented to publics, for everything from wars, to the overarching logic of political power (e.g., capitalist versus feudalist), to the structure of government (e.g., right wing versus left) is bound to make a difference. Had Cobra Mist occurred in George Orwell's (1949) superstate of Oceania, for example, things would have no doubt unfolded much differently than they did in late-1960s Cold War Britain.

Cover storying is the main conceptual lens adopted in analysis of Cobra Mist in Chapter 4. In the course of the analysis, each of the above elements of cover storying is 
further developed and substantiated empirically. With respect to Abrams (1988), I argue that dispersed governmental programmes speak to publics through the language of the State, a language of order, interconnection, and coherence. Government agencies carefully move from back to frontstage and back again to share with attentive publics a narrative that recasts their actions in terms of consumable rationalities and inter- and intra-governmental consensus, participation, and competency. Yet behind the curtain of secrecy is the contingent assemblage of actors and artifacts, which I am calling government, responsible for what is presented to publics frontstage. Cover storying is thus central the performance of the identity of the State, for it is through the ability to deceptively govern publics through such technologies that information can be publicly withheld, disinformation spread, and distorted self-images realized. Next, I discuss research design and method. 


\section{Chapter: Research Design and Method}

'Like any other kind of work, empirical research is not a matter of mere 'application' of a given set of paradigmatic assumptions, but of active determination of those assumptions in practice... Researchers do not so much "apply" or "follow" paradigms in their work as they explore particular topics, in particular sites and, having to cope coherently with all the puzzles and tensions stemming from the complexity of the phenomena they investigate, they extend, synthesize, and/or invent concepts'

(Tsoukas and Knudsen 2005:13)

To examine matters of secrecy and deception in Cobra Mist, this thesis uses a case study research design (Compton-Lilly 2013; Stake 1995). A central tenet of the case study method in sociology is to provide justification for why we chose a particular case over others. Existing methodological wisdom, however, is complicated by the selection of sites that are distinctively secretive and deceptive. Flyvbjerg (2001:79, Figure 6.1), for example, outlines four 'information-oriented' strategies for case selection: extreme/deviant, maximum variation, critical, and paradigmatic. Iterations of the same four strategies can be found throughout the literature on case study research, often under different names. While these four strategies neatly apply to cases of known or at least generally knowable sociological phenomena, their applicability to secret and deceptive sites is much less clear.

It is tempting to suggest that a secretive and deceptive case like Cobra Mist is atypical. But how could we know? The whole idea of operating certain government programmes in secret is to remain undiscovered by unwanted observers. Without any sense of the success and fail rate or total number of secretive and deceptive sites, one cannot reasonably infer that this or that case is unusual. Something similar can be said for critical case selection, wherein cases are chosen for their ability to speak to other cases deductively: 'if this is (not) valid for this case, then it applies to all (no) cases' (Flyvbjerg 
2001:79, Figure 6.1). Again, given the objective of secret sites is to remain secret and provided the lack of data about secret sites that effectively escape the limits of public knowledge, case deductions of this type are out of the question. Instead, what one finds in research on secrecy and deception in organizations is case study opportunism.

There are two ways of being opportunistic in this sense. If a first move is for sociologists to expend greater energy scouring the declassified corners of different archival facilities in search of cases like Cobra Mist, a second move, following Arendt, is to directly engage with unfolding controversies, such as those involving leaks and whistleblowers (Best and Walters 2013). Indeed, research openings on secret sites are often not discovered by social scientists, but presented to them in the form of an unfolding scandal or controversy. Thus, Arendt's (2001) most pointed commentary on government deception comes not from her decades of experience in the archives, but from the highly politicized leaks of ex-Pentagon staffer, Daniel Ellsberg. The recent and ongoing leaks initiated by former NSA employee, Edward Snowden present a similar opportunity to sociologists. Other examples of such opportunism include Gibson's (2014) analysis of Bernie Madoff's Ponzi scheme, Morselli and Giguere's (2006) social network analysis of the role of different professionals in structuring a Canadian cocaine and hashish importation network, and Baker and Faulkner's (1993) examination of GM pricefixing conspiracies. Cobra Mist belongs in the same opportunistic category, as it is relatively rare in archival research to stumble upon a wealth of declasssified documentation detailing the backstage organizational practices of cover storying.

A second justification for the choice of Cobra Mist is the heterogeneity of actors and institutions involved. Cobra Mist lies at the intersection of an array of social and 
political actors, including British and American politicians, publics, journalists, radar scientists and technicians, military and public relations personnel, and Soviet and Sovietbloc forces. The lasting legacy of Cobra Mist, particularly in Britain, brings in British and international tourists (public tours are carried out on the land adjacent to Cobra Mist during the summer season, where visitors are encouraged to learn about Cobra Mist from a distance), audio-visual artists that wish to capture the intrigue of the site, such as Emily Richardson, ${ }^{3}$ and even UFOlogists who take interest in the site's possible connection with the Rendlesham Forest incident in 1980, Britain's most famous alleged UFO sighting. All of this to say that the broad range of actors involved in the construction, operation, politicization, and representation of Cobra Mist make it an especially rich empirical entry point into the rhizome of government secrecy.

\subsection{Data Collection}

It is surprising that only a fraction of sociological research on secrecy involves analysis of declassified records from the backstage, either accessed through publicly accessible archives, ethnography, or access to information laws. As Baker and Faulkner (1993:841) observe in their seminal examination of secrecy in three American price fixing schemes, in most existing literature in sociology, 'the internal organization of conspiracies is treated as a "black-box".' This is especially true for governmentality studies, which seems to favour documents that are public rather than internal given the interest in rationalities and technologies of government in official discourse. In general, most sociological investigations into issues of political secrecy are based on publicized reports

\footnotetext{
${ }^{3}$ http://www.animateprojects.org/films/by_date/films_2008/cob_mist. Accessed 6 April 2015.
} 
and newspaper articles. Melley (2012) is notable for having stressed in recent years the importance of fiction in research on secrecy. But while official publications, the news media, and fiction are significant data sources for exploring sociological questions about secrecy and deception in government, they do not exhaust all that is available. The declassified texts acquired through public archives and access to information law inform the analyst of processes these other three data sources cannot (on access to information in sociology, see e.g., Walby and Larsen 2012). Whereas these first three data sources (i.e., official reports, newspaper articles, fiction) can speak to the frontstage of government process, backstage texts allow us to examine, however incompletely, processes of government knowledge creation, decision-making, and power relations carried out in secret. The point is that while there is a growing literature on government secrecy in sociology, few of these studies analyze secrecy in terms of the various insider actions, contestations, and beliefs that are represented in backstage texts, and which can be systematically acquired through archives and access to information requests.

Declassified records on Cobra Mist were collected from four different archival facilities in the UK: the National Archives in Richmond, Surrey; the British Library archives in London; the Suffolk Public Records Office in Ipswich, Suffolk; and the National Trust Collections in Bury St. Edmonds, Suffolk. A major limitation of this project is that it does not include analysis of records from archives in the US, and therefore is limited to the story of Cobra Mist from records available in the UK which pertain mostly to the deliberations, decisions, and communications of officials in the Ministry of Defence (rather than from the US Department of Defense and United States Air Force). The same can be said for newspaper articles and press releases, which for this 
project come primarily from UK sources. No doubt an entirely separate account of Cobra Mist could be told from the perspective of the US. At each of the archives I visited, records were either digitized using a personal camera or copied and printed, as some sites do not allow digitization of records. At the National Archives, a total of 3,760 pages of declassified insider records were digitized on Cobra Mist. From the news section of the British Library archives and on microfiche at the Suffolk Public Records Office, printed copies of newspaper articles on Cobra Mist were obtained from the Daily Express and East Anglian Daily Times, respectively. At the National Trust Collections, permission was provided to digitize any National Trust records which contained references to Cobra Mist. Leads as to which records might prove more pertinent than others were provided by a long time National Trust employee who had played a pivotal role in the National Trust's acquisition of the Atomic Weapons Research Establishment side of Orfordness in the early 1990s. (Although the National Trust does not own the Cobra Mist facility or the part of Orfordness it occupies, by taking control of the remainder of Orfordness and opening it up for public viewing, it had frequently encountered the subject of Cobra Mist in its research on Orfordness history, its writing of scripts for public tours, and so on.) Declassified records from the National Archives make up my primary dataset.

To add an ethnographic component to the study, a three-hour public tour of Orfordness was attended with Dr. William Walters (supervisor) and Dr. Seantel Anais (University of Winnipeg) in July 2014 called 'Bombs and Beasties.' As the tour is described online: 'Discover the natural and military history of the Ness on this all day leisurely walk with a warden. See areas not normally open to the public.' The tour is offered once a month during the summer season. Throughout the tour, pictures of the site 
were procured and questions posed to the tour guide on the theme of secrecy and Cobra Mist. Thoughts and observations were recollected by writing fieldnotes after the visit.

Finally, with approval from the Carleton University Research Ethics Board (case \#101292), many locals in nearby towns were conversed with on the topic of Cobra Mist, met opportunistically through encounters in stores, museums, streets, and especially pubs. As it was not the focus of my project, I did not record and transcribe interviews and I do not quote the individuals I conversed with. But these conversations were still significant in shaping my understanding and analysis of Cobra Mist, and so should be mentioned. Conversation came about easily as most of the locals were exceptionally friendly and keen to talk about Suffolk's military history, a topic on which many were extremely well versed and knowledgeable. My Canadian accent, which many confused for American, also proved an asset, as the simple act of speaking aloud to someone was usually enough to receive a host of questions about origin ("Where are you from?") and purpose ("What brings you to England?'). In most cases, stating interest in Cobra Mist as the purpose of the trip was sufficient to spark what were sometimes lengthy conversations about the operation, usually learning far more than could be recalled on paper after conversation. Data from conversations with locals was used to contextualize my analysis of archival records, providing me with leads on interesting themes and with a sense of how locals think and feel about Cobra Mist.

\subsection{Data Analysis}

Data were analyzed using open and theoretical-based coding strategies combined with discourse analysis. Open coding was used to address interest in the substantive content of 
the different texts. Following broad theoretical interest in the relationship between the State, government, and secrecy, having read Abrams (1988), an open coding approach was used to first code the data for any statements related to the themes of secrecy and representations of State and government. The first includes a broad sweep of the data of any direct or indirect mentions of secrecy, closure, deception, and invisibility, from talk of keeping certain details secret, to cover ups, to the obvious top-secret classification stamps at the tops of pages. The goal was to work with an operationalization of secrecy that was as broad as an unspecified as possible, coding any material that seemed, even by the wildest extent of the imagination, to pertain to secrecy and deception. The notion of representations of the State and government entailed similarly coding for different conceptualizations and articulations of governance that inside actors discussed, debated, and developed backstage before and after going public. This first phase also involved forming a selective index of available archival documents by compiling a brief summary of the content of potentially relevant texts to be referred in later stages of the analysis.

Theoretical interest in the dramaturgical perspective of Goffman, which came after reading through the data on Cobra Mist, entailed going through the same dataset again this time coding for any mentions of backstage/frontstage strategic maneuvering along with the concepts of backstage talk, performance disruption, and impression management. Coding for the first meant highlighting any instance in which government actors could be interpreted as moving, physically (e.g., releasing a press statement) or imaginatively (e.g., discussing backstage how a public might interpret a published leak), between the two worlds of frontstage and backstage. As new secrecy-related themes and ideas emerged during the analysis and writing phases, they were compiled, returning to a 
more focused sample of the dataset whenever possible in search of supporting passages, albeit often to find more yet unexpected themes and ideas (Timmermans and Tavory 2012). However, since coding in this way only provides a denotative understanding and general overview of how often the three themes emerge within the dataset, the shift to discourse analysis is necessary to analyze the data's broader rhetorical configuration.

Sociological (versus socio-linguistic) discourse analysis is resistant to any rigid, step-by-step formulaic rendering, making it a difficult strategy to account for 'methodologically' (Baker 1994; Tamboukou 1999; Tonkiss 2004). This thesis takes discourse analysis to be a dynamic approach to data analysis, moulded and remoulded throughout the analytic process according to an iterative cycle set in motion by emergent analytic concepts and the needs of the research question as they become more intelligible to the analyst. As the researcher goes through the data, they read and re-read, but rarely, if ever, do they reach a state of complete familiarity with the texts analyzed. Just as is true in phenomenology (Marion 2002), such a state of total understanding is impossible in the world of discourse analysis, particularly when the texts one is analyzing come from a world far removed from their own. Indeed, such a total state of familiarity with a set of texts is not even desirable, for the major goal of discourse analysis is not to familiarize readers with elements of social life, but precisely to estrange them from certain discourses and practices by making them unfamiliar (Berger 1963).

On the one hand, questions about why specific documents are classified according to this or that level, what parts of the document are the most sensitive, what parts mattered most to insiders at the time, an actor's intentions in preparing a document, or even the sense of urgency understood in reading certain texts before declassification, will 
always remain unanswered to some degree (Rappert 2012). In some ways, the remnant classification stamp at the top of declassified documents tells us more about our distance from declassified texts than our proximity. On the other hand, this is not to suggest a hierarchy of positions, as if having worked at Cobra Mist meant possessing the knowledge and perspective of the discourse analyst and more. For one, the highly compartmentalized organizational makeup of secret government operations inhibits insiders to closed worlds from knowing any more than strictly necessary. ${ }^{4}$ Apart from select offices and officials, few insiders could possess a total awareness of the workings, plans, and decision-making processes of Cobra Mist. At the time of its operation, insider communications were mediated and controlled by the expanse of inside communication networks, determined by individual need to know bases, clearance levels, and chain of command. There is thus no "deeper level" or ultimate "inside position" from which all secret work of the covert state is visible' (Melley 2012:26).

All of this to say that what the discourse analyst has access to in declassified form, in this case final and draft reports, maps, and documented communications from a broad network of State, public, and private actors, is different than the limited access experienced by most Cobra Mist insiders. As Curtis (2004:250) reminds us, 'without a working understanding of the organization of knowledge production, one cannot locate the traces of it.' Examining the organization of knowledge production is precisely the aim of a Foucaultian-inspired discourse analysis. Discourse analysis allows us to adopt a perspective that insiders to this same material were not necessarily aware of. Such a

\footnotetext{
${ }^{4}$ While the post 9/11 era has placed a great deal of emphasis on enhanced insider access and information exchange (Gill 2006), a change that worked to the advantage of recent American whistleblowers like Chelsea Manning and Edward Snowden (i.e., lateral access to multiple file databases), recall that Cobra Mist is some 15-20 years from the official dissolution of the Soviet Union. Therefore, compartmentalization remains especially high.
} 
perspective is novel, but can also be dangerous, particularly when the research is principally evaluative (i.e., assuming the actors could have done $\mathrm{X}$ having known $\mathrm{Y}$, when in reality $\mathrm{Y}$ was not generally known due to the institutional structure), or when researcher's believe that their unique perspective on the material constitutes the final and most truthful account of events rather than a valuable piece of a larger puzzle.

Following a core methodological emphasis in Foucault, my the use of discourse analysis began by, first, identifying central and recurring themes, logics, and arguments within the texts, in particular those seen as related to my theoretical interests in representations of secrecy. This first move in discourse analysis is long, tedious, and confusing, and often involves producing more analytic connections than one can reasonably make sense of. The research question at this point is meant to stay as open as possible coupled with the agnostic analytic ethos necessary to capture as much of what is at stake in the texts as possible. Agnosticism here does not mean 'disinterestedly objective' in the positivist sense, as if failure to set aside entirely one's idiosyncrasies were failure to be objective. Rather, agnostic refers to the ability to 'suspend disbelief' (Curtis 2004:242) as much as possible in order to identify the broadest range of relevant actors, artifacts, associations, logics, themes, arguments, and mobilizations in the text as we possibly can without abandoning the reflexive embrace of one's unique self and 'positionality' both inside and outside the text (Adler and Callero 1987; Haraway 1988).

Second, with this first move of broad identification comes a deeper reading into what Tonkiss (2004) calls patterns of association and variation. Patterns of association are seemingly natural, taken for granted connections between words, sounds, feelings, arguments, people, objects, etc. Naturalized patterns of association are pervasive in 
everyday discursive formations and practice, and it is their denaturalization as contingent and contested social constructions that has long occupied much genealogical work detailing the forgotten moments of knowledge creation that make us up today. Patterns of variation refers to the opposite, finding breaks, contradictions, and connotative differences as in the construction and reproduction of taken for granted binary discursive codes (Alexander and Smith 1993). The popular political dichotomy of an unproblematic, zero-sum relationship between secrecy on the one hand, and openness on the other is an example (Ku 1998).

Third, there is the question of presence versus absence. Discovering the presence of silences in discourse is central to the genealogical ethos adopted by Foucault in his 'insurrection of subjugated knowledges' (Foucault 1980:81). Foucault's insurrection of subjugated knowledges does not occur in a vacuum, but in constant proximity to acts of collective contestation and struggle in society—struggles around access to archives, for example (Moran 2012; Moynihan 1998). ${ }^{5}$ Where one regime of truth prevails, other possibilities are subjugated and forgotten. Here Foucault (1972:27) asks, 'how is it that one particular statement appeared rather than another?' Silences must be read against the backdrop of history. Within the power of a certain regime of truth to create, shape, alter,

${ }^{5}$ This project benefits from the large dump of declassified documents made available in Britain's National Archives after the Cold War by then Cabinet member, William Waldegrave under Prime Minister John Major (1990-1997). The Waldegrave Initiative pressured the UK government at the time to re-review and release a greater number of secret Cold War documents to the National Archives. Waldegrave collaborated with British historians on the matter, determining at a series of meetings with British academics like Peter Hennessy, the kind of records that would be of interest (Hennessy 2012). At the forefront of these discussions between Whitehall politicians and academics were records that were deemed too sensitive to release after the normal 30 year classification expiration period. By the end of 1990s, an additional 96,000 files were released into the archives, covering matters that were until then concealed from public viewing, especially files on atomic weaponry and espionage. Coupled with the introduction of the UK's Freedom of Information Act in 2000 (put into force in 2005), lasting momentum from the Waldegrave Initiative has proven a crucial force in ongoing struggles around declassification and information access in the UK to which this project is indebted. 
and reproduce normative subject positions, actor enrolments, and webs of belief lays the suppressed possibility of counterfactuals that can be resurfaced through the creative work of radical historicism. The dual emphasis on denaturalization and digging up subjugated knowledges means that discourse analysis is not a neutral project, but an inherently political one. Rather than reproduce the status quo, discourse analysis destabilizes what is taken for granted in order to open up the possibilities of an 'otherwise,' a new way of thinking, acting, and relating to self, one another, and the world's objects (Colwell 1997; Walters 2012).

Fourth, on the topic of scale, rather than focus on the big stuff of broad social forces and hardened social structures, a Foucaultian-inspired discourse analysis is one that highlights the overlooked significance of the often mundane little things in accounting for a specific discursive and practical field of government. This emphasis on the more minor and concrete moments of social life is one that benefits from a radical treatment of interaction already found in Foucault, but pushed further by scholars like Bruno Latour (e.g., 2005, 2013) in actor-network theory (ANT). In ANT, people and material objects are treated symmetrically, a principle which is meant to operate as a 'heuristic device to resist common habits of thought' (Bourne 2012:154), rather than some overarching statement about the equality of actor/object power relations, which in any case remain unequal. As a methodological strategy, ANT's principle of symmetry helps one better capture moments of object agency overlooked in classical approaches to sociology, but without falling prey to a material and technological determinism. All objects can exercise something akin to agency under the right conditions, including the mundane tools central to bureaucratic and administrative routines. Too often are non- 
human actors as seemingly insignificant as classification stamps or military emblems (see Paglen 2010b) put to the wayside in conventional sociological accounts of government secrecy, although one must be careful here not to be overly reductive and deterministic.

Archival texts, from this perspective, can be irreducible actors like any other (Prior 2008). Examples include the instrumental function of texts as delegates to achieve specific ends such as the biopolitical governance of population by statistics (Foucault 2009), or the use of maps to mobilize publics around a specific problematization of borders and immigration (Walters 2009). In turn, these texts can have effects of their own by reciprocally acting on human agents and other objects in networks. The discourse analyst is part of this web of influence in that they not only use certain texts to achieve a desired end, but can also be acted on by these texts in ways that can be at least partially acknowledged through reflexivity (e.g., pushing us to draw a certain interpretation, inciting an emotional response, and so on). Here the goal of reflexive practice is not simply to make visible one's social and political propensities in order to overcome difference, but to embrace dissimilarity and bearing on the things we study as an inevitable component of social inquiry (Haraway 1988). Sociologists, accepting this view, do not simply discover and describe the social world, but 'participate in, reflect upon, and enact' it in ways specific to their worldview (Law and Urry 2004:392).

Simply put, discourse analysis is shaped by our unique positionality in and in relation to the things we study. Each of us possesses a situated 'intellectual self-concept' that shapes our work in ways greater than 'the range of large-scale social groupings like race, class, gender, and sexual orientation' alone can explain (Gross 2009:274). Our position in the world is thus always a multiplicity, and concerns both past and present. 
The multiple positions we occupy in and in relation to the things we research shape our observations, our account of those observations, and the way we explain them. The point of acknowledging our multiple and situated positionalities in the research process is not to somehow escape them, what Haraway (1988:581) calls the 'god trick of seeing everything from nowhere,' but to accept the partial and situated nature of our observations, descriptions, and explanations in the messy and chaotic form they come. Objectivity, according to this standpoint, is thus reconceptualized to denote the intersubjective possibility of different viewpoints cumulating into a larger, but still incomplete, epistemic whole.

In conclusion, the qualitative analytic approach adopted in this thesis is meant to fulfill two theoretically and empirically based interests in texts (see here Prior 2008). In the first, texts are treated as containers of information. Open and theoretically driven coding is used to identify relevant content in texts. Second, using a Foucaultianinfluenced approach to discourse analysis, texts are analyzed for their broader discursive configuration and constitutive materiality. Discourse according to this view does not mean language, but language on, through, and in the context of the material world (Campbell 1995). The latter emphasis on materiality, already found in Foucaultian genealogy, is further developed by borrowing methodological insights from ANT on the symmetrical relations between actors and objects in networks of interaction. In the next chapter, I present the results this method by turning to my analysis of Cobra Mist. (A brief timeline of events in the programme can be found in Appendix A.) Focusing on the art of deception through cover storying, I begin by situating Cobra Mist in broader historical context and then develop six interrelated themes on cover storying: scripting 
and rehearsing, going public, backstage struggles, managing leakage, exit strategy, and mystery versus transparency. In the Discussion and Conclusion, I return to many of these themes in order to recommend future lines of research into Cobra Mist and the art of cover storying in general. 


\section{Chapter: State Secrecy and Cover Storying in Cobra Mist}

Operation Cobra Mist, a top secret Anglo-American radar intelligence operation, was constructed and operated between 1967-1973 during the latter half of the Cold War. Cobra Mist was strictly a US-UK programme and had no affiliation with NATO. The Radio Corporation of America (RCA), in partnership with Balfour Beatty Construction Ltd, won the construction contact in 1967 and together designed and built the site's physical infrastructure. A number of RCA technicians stayed on to help operate and maintain the site after it was built, working with military officials from United States Air Force (USAF) and UK Ministry of Defence (MoD), the two agencies principally responsible for the site. While the exact start date of the Cold War remains a debated point among historians, for purposes of this thesis let us assume that the conflict materialized most intensely at the end of World War II with the USSR's consolidation of the Eastern Bloc and the United States' increased efforts toward the 'containment' of Western Europe from communist threat. Although the two superpowers never fought directly, major proxy wars were fought in Korea, Vietnam, and Afghanistan in which both superpowers and their allies provided strategic and tactical military support for the opposing sides. In connection with proxy wars and the development of nuclear weaponry, radar intelligence and espionage operations like Cobra Mist, called RADINT in military parlance, formed a major component of the Cold War (Aldrich 2003). Although short lived and largely unsuccessful, Cobra Mist was a significant development within the broader nexus of US-UK joint intelligence programmes for two reasons.

First, Cobra Mist was at the forefront of American advancements in military radar technology at the time. By basing Cobra Mist on the most recent breakthroughs in High 
Frequency over-the-horizon radar (OTHR) technology, Cobra Mist was set to be, in the Pentagon's view, the most complex and powerful radar station of its time. Cobra Mist was cause for much American and British optimism concerning the future of radar intelligence capabilities. Its integral place in the history of Cold War espionage has been noted by several historians and intelligence scholars (e.g., Aldrich 2010), but still, little remains known about the details of the operation, its successes and its failures.

Second, Cobra Mist was a programme fraught with tensions between US-UK officials, and in this way helps balance the official historical record on US-UK Cold War military relations which emphasize inter-State cooperation and efficacy, in turn contributing to the reproduction of the image of the State as an unified and coherent entity. As Aldrich (2003:9-10) writes in his monumental and ambitious historical account of US-UK intelligence relations during the Cold War,

There can be no question but that the Anglo-American intelligence relationship has been uniquely close. More than half of the intelligence circulated in Western capitals during the twentieth century was gathered by a process of exchange with allied services, something of which even their political masters were not always aware.... But intelligence has served to increase tension among the Western powers.... Both of these facets - co-operation and conflict—have their counterparts in reality. But official history and official archives tend to emphasize the first.

Elsewhere, Aldrich (2010:285) points to Cobra Mist as being one such instance of 'unhappy experiences with major Anglo-American intelligence projects,' but devotes only two pages to describing the nature of the operation which took place. Moreover, 
Aldrich does not mention the use of a cover story, but focuses instead on US-UK tensions around cost, technological failure, site cleanup and closure, and labour relations (laying off employees on short notice, which resulted in major strikes). A more extensive analysis of Cobra Mist can be found in Heazell (2011:Ch.10) who, while discussing it, does not go into sufficient detail about the use of cover storying as a governmental technology either. The goal of this thesis is not to supplant these and other existing accounts of Cobra Mist by providing a more 'complete' and 'uncensored' (were such a thing possible) description of the operation. Indeed, where these other accounts of Cobra Mist are strong, mine is lacking. Interested readers should therefore consult the work of Aldrich, Heazell, and others for a more in-depth and detailed understanding of the operation. Simply put, the analysis which follows should be treated as supplementary to existing research done on the programme rather than as supplanting it.

In addition to thoroughly investigating the use of cover storying in Cobra Mist, this thesis contributes to existing accounts of the operation through its explicit commitment to theory and concept development. In this sense, my project is not so much historical as it historically sociological in Abrams' (1982) sense of the term. For Abrams (1982:x), debates over the convergence or non-convergence of history with sociology are 'essentially misconceived':

In my understanding of history and sociology there can be no relationship between them because, in terms of their fundamental preoccupations, history and sociology are and always have been the same thing. Both seek to understand the puzzle of human agency and both seek to do so in terms of the process of social structuring. Both are impelled to 
conceive of that process chronologically; at the end of the debate the diachrony-synchrony distinction is absurd. Sociology must be concerned with eventuation, because that is how structuring happens. History must be theoretical, because that is how structuring is apprehended.

Abrams' model of historical sociology involves making explicit sociology's inseparable commitment to the study of history, of 'reality in time' (Abrams 1982:2), and history's implicit commitment to theory despite claims to explain social life on the basis of empirical evidence alone. As Walsh and High (1999) suggest in their discussion of the concept of 'community,' process based definitions of concepts rather than static ones can help bridge the disciplinary gap between history and sociology. In adopting a conventional 'atheoretical' approach to historical analysis, much of the existing narrative on Cobra Mist ascribes to the perceived disciplinary boundary between history and sociology. By tracing the micro-historical processes involved in cover storying and utilizing the theoretical perspectives of Abrams (1988), Goffman (1959), and Foucaultian governmentality studies, this thesis aspires toward a more sociological account of the operation's eventuation and activities than has been written to date.

As a final caveat before turning to the major themes of scripting and rehearsing, going public, backstage struggles, managing leakage, exit strategy, and mystery versus transparency, it must be noted that the backstage art of cover storying is something which occurs only on a strict 'need to know basis.' High-ranking officials, in particular the heads and directors of various MoD departments, are among the few trusted with such secrets as those involved in cover storying. With Cobra Mist, it was the Head of S9(Air) and several Defence Intelligence staff which took the lead on the preparation, 
maintenance, and modification of the chosen cover narrative. Public Relations (PR) officials were also involved in the process of cover storying, but it is difficult to know the extent to which they were truly 'in the know.' PR officials in Cobra Mist were tasked with drafting and editing press releases, Parliamentary Q and A scripts, and other materials, but often based only on the limited disinformation they were provided. A note from the Head of S9(Air) of the MoD on 'Project Backscratch,' another Anglo-American intelligence operation based in the UK, sums up nicely the backstage structure of USAFMoD operations engaged in the secret art of cover storying. The note was disseminated to only a handful of senior level MoD officials. As he writes,

I fully appreciate the difficulties of maintaining security during the planning and construction phase of the project [Backscratch]; but I believe that I ought to draw attention to it. Only those members of the staff concerned who need to know details for planning purposes - and these, I hope will be very limited in number-should be so informed on the basis of the 'need to know' principle. Others who may be less, or marginally, involved with the project should be informed about it only in terms of the agreed Anglo-US cover story. (Ministry of Defence 1971f)

In what follows, the terms Cobra Mist insiders, officials, actors, and staff, unless otherwise specified, is meant to refer only to those twenty or so individuals within Cobra Mist, and the MoD and USAF generally, directly tasked with the work of cover storying. The extent to which PR officials, which are included in my analysis, knew they were involved in the art of cover storying, is beyond the means of this project. For the most part, I believe we can assume that they were not. 


\subsection{Scripting and Rehearsing}

Before going public, a cover narrative has to be discussed, written, and assembled backstage. I call this scripting and rehearsing. Scripting and rehearsing it is the secret art of designing, drafting, and envisaging an effective cover story. Government authorities intending to account for their plans and actions publicly enjoy the radical capacity to 'think before they speak,' or, to put it more bluntly, speak secretly before speaking publicly. Routine meetings, formal and informal conversations, and reports, executed and written in secret, hone in on the question of how best to go public about the start of a secret operation and through what narrative and means of notification (Ryan 2006). For Cobra Mist officials, this means assembling a script that is explicitly deceptive, a specific technology of cover storying, first designed, then drafted and refined (scripting). An appropriate technology of cover storying is one that passes the litmus test of government actors' efforts to consciously envisage an audience's reactions, a practice indebted to the power of one's imagination, interpersonal network, and experience (rehearsing).

Why the need for a cover story? One reason is of course to remain secret from the Soviets, although I did not find explicit discussions of this rationale in the data. Even if this was the main rationale, as Peter Laurie reported in the New Scientist in 1974, it would be near impossible for the Soviets to be unaware of giant bursts of radiation being transmitted over their territory (Heazell 2011:266). Another reason for needing a cover story, which was only to be temporary any in case, appears to be the desire to avoid political embarrassment. Should Cobra Mist fail to reach operational capacity, as it did, the cover story would serve as an easy way out of justifying money spent on an otherwise unsuccessful military endeavour. Here cover storying becomes a matter of reputation. 
Still, a third reason may have to do with the ease through which the assembled cover story could deflect public opposition, as labeling Cobra Mist an operational radar station was likely to generate public fears of retaliation from the Soviets-an issue which later surfaced in the media anyway (e.g., Pincher 1971).

In the available declassified records from the National Archives, the story of cover storying and Cobra Mist begins in early December 1966 with a secret note to the Prime Minister's office on the proposed use of the Northern portion of Orfordness for an OTHR station labeled System 441A. Cobra Mist was to be based on US developments in OTHR technology developed in the 1950s and 60s in attempts to better preempt and prepare for incoming military interventions, called early warning radar systems. The 1966 letter, from the MoD, states that they were approached by USAF officials for the building of the site, and that $\mathrm{MoD}$ staff would take a backseat role in the programme, limiting participation to the "minimum necessary to obtain the scientific value and full military output' (Ministry of Defence 1966). As Pentagon papers state, the mission was to detect and track aircraft; detect missile and earth satellite vehicle launchings; fulfill current and critical intelligence requirements; and to provide a research and development test bed for determining optimum back-scatter techniques for other operational missions. ${ }^{6}$

Cobra Mist 'was the largest, most powerful and most sophisticated OTH (over-thehorizon) radar of its time; and the OTH community as a whole had high hopes that in performance and capability Cobra Mist would set new standards for the OTH radar art' (Fowle et al. 1979:289). Fowle et al. (1979) is a declassified technical radar report on Cobra Mist summarizing the findings of the joint US/UK Scientific Assessment

\footnotetext{
${ }^{6}$ http://www.cufon.org/cufon/cobramst.htm. Accessed 26 March 2015.
} 
Committee commissioned to assess problems with Cobra Mist in January 1973. The authors of this text were former employees at the site. The 700-acre site consisted of large aerial arrays in a fan like configuration (Figure 1), connected to a grey, two story building with triple-layered walls and an absence of external windows to inhibit intelligence penetration from the outside (Figure 2). The entire site was surrounded by a six-foot fence, armed US Marine guards, and a 120-foot buffer zone between the fence and the site's infrastructure (Heazell 2011:254). The OTHR installation on Orfordness worked by bouncing High Frequency signals, between 3 and 30 megahertz, off the layer of the Earth's atmosphere known as the ionosphere $(75-1000 \mathrm{~km}$ above Earth), acting as a 'virtual mirror' (Thomason 2003:599), which would then bounce off any nearby objects back to the ionosphere, and finally this signal would be reflected back, called backscatter, to the station.

Backscatter is OTHR intelligence in raw form. Once received, backscatter must be processed, analyzed, and interpreted by intelligence experts in the station whose mission is to generate intelligence about both routine happenings and the more immanent threats of aircraft movements, missile launches, incoming war ships, and so on. Cobra Mist had two methods of collecting backscatter: a searchlight mode and scanning mode (Fowle et al. 1979). If a target's spatial coordinates were roughly known the station's operators, it could hone in more precisely on that area (spotlight mode). Whereas without an a priori target area, Cobra Mist officials could simply scan the area using the radar's maximum azimuth and range (searchlight mode). An 'oligoptic' (spotlight) and a 'panoptic' (searchlight) means of military surveillance (cf. Foucault 1977:Ch.3; Latour 2005:175-190; Manley, Palmer, and Roderick 2012). Key to the processing of backscatt- 


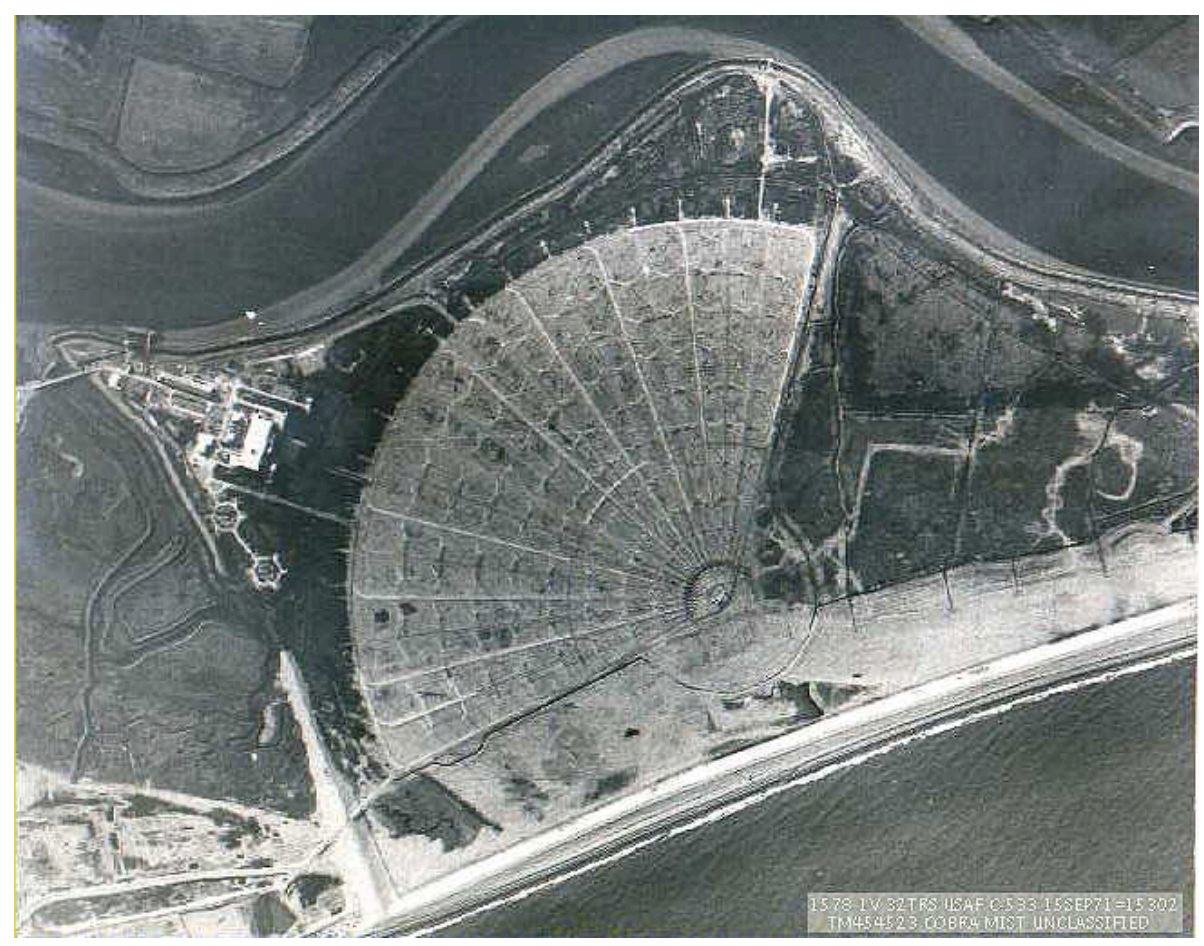

Figure 1 Orfordness, River Alde, and Cobra Mist from Aerial View, adopted from Flint (2005)

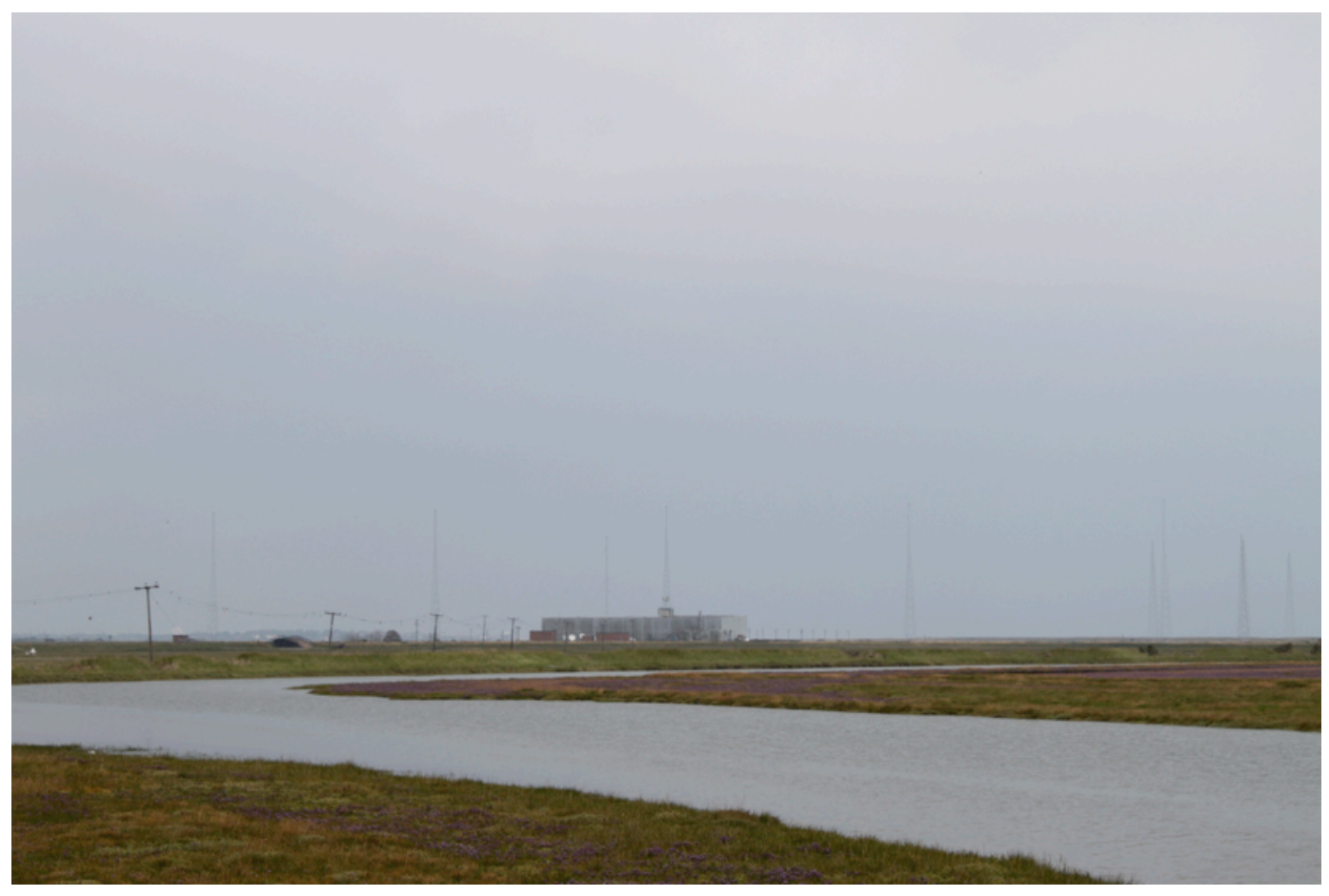

Figure 2 Remnants of Cobra Mist, photo courtesy of William Walters 
er is the ability to filter the signal generated from a desired target from background noise, called clutter.

Cutting-edge advancements in clutter filtration date back to research taking place at the Naval Research Laboratory in the early 1960s. Initial research on OTHR in the 1950s and 60s sought to increase the range upon which distant targets - ground, marine, airborne - could be detected. Much of this early research on OTHR was led by experimental physicist, Dr. William J. Thaler at the Naval Research Laboratory in the US in the 1950s. The earliest prototype of OTHR, called MUSIC (Multiple Storage, Integration, and Correlation), could detect ballistic missiles just under 1000km away, and nuclear explosions at 2700km. In 1961, the improved MADRE (Magnetic-Drum Radar Equipment) system was built at Chesapeake Bay, this time detecting inimical objects up to $3700 \mathrm{~km}$ away, and which was the model radar system installed at Orfordness in 1967 , known as AN/FPS-95. MADRE differed from previous OTHRs in that it used High Frequency electromagnetic radio waves, capable of traveling further distances beyond the horizon. A formative result of this research at the Naval Research Laboratory was the invention of 'matched Doppler filtering' (Thomason 2003:599), the ability to detect and filter out known signals (e.g., rain drops, ocean waves, rocks, tree stumps) from unknown signals (i.e., possible target), thereby removing different sources of clutter. Matched Doppler filtering works by creating a series of Doppler filters that are each attuned to a separate kind of clutter (e.g., rain versus tree trunk clutter). These different Doppler filters can then be applied to a given return signal to filter out the clutter. An area with a known geomorphological profile can be targeted using the necessary Doppler filters, called matching. Over the years, the process of Matched Doppler filtering has become 
more effectively automated. It was, according to one plausible explanation, an issue of clutter which would cause the shutdown of Cobra Mist in 1973.

Orfordness, an isolated shingle spit adjacent to the town of Orford, and separated by River Alde, was advocated as an ideal location for such an operation given the relative ease through which secret sites are constructed in already secret geographic regions: 'As Orfordness is already closed to the public, its use is unlikely to provoke serious public opposition, though with its aerial antennae the structure will be extensive. A suitable cover story may be necessary' (Ministry of Defence 1966). Orfordness was not a first choice. USAF's initial plan, which the MoD was not part of, was to replicate the OTHR system constructed in Chesapeake Bay in Diyarbakir, Turkey, deemed a more ideal geopolitical position from which to monitor the activities of the Soviets and other nearby nations. When Turkey declined to provide the necessary base for the proposed station, USAF turned to the British and was offered a location on Orfordness. In this sense, questions about military secrecy and deception are therefore inseparable from geographic questions of space and place (Davis 2008; Perkins and Dodge 2009; Woodward 2004). Yet there is also a sense of irony at work here, for who is likely to accept at face value the frontstage claims-making activities emanating from an inaccessible land mass known best for its secretive and deceptive ways? As Heazell (2011:241) observes, 'the attempt to provide "cover stories" for this operation was as futile' as the array of others fed to publics by different programmes in the past. But to stop here would be to overlook much of the curious and puzzling nuance that surrounded the cover storying process in the years to come. Regardless of whether or not publics initially accepted or rejected the assembled cover story for Cobra Mist, as a governmental technology it continued to 
organize the work and activities of USAF and MoD officials, and later occupied a central place in the reconfiguration of political relations in terms of mystery (discussed later).

Thus, on the one hand, Orfordness was acknowledged as the model space for Cobra Mist given the site was 'already closed to the public.' Public opposition could be kept at a minimum. Much of the performative and architectural work needed to establish the site as closed rather than open was already in place given the site's longstanding history of military use since World War II (cf. Heazell 2011; Kinsey 1981). As far as British publics were concerned, military experiments had always been a part of Orfordness' history. To do otherwise, by and large secret and militaristic in all of its doings, is likely to have undermined the normative expectations of UK publics who had come to accept a certain discreet and martial identity for that visible yet invisible Orfordness, known locally as 'the island.' On the other hand, the spatial proximity of Orfordness to open civilization meant that the extensive physical infrastructure of the operation — large aerial antennae, among other things—-would be visible to the public and therefore would need accounting for. (While shifting to the use of the High Frequency radio band meant greater range capabilities, its wavelength dimensions, spanning from 10 to $100 \mathrm{~m}$, require much larger antennae [Thomason 2003:599].) As Flintham (2012) writes comparing US and UK secret geographies in general: 'Compared to the vast and isolated militarised landscapes of the USA, restricted sites in the British countryside are a lot more difficult to hide.' The availability of large expanses of desert for US military programmes makes it far easier to construct secret sites that cannot be easily seen. Upon arriving at ferry dock in Orford in July 2014, I too was amazed by the sheer visibility of the site from non-secret side of River Alde, the moat-like river separating Orford from its 
top secret and highly geopoliticized counterpart, Orfordness. Under these circumstances, one can certainly understand why insiders felt a 'suitable cover story may be necessary.' Key to this phrase is the word suitable, for it is not just any cover story that was needed, but a suitable one.

The idea of a suitable cover up, first expressed in the passage above debriefing the UK Prime Minister, Harold Wilson, in 1966, is carried through subsequently in various secret reports, minutes, and letters between Cobra Mist insiders. With the exception of the Prime Minister's office, UK politicians and government agencies, including most employees of the MoD, were to be fed the same disinformation as lay publics. As one MoD official wrote in April 1968, specifying the content of the assembled cover story, a suitable cover story has been necessary. This is that the station will be a radio research station.... The line has been agreed with the US Government. It is literally correct to say that the station will carry out research and that it will not form part of any early warning or AMB [antiballistic missile] system, but it is of course expected to prove valuable in supplementing such systems. This, however, cannot be revealed. (Ministry of Defence 1968a)

Thus, the chosen cover story was that of a radio research station, a relatively safe form of deception insofar as it occupied a peculiar position between the two discursive strategies of lying and paltering. While on the one hand the narrative about radio research constitutes a cover story in that it masks crucial details that 'cannot be revealed,' the assertion that Cobra Mist was a radio research station was also 'literally correct to say.' If one strategy of deception lays in the ability to assemble a convincing yet fictitious 
narrative about reality, another less disreputable one according to Western moral and legal standards is to evade certain elements of the truth through vague descriptions, misplaced emphases, and omissions. As another MoD official commented on the perceived truthfulness of the cover story: 'I think we should stick to our present line that the Station at Orfordness is a Research Station, which in any case has the merit of being very largely true!' (Ministry of Defence 1968d).

The desire to minimize the disreputability of the cover story stems in part from the shared belief that no government secret is eternal. The 'entropic' nature of organizations means that, with time, information concealment inevitably becomes information leakage (Gibson 2014). As one MoD official communicated, 'Sooner or later it will be necessary to correct the record so far as Parliament is concerned' (Ministry of Defence 1971c). The assumption that secret knowledge inevitably goes public means that government actors, at least those that wish to avoid public controversy, must always take into account the future moment when a more comprehensive truth of the operation will need to be justified in light of the decision to deceive.

A suitable cover story was not only drafted according to future publicity, that one day the real story will go public, but also according to the two additional considerations of material correspondence and the plausibility of discursive frames. The materiality of Cobra Mist informed USAF and MoD officials' decision to frame the operation as a radio research station rather than something else. Cover storying the operation as a hangar for the Royal Air Force was not bound to work given the presence of large radio masts visible from the shore. And had Cobra Mist informed publics it was a shipping port rather than a radio research station, matters would have been made unnecessarily difficult. A 
shipping port cover narrative might work given that Orfordness once served such a function centuries ago in the past, but not only would this pose more questions than available answers, like what is being shipped and by whom, it would also require a whole elaborate architecture of docks, boats, and so forth, none of which would be of immediate value to the operation. This would have been an elaborate performance, but one far too precarious and unwarranted to be sustained for any long period of time. And if Cobra Mist insiders knew anything, it is that no cover story is permanent.

Another likely reason behind MoD and USAF's decision to cover story through the narrative of radio research concerns the relative constraint of different discursive frames. Research, it would seem, was not only 'literally correct to say,' but general enough to allow MoD and USAF officials to justifiably engage in a diverse range of radar related activities without overstepping its public identity. On the other hand, as a lengthy document distributed by the MoD in early January 1971 suggests, even a cover story about research has its limitations. The report details outstanding concerns and logistical issues with going forward with operational trials scheduled for later that year. Chiefly among the concerns was the potential interference of the site's radio frequency output with proximal aircraft, boats, and local citizens who have certain brands of pacemakersalthough the latter issue was never publicized. The report reflects on the limits of the cover story as a source of constraint:

The job of devising material [for a press statement on radio interference] will be complicated by the fact that we have not revealed, and it is not the intention to reveal, the true purpose of Cobra Mist. For public presentation it is merely 'a radio research station' which will conduct 'joint (Anglo- 
American) research into problems of long-range propagation of radio signals.' It will thus be difficult to advance strong defence reasons for persuading the public to accept such nuisance and restrictions as the station causes. (Ministry of Defence 1971a)

The chosen cover narrative is acknowledged, albeit in hindsight of going public, as a constraining factor limiting what can be plausibly stated on the frontstage. Specifically, the choice of a research storyline comes with the loss of 'strong defence reasons' as justification for going forward with the trials of an operation that is considered publicly contestable. Later, MoD officials faced a similar realization when contemplating whether or not it would be acceptable to accept the site as a gift from USAF after terminating its participation in the programme in June 1973. MoD staff determined that taking over the programme as a strictly national venture was bound to raise more public suspicions than could be reasonably accounted for through the lens of radio research, thereby rejecting USAF's gift proposal.

A final consideration $\mathrm{MoD}$ and USAF actors would seem to have taken into account when scripting and rehearsing a suitable cover story was the likelihood of reaching a working consensus with publics on the frontstage. Would publics accept the definition of the situation put forth by MoD officials in Britain and USAF officials in America with minimal fuss? The problems of NIMBYism are well known and suggest quite clearly that some government programmes garner a public's working consensus easier than others. Prisons, half way houses, mental health facilities, and waste incinerators are notably among some of the more difficult sites to construct in this sense, particularly when in close proximity to towns and residential neighbourhoods. Suitable 
cover stories afford ruling authorities the freedom to perform a master identity for a programme that they hope will not result in public controversy, and will have the best chance of achieving working consensus with a range of publics. Radio research is one such discursive frame, for who could effectively resist the public good of research on a matter that is both as practical and safe, if not entirely monotonous, as radio? By contrast, radar, over-the-horizon, surveillance, early warning, missiles, and other familiar Cold War catchwords were omitted from MoD and USAF's lexicon on the frontstage. A range of documented communications between Cobra Mist staff detail the conscious avoidance of such language in the work of scripting and rehearsing an effective cover story. So too, is the need for a codename. While the site was referred to internally as Sentinel Fan (1967), Sentinel Mist (1968), and finally, Cobra Mist (1969-1973), in the first press release in August 1967, MoD insiders simply described the operation as a joint US-UK research venture. After all, what kind of radio research station needs a codename? ${ }^{7}$

\subsection{Going Public}

An assembled cover story, scripted and rehearsed backstage, does not formally take effect until reterritorialized from the backstage to the frontstage of government by making it

\footnotetext{
${ }^{7}$ While the first codename, Sentinel Fan, calls attention to the fan-like resemblance of the operation's antennae configuration, Cobra Mist links the operation with various other 'Cobra [insert]' operations built around the same time (e.g., Cobra Shoe). The word 'mist' in the latter two code names would seem to refer to the site in both a literal and figurative sense, although the precise reasoning behind the Cobra Mist codename is unknown to me. Literally, Orfordness can get exceptionally misty, the Cobra Mist facility often seen from a distance, from the town of Orford, for example, poking through a thick and unwavering throng of vapour originating from the North Sea. The site appears, in this sense, as a blurry silhouette in the nearby yet unapproachable distance, albeit a still more in focus counterpart than the far away secret sites in the US photographed by 'limit telephotographer,' Trevor Paglen. Figuratively, the secrecy, the deception, and the still uncovered mysteriousness of the operation make it a forever misty one, even on those days when the literal mist is at rest.
} 
public. The radio research cover story is made public in Britain on 25 August 1967 in the form of a carefully prepared statement disseminated to the local British press. In both the press release and the published version we encounter the artificial language of the State: a simple narrative about two rational and unified government agencies from independent countries entering into a collaborative partnership that meets their respective national interests in radio research. The messiness and local contingency of this joint decision between States is masked from view. In reality, the station was a transnational muddle of US and UK military actors, one in which the line between States becomes increasingly difficult if not impossible to fix and locate.

In Britain, the chosen cover story went public through the reporting activities of local journalists informed by the MoD of the site's construction in the form of a press release. Specifically, it was the East Anglian Daily Times, Suffolk's major regional paper, that was delegated to mediate the relation between backstage and frontstage, empowered by ruling officials to serve as messengers between the State and publics. The local Member of Parliament, Colonel Sir Harwood Harrison, the Atomic Weapons Research Establishment, the Board of Trade, the General Post Office, the Ministry of Public Buildings and Works, the Clerk to the Council of Aldeburgh Corporation, the East Suffolk County Council, the Debden Rural District Council, the Ministry of Housing and the local government in Orford were provided with the press release a week earlier so they could prepare for the announcement going public, but 'asked to treat the information as confidential' until then (Ministry of Defence 1968e). In other words, by sending out this message and request for secrecy, MoD officials created a temporary and informal backstage for certain privileged audience members. The press statement, prepared by 
communicative experts in the MoD Public Relations office based on the limited disinformation they were provided, was one of a few official announcements released throughout the small lifespan of the operation. The original press release, as distributed to the East Anglian Daily Times and the above stakeholders, stated the following:

The Ministry of Defence and United States Department of Defence have agreed to collaborate in the construction and operation of a radio research station at Orfordness, Suffolk. The station will conduct joint research into problems of long-range propagation of radio signals. Orfordness is a peninsula of barren shingle and marsh, much of which is below sea-level. It was used for many years as a bombing range by the Royal Air Force; it is uninhabited and still closed to the public. The station will consist of a large aerial array and some associated buildings. Most of the technical equipment will be American design and manufacture, though there may be opportunities for British firms to tender for supporting equipment. The civil engineering and construction work will be carried out by British firms. Work on the site is expected to begin towards the end of the year, and the station should be ready for practical research within two or three years. The transmission from the station are not expected to cause any interference with radio or television receivers in the vicinity. The aerials will be well away from the bird sanctuary, and those areas where radiation might possibly affect human beings will be clearly marked or fenced off. The research programme will be undertaken jointly by the R.A.F. and U.S.A.F. About 130 U.S. personnel will eventually be associated with the 
project but none will live permanently on the site. (Ministry of Defence

1967)

It is entirely plausible that MoD officials intended for the above press statement to appear in local newspapers exactly as it was written. But when one compares the original statement released by the MoD with the published version as it ran in the East Anglian Daily Times, subtle but significant discrepancies can be found.

Although the release sparked little to no visible controversy on behalf of outside publics ${ }^{8}$ - as one MoD actor reflected a year later, 'From the press reports it did not seem that the press were very interested' (Ministry of Defence 1968d) — a contrast of the initial MoD statement with the actual published press statement in the East Anglian Daily Times highlights a crucial uncertainty in the deceptive performance of government secrecy: going public, like any first impression, carries risks. Questions about how the release will be taken by outside publics, whether or not the newspaper agency will interpret the statement in an unexpected way, or how persuasive the press statement was the principal domain of experts in the MoD PR branch. But even PR experts cannot govern for the future possibility of everything. On August 25, 1967 the following version of the press release appeared on the front page of the East Anglian Daily Times under the headline 'Orfordness site for radio station':

\footnotetext{
${ }^{8}$ Although the August 1967 press release was relatively successful in this sense, Cobra Mist was not entirely unfraught by public resistance. Controversy in the town of Orford later arose in response to the issue of transporting building supplies to Orfordness. The original plan was to move supplies by truck through the main road in Orford and ferry them across River Alde from the town's main shipping dock. Resistance from various well connected and influential local retirees, with former careers in politics, diplomacy, and military, stopped this from happening. The building supplies for the site were instead transported in through the Northern portion of Orfordness and by ships, thereby reducing the traffic through Orford (cf. Heazell 2011).
} 
The Ministry of Defence and the United States Department of Defence have agreed to collaborate in the construction and operation of a radio research station at Orfordness, it was announced yesterday. The station will conduct joint research into long-range propagation of radio signals. Orfordness, used for many years as a bombing range by the R.A.F. [Royal Air Force], is uninhabited and still closed to the public. The civil engineering and construction work will be carried out by British firms. Work on the site is expected to begin towards the end of the year, and the station should be ready for practical research within two or three years. Trinity House said yesterday that they are to have discussions with the Ministry about the new station as there was a possibility that the aerials might obstruct the light from Orfordness Lighthouse in certain directions. (East Anglian Daily Times 1967)

Comparison of the foregoing news article with the earlier quoted MoD statement reveals similarities, but also a crucial difference. The foremost purpose of the MoD statement to the press was make the operation known to public audiences in the MoD's terms and according to its misleading discursive frames. Notice in this respect that the word research appears not once, but four times in the MoD's unpublished statement, presumably in an attempt to clarify the cover story to readers via the rudimentary strategy of repetition. To the MoD's benefit, three out of four of these references to research were retained in the East Anglian Daily Times' version. The simplified and distorting language of the State is also left in tact, with an uncritical mention of two agencies, the MoD and the Department of Defence (which USAF is part of), cooperatively coming together to 
construct and operate a joint programme. Moreover, some sentences in the unpublished press statement, which also reappeared in the East Anglian Daily Times' version, evince a desire to suppress the possibility of specific lines of public resistance to the operation, from NIMBYism (i.e., 'uninhabited') through to UK nationalism and labour politics (i.e., 'carried out by British firms'). As Heazell (2011:245) points out, it was in large part the 'willingness of the US to place the construction contracts with British firms' that made the Cobra Mist programme 'so attractive to the UK government' in the first place.

But there is also a difference between the two versions. A discrepancy between the two press statements suggests that MoD officials were not as thoroughly preemptive in their scripting and rehearsal as they might have hoped. In the final sentence of the news article, the East Anglian Daily Times links the construction of the alleged 'radio research station' with the concern of Trinity House over possible interference with the Orfordness Lighthouse, adding to the press release a conceivable source of performance disruption that MoD actors do not seem to have accounted for. The oversight proved harmless politically, but nevertheless exemplifies the structural uncertainty of making a script public through a network that not only 'objectively' reports on matters of fact, but also seeks to denounce government officials through challenge, criticism, and exposure. Had the East Anglian Daily Times thought of something juicier to add to the statement, the MoD's appearance frontstage may have played out far differently, even catastrophically.

Yet if performance disruption was to ensue over the building of Cobra Mist, Trinity House was a likely stakeholder to lead it (cf. Heazell 2011:244). Cobra Mist was not the first radar station the Americans had tried to build on Orfordness. In December 
1963, the Americans sought access to Orfordness in the hopes of constructing a radar station to monitor nuclear test explosions in the Soviet Union. The station was to be built on the portion of Orfordness owned by the Atomic Weapons Research Establishment, Britain's nuclear warhead manufacturer. Two factors obstructed the deal from going forward. The first was the extent to which US officials required unrestricted access to the site at all times, a condition that Atomic Weapons Research Establishment officials were unwilling to accept. The second was Trinity House, as the proposed radar station would have limited access to the lighthouse.

For Cobra Mist, the press release marks the opening act of the deceptive performance of government secrecy, with MoD officials moving from back to frontstage through local news media in pursuit of consensus with outside publics. MoD officials monitored the story by keeping tabs on which additional newspapers (e.g., BBC News) took an interest in the operation, and which did not. The press statement is the product of voluminous backstage iterations and the expertise of a PR branch. The MoD's press statement is purposive in its language, working to minimize the potential for divergent interpretations, performance disruption, and indicators of suspicion. The encoding side of the communicative exchange, the $\mathrm{MoD}$, has its intended meaning, while the decoding side, the employees and readers of the East Anglian Daily Times, interpret the text according to their own interests, knowledge, and beliefs. Some of these decodings will align the MoD's intended meaning, others will not. Going public is therefore necessary, but always dangerous. The creative capacity of the news media, an institution which specializes in both uncritical reporting and denunciation, and the reactions of public 
spectators, are never entirely predictable. Ultimately, press release failure can result in heightened programme visibility, parliamentary questioning, and public controversy.

\subsection{Backstage Struggles}

So far we have examined two moments in the art of cover storying in Cobra Mist. These are scripting and rehearsal, or the backstage preparation of an appropriate discourse to present to publics frontstage, and going public by means of a carefully crafted statement to the local news media. The next two sections turn to the matter of, first, the breakdown of dramaturgical cooperation between insiders backstage over the use of cover storying and information leakage (this section) and, second, strategies used for the management of information leakage (next section).

Among other things, including cost and slow construction times, cover storying proved a recurring source of MoD-USAF conflict in Cobra Mist. A major source of tension was the unauthorized leakage of information, which threatened the integrity of the cover story. The first significant leak occurred in the US in February 1968. Without MoD input or approval, USAF authorities in Washington responded to an inquiry from an employee of Fairchild Publications concerning whether or not the American government was 'holding discussions with the United Kingdom Government on over-the-horizon radar' (Ministry of Defence 1968b). A USAF official had responded to the public inquiry in March affirming that OTHR was in fact under discussion. This statement made its way into the hands of the Associated Press the same day. MoD officials learned of the statement when one of them saw an article in the then Evening Standard the next day on the topic of a joint OTHR station at Orfordness. USAF officials immediately channeled 
an apology to the MoD via the US Embassy in Britain for making the statement without first consulting them. As to whether they had made the admission that 'the station would be operated under a joint agreement,' a line quoted from the Evening Standard article, USAF authorities ambiguously denied responsibility: 'The US authorities are unable to determine whether such a statement was made but they are quite sure that no official statement was made' (Ministry of Defence 1968b). As the MoD report concludes:

As I see it there is no inconsistency between the Washington statement on 4th March and what we have disclosed over a period of time in answer to enquiries, but it would perhaps have been preferable if the Washington statement had included the word research' (Ministry of Defence 1968b)

In other words, USAF officials had not so much failed for their leak of classified information. The leak could be accounted for and was in any case information that was already part of the British public record. The real fault was in the failure of USAF officials to mediate their statement through the assembled cover story by the inclusion of the word research.

Performance disruption via information leakage spiraled into struggles between USAF and MoD officials over administrative policies for keeping information secret. USAF officials espoused the position that information leaked to publics should be declassified, if only because it would be one less bureaucratic setback for the programme. Disagreement over classification policy transpired in 1971, as USAF officials grew increasingly frustrated with the programme's commitment to the assembled cover story. Authorities from USAF headquarters directed a letter to MoD officials seeking their 
approval to amend classification policy. The memo counseled MoD staff that there was no longer a need for strict classification procedures given much of the information protected was already publicly available in the US and UK.

Specifically, USAF advised the declassification of the following information and its affiliation with Cobra Mist, Britain, and Orfordness: program 441A; the concept of OTHR; and the radar equipment code, AN/FPS-95. USAF's rationale for the proposed declassification

being that the exposure by the press, primarily in the UK and the fact that the site is now revealing all of its physical and electronic characteristics, allows any interested, intelligent person to determine the nature of the system and the relationships that exist between the involved organizations. Further, many hundreds of drawings, handbooks and documents have been produced by the Radio Corporation of America (RCA) for us on site which carry the program number, the equipment nomenclature, or the contract number (which can be cross-referenced to the program number) but which from a technical information content are strictly unclassified by either our or your rules. (United States Air Force 1971)

MoD officials disagreed, urging USAF that the cover story was still necessary and in tact, making existing classification procedures indispensable. While the larger plan was to utilize a suitable cover story that was largely truthful, and which could be eventually used to 'bridge' the programme into a state of increased openness (discussed below), now was not the time. For in the event that the operation failed, MoD authorities reasoned, the cover story would serve as a means to avoid political embarrassment, a concern that is 
presumably less relevant to government actors in America given the location of the operation in a national jurisdiction removed from its own. As MoD actors put it, From the present UK point of view, the degree of classification accorded to the project is very much inter-related with the published cover story, and recent press releases associated with the initiation of activity at the site. The initial cover story, referring to joint research into problems of long-range propagation of radio signals, was designed to protect the real nature of the COBRA MIST project. This story has been maintained consistently in spite of persistent probing in Parliament, and by the Press. Our attitude has been that the cover story is true, as far as it goes, and could be further developed at an appropriate phase of the trials programme, assume that the project proves successful. Any sudden change in cover story at the present juncture, with public awareness that trials are in a very initial stage, could create an embarrassing situation for the responsible Ministers. This would be further aggravated at a later stage should the project not prove sufficiently successful to continue. (Ministry of Defence 1971e)

Not only would it embarrass the responsible Ministers, it would also call into question the presumed unity of the relation between the MoD and Parliament, as if UK politicians had sanctioned an operation they knew little to nothing about — which was largely true! MoD officials eventually offered USAF a minor relaxation to classification policy, but nothing that would make the debated secret information public. 
Backstage struggles reignited in December 1971 with another series of leaks this time published in the American journal Aviation Week \& Space Technology. Political embarrassment was again cited as a central concern: '[the article] gives serious political embarrassment since both in parliament and in the press we have taken the line that Cobra Mist $[s i c]$ role is connected with experimental radio propagation' (Ministry of Defence 1971b). MoD officials immediately blamed USAF for the leak, alleging that they had failed to remove secret information from published testimony before Congress. USAF authorities denied all backstage allegations of information mishandling, claiming they had deleted the information from published testimony, and that in any case the article 'was not based on revelation of wholly sound factual information' (Ministry of Defence 1971c). For one, USAF officials reasoned, the article erroneously assumed that the primary goal of Cobra Mist was missile warning, 'while in fact its primary mission, if successful, will be aircraft movement intelligence and warning with a secondary mission to provide IR/MRBM [intermediate/medium-range ballistic missiles] warning' (Ministry of Defence 1971c). Second, while the article accurately reproduced the location of the site, this information was not provided in the published testimony, which 'appears to confirm [the article's] probable reliance upon several sources of varying degrees of validity' (Ministry of Defence 1971c). MoD officials remained skeptical of USAF's defence, responding to USAF officials that they 'found this explanation difficult to accept' (Ministry of Defence 1971c). USAF officials used the opportunity to again press for the declassification of the information mentioned previously, but to no avail. 


\subsection{Managing Leakage}

The backstage struggles that ensued around the information leaks published in Aviation Week \& Space Technology illustrate a key consideration in the government art of cover storying: how and when should government insiders respond to threatening information leaked into the hands of publics? Evident in USAF's above response to the leaks published in Aviation Week \& Space Technology is a strategy frequently used by Cobra Mist insiders to manage leakage. This is the backstage art of continuously monitoring, evaluating, and destabilizing the truth claims of publics, journalists, and politicians, by calling into question the source of their evidence, all behind closed doors, even when their truth claims are accurate. Akin to Rappert's (2012) strategies for 'fomenting ignorance,' anxieties about leakage are alleviated by subverting backstage the methodological basis of outside efforts at performance disruption. Here the relevant question for government officials is not what is known, but how it is known. Without concrete evidence, the coincidental accuracies of outside truth claims are believed to hold minimal weight in the broader politics of denunciation.

At the same time, while Cobra Mist insiders opt to ignore certain leaks, it would be absurd to suggest that an accumulating body of publicly accessible knowledge publicized in newspapers, journals, and other mediums had zero impact on public perception. As Bail (2015:104) rightly suggests, 'Because leaks reveal the hidden activities of the ruling administration, ignoring leaks implicitly affirms or endorses the classified activities that are exposed.' While silence is a common strategy used by governments in response to leaks, and may help avoid calling additional attention to their content, by no means does the information exposed simply vanish unverified and 
unworthy of retention. Rather, it is precisely the publication of leaked information and the government's fleeting refusal to debunk or validate such efforts at denunciation that brings to life the moment of a publics' awareness of the performance of cover storying as a potential performance, but one that is not generally recognized as such. The secret becomes an open one, and few people are shocked or surprised when the truth of the operation is turned from journalistic speculation into State-confirmed truth.

Two examples from the data illustrate the strategies used by Cobra Mist officials to manage information leakage. The first example is found in the counter-response of MoD actors to the leaks in the Daily Mail in 1968 discussed in the previous section. Following the incident, MoD officials put together a lengthy report, called a 'postmortem' (Ministry of Defence 1968c), summarizing how the journalist responsible for the article, Angus McPherson, might have acquired the information, and any slipups made or counter-actions taken by the $\mathrm{MoD}$ in response to his inquiries. A lengthy portion of the report is designated to debunking the epistemological basis of the article. The validity of each major statement is assessed individually:

There are 12 main points in the McPherson article:- -1 . The figure of $£ 55$ million is so far wide of the mark as to be pure guesswork - the figure which we have been working with is 38 million dollars... 2. The height of the masts was mentioned in [a public document]. The reference to 'looking over the horizon' presumably refers to the information he obtained from DPR's staff. 3. This is clearly a piece of guesswork — bearing in mind that we know he had access to Mr. McNamara's statement. 4. The cash figure is wrong and the warning time is probably a guess. 5 . The cash figure of 
Britain's contribution is so completely wide of the mark that it must be a guess - the figure we had in mind was about $£ 1.5$ million but in the event it may have to be larger. I understand that the reference to 15 minutes could be right but is not necessarily right. 6 . This is well known. 7. I am informed by the experts that anyone who knows anything about the OTHR systems would know that the limit is about 2,000 miles. 8 . This is clearly his own opinion to which he is entitled. 9. The fact that there could be radiation hazards is clearly indicated in the press release and we have said that the areas will be 'clearly marked or fenced off'. 10 . This is mentioned in our press release. 11 and 12 . These are also true and there is no security significance. (Ministry of Defence 1968e)

On closer reading we can see that there are five categories of knowledge claim according to this assessment. The goal of identifying these categories is to determine how an outside claims-maker came to know what they know. Unwanted publications that threaten to undermine the use of cover storying, whether accurate or not, are thus assessed at the level of 'meta-notification' (Ryan 2006). First, there is the knowledge claim based in information that has already been made publicly available, as through press releases. Second, there is common knowledge of the more general sort, stemming from our knowledge of comparable sites and operations in other places. As noted later in the report invoking this second category of knowledge claim, articles published in Electronic News and Aviation Week \& Space Technology 'give a considerable amount of information about over the horizon radar. No doubt both were available to Mr. McPherson' (Ministry of Defence 1968e). Third, there is personal opinion, which every person is entitled to. 
Fourth, there are claims that are accurate but irrelevant in that they are of "no security significance.' Fifth, there is guesswork or speculation, which is not necessarily accurate, but can be. This fifth category of speculation differs from the fourth because it is seen a relevant disruption of the performance.

These five categories of knowledge claim allowed MoD officials to assess the degree of validity in each of the author's statements, and in turn evaluate the level of threat posed by the article, particularly in terms of follow up investigations by politicians or other journalists. On the basis of this assessment, and having seen little public reaction to the article, the counterstrategy adopted was to simply 'let the matter drop' (Ministry of Defence 1968b). As another MoD official advised:

I think [the] report [discussed above] covers all the points that any investigation is likely to reveal. In light of this report and in view of the very satisfactory reaction from the United States Embassy, plus the fact that nothing more has appeared in the press, I feel that the best course of action now is to let the whole thing die. (Ministry of Defence 1968f)

As mentioned, this does not mean that McPherson's article in the Daily Mail was debunked or entirely forgotten by politicians and outside publics, as MoD and USAF officials would appear to assume. While the ideas raised by the article were not pursued further, nor explicitly validated or debunked by MoD officials, the publication of the article alone in a reputable news source makes it significant. It is a part of the broader 'covert sphere' (Melley 2012) of available information about the secret site.

The second example of managing leakage concerns the classified information published in Aviation Week \& Space Technology. MoD officials identified four ways the 
article accurately-leaving suspended the question of successfully-disrupted the performance. First, it accurately described a key component of the operational aim of Cobra Mist which was missile detection. Second, it leaked the purpose of the programme as a radar station, "whereas the agreed US/UK "cover" story has been at pains to emphasise its experimental radio propagation role. Parliament, press and public have been told that this is its purpose' (Ministry of Defence 1971d). Third, the article pointed to the relationship between Cobra Mist and the broader governmental programme of System 441. Finally, it exposed the central agencies involved in Cobra Mist: 'The relationship of COBRA MIST, 441, RCA (the prime contractor) the UK site and USAF OTHR military R\&D [Research \& Development]' (Ministry of Defence 1971d). On the question of whether or not the leaks successfully undermined the integrity of the cover story, the report concluded that the leaks were likely to hold weight for two reasons:

'Aviation Week' is regarded as a reliable and well informed source.

Moreover, the official attribution of what is said in the article to congressional records will inevitably lead credence to it. It is, therefore, likely that there will be follow-up articles in the UK press and further questions may be asked in the House. (Ministry of Defence 1971d)

Anticipating backlash, the document advises that the cover story may need to be 'modified' pending the views of USAF officials on the matter (Ministry of Defence 1971d), what Bail (2015) calls the ad-hoc shifting of discursive frames.

As discussed at the end of the previous section, MoD officials blamed those with USAF for the leakage of secret information published in Aviation Week \& Space Technology, while the latter denied responsibility by arguing that the information came 
from another source. In a manner akin to the assessment of the Daily Mail article above, USAF officials reconstructed the meta-notificational basis of the article as one based in something other than congressional records and USAF information mismanagement. On the other hand, a key difference between the Daily Mail leaks and the ones in Aviation Week is the seriousness of the counter-response prepared by MoD actors. The blame game could go on forever, but at the end of the day there had to be a plan.

Specifically, MoD officials gave sober thought to the possibility of carrying out what they called an 'inspired' Parliamentary Question on the topic of Cobra Mist, a practice which says as much about the MoD's respect for the principles of democracy as it does its expertise in impression management. MoD officials intended to handpick an MP whose interest in Cobra Mist would appear 'natural' rather than provoked, with written answers to pre-fabricated questions:

there is the separate question whether, in view of the information now made public by the Americans, Ministers should seek an opportunity of giving Parliament further information about the COBRA MIST project.... This could most appropriately be done by means of an inspired Parliamentary Question by the local MP—Sir Harwood Harrison—and a written answer in the House. As the local MP for Orfordness it would be quite natural for Sir Harwood Harrison to show a continuing interest in the facility by asking for a periodic progress report on its activities. (Ministry of Defence 1971c)

The objective of the Parliamentary Question was to offer just enough information to serve as a performative 'bridge' between the assembled cover narrative and eventual exposure, 
while avoiding disclosing the ultimate truth of the operation. Here, we re-encounter the theme of cover storying and suitability, of scripting and rehearsing, the appropriate cover narrative being one that can serve as a transitional medium between present and future without exposing the use of cover storying as an intentionally deceptive strategy. As reasoned by MoD officials, the staged question and answer would serve as a 'bridge' between the position hitherto taken that the role of the station was to conduct research into long-range radio propagation and the situation which could develop in due course if the trials planned for 1972 are successful and it is consequently decided to develop the facility in a fully operational OTHR role. (Ministry of Defence 1971c)

Staging talk led MoD officials to the conclusion that without any statement issued frontstage they could be pressed further and eventually put into a situation over which they would have less control. However, by initiating a Parliamentary Question, they could solidify a concrete response, which would serve as an eventual bridge, and thus avoid any future disruptions from journalists and politicians on the matter. As one MoD official put it, citing persistent pressure from legendary investigative journalist and Daily Telegraph columnist, Chapman Pincher (For an overview of Pincher's work and influence in challenging British security programmes, see Moran [2012]):

I think it is finely balanced whether to put it down or let the matter sleep, but I am inclined to the former course because Chapman Pincher has raised this problem in the past and spoken to the office about it recently, so it is only a matter of time before he raises it again. It would therefore only be wise to put down this PQ [Parliamentary Question] to get in the 
innocuous answer now which could enable one to establish a position so that one need say nothing further when Pincher brought the subject up again; while if nothing had been set down one might be forced into a more positive position in order to reply to some future statement of his. (Ministry of Defence 1971c) ${ }^{9}$

The decision was eventually put on hold, waiting to see whether or not the matter was taken up by journalists in Britain. As an MoD official reflected a year and a half later: 'There was some discussion in the Department of whether to confirm the "Aviation Week" story by means of an arranged PQ, but press interest fell away and the report was neither confirmed nor denied. Thus the cover story remains formally extant' (Ministry of Defence 1973a).

In sum, classified information was leaked and published in reputable newspapers and specialist journals like Aviation Week \& Space Technology, responsibility for the leaks is denied among actors backstage, and the credibility of journalists is internally called into question by destabilizing the meta-notificational foundations of their knowledge claims as founded in something other than evidence or insider validation. Journalistic and expert knowledge claims determined to be guesswork are given low to zero threat potential. Guesswork can be accurate, but guesswork is still speculation and thereby unworthy of any counter-performance to deny or verify its validity frontstage. Cobra Mist insiders hope instead that knowledge claims founded in guesswork will fall to the wayside of public interest. A key measure of this is the response the article ignites in other newspapers, in MoD interactions with Parliamentarians, and in terms of probing

\footnotetext{
${ }^{9}$ According to Heazell (2011:262), Cobra Mist officials had also debated an opposite and more radical course of action to respond to the leaks, debating 'whether to employ Chapman Pincher (no less!) to cover over the cover up.'
} 
and inquiries from different publics. Without follow up, MoD actors chose to 'let matters drop.' But just because USAF and MoD actors assume that lack of follow up equates to a lack of political impact and significance does not make it true. Surely, readers of the Daily Express did not permanently erase knowledge of McPherson's article after reading it. The same goes for subscribers to Aviation Week \& Space Technology. Whether or not they believe it, the information becomes a part of the broader 'covert sphere' (Melley 2012) of knowledge about secret sites, concerning Cobra Mist and secret government programmes generally. Simply put, publics become aware of the possibility that a government program is performing a cover story. Some publics will no doubt accept the new truth about the operation at that moment, but still will not know many of its specific details. Others will decide they cannot reasonably recognize the performance as a deceptive one until there is a stronger evidence base. In either case, the secret becomes an open one. Politicians, journalists, and publics become aware of the possibility that Cobra Mist is encompassed by false narrative. The eventual exposure of the ultimate truth is unlikely to come as any surprise; unless of course, as discussed in the final section, the work of exposure fails yielding not ultimate truth and transparency, but mystery.

\subsection{Exit Strategy}

Closing secretive and deceptive sites is fraught with two main possibilities in terms of impression management: to preserve the original performance, seeking ways out that preserve the assembled cover story; or enact an image of transparency by exposing its ultimate truth as a deceptive government programme. Operations that go public as one thing having disguised themselves as another achieve this by scripting and rehearsing 
backstage a convincing storyline about why an assembled technology of cover storying was necessary for the good of 'the Public' and the protection of 'the State.' With Cobra Mist, we encounter an instance of the second. The failure of the programme to achieve the necessary operational capacity in OTHR meant that terminating the programme carried serious risk of political embarrassment for the MoD, the Prime Minister's office which sanctioned the operation, and other UK governmental officials and departments that were involved. In other words, it would be bad for the unified and coherent image of the State. As discussed, MoD and USAF actors were aware of this possibility all along, seeing their chosen cover story as having the flexibility needed to seamlessly bridge the operation into a sequel performance about operational radar capacity; or in the event that the programme proved unsuccessful, retained as an exit strategy and stable medium through which to act out the programme's finale. It was the latter option which $\mathrm{MoD}$ and USAF officials attempted to use in framing the site's closure in 1973.

The reasons the programme failed, although still somewhat unclear, concerned the strength and quality of the backscatter the station received from clutter and target objects. For success, Cobra Mist required a signal return strength of 80 decibels. No British or American OTHR station in history had ever achieved this calibre of backscatter, putting Cobra Mist on track to be the most powerful OTHR station in the world. To achieve the needed return signal strength, the maximum power output of Cobra Mist was specified at 10 megawatts and an average of 600 kilowatts, whereas in practice it never surpassed 3.5 megawatts peak power (Fowle et al. 1979). The desired 80 decibels was therefore never met, the strongest return signals ranging between 60 and 70. Among other sources of inadequacy, the quality of the backscatter was fraught with an unknown source of excess 
noise that could not be filtered out using Doppler filters. The excess noise was present in both clutter and target signal (Ministry of Defence 1973c).

In January 1973, a joint United States/United Kingdom (US/UK) Scientific Assessment Committee was tasked with diagnosing the problem. The committee was comprised of a chair, seven members, and a secretary: chair: Dr. Balser (Xonics Corporation); members: Dr. Shearman (Birmingham University), Dr. Aarons (Air Force Cambridge Research Labs), Dr. Bromley (Radio and space Research Station), Dr. Crain (Rand Corporation), Dr. Croft (Stanford University), Mr. Kingsley (Ministry of Defence), Dr. Roberts (Royal Radar Establishment); secretary: Mr. Evans (Royal Air Force). The purpose of the committee was to determine the principal causes of the degradation in performance of the site, to recommend ways of resolving the problems, and to assess the future potential of the radar station overall. The findings of the committee were presented to USAF and MoD officials in May 1973. Among the priority recommendations was the need to further investigate the problems of excess noise, as the committee was unable to pinpoint exactly where the noise was originating. As Fowle et al. (1979:289) wrote six years later, 'the source of the difficulty that caused Cobra Mist's demise was never found.' One possible explanation entertained by the committee and other OTHR experts, although unproven, is that the noise was generated deliberately by the Soviet military in a process called 'covert jamming' (discussed later). Shortly after the recommendations were received, it was decided to terminate the programme on 30 June 1973.

USAF officials, who were the first to back out of the programme, gave the MoD two options in going forward. Either both agencies pull out of the operation, or USAF officials withdraw their participation giving 'the existing installation free of charge to the 
UK to operate as it wishes, with a promise of US support in the provision of spare parts, or repayment' (Ministry of Defence 1973b). However, rather than see the second option as an expression of generosity, MoD officials saw the proposed gifting of the site cynically as a strategy 'designed to eliminate the heavy cost to the US of clearing the site, to which it believes itself committed' (Ministry of Defence 1973b). MoD actors also considered the future narrative plausibility that would come with the gifting of the site. Accepting the site as a gift from USAF would require the MoD to alter the existing performance of secrecy in ways that were likely to prove difficult, even problematic, from the standpoint of the assembled cover story. As the MoD reasoned,

On the other hand, if the UK took over COBRA MIST as a solely national project, it would be confronted with the necessity for publicity explaining the development. It would probably be difficult to clam that it was necessary to retain the station unilaterally in operation for the purposes of radio research, when other similar establishments are known to exist; and it would probably be necessary to acknowledge - as Chapman Pincher amongst others has for sometime claimed - that it was engaged in work connected with OTHR. The reasons for the UK pressing ahead with this in face of a US withdrawal would not be easy to defend. (Ministry of Defence 1973b)

MoD officials thus acknowledged the assembled cover narrative as a constraining factor limiting what could and could not be plausibly stated to publics frontstage. The deceptive image of Cobra Mist as a benign radio research station did not allow MoD officials the freedom to take over the programme as a national venture in the absence of US 
participation. As the report concludes, 'It is out of the question for the UK to take over and run COBRA MIST alone, and therefore the UK should not accept any US offer of a gift of the existing installation' (Ministry of Defence 1973b).

Among the host of reasons USAF officials had for pulling out of the programme, including mounting financial costs and failure to reach expected operational capacity during trials, there were also the Strategic Arms Limitations Talks (SALT) taking place between US and Soviet political leaders at the time. It is unconfirmed whether or not the closure of Cobra Mist was on the table during these talks, but very well could have been (Heazell 2011:266). In any case, if the SALT agreement was behind USAF's rationale for leaving the programme, the MoD does not seem to have been informed of this. The main MoD backgrounder on Cobra Mist summarizing USAF officials' reasons for withdrawing from the operation makes no mention of the SALT agreement (Ministry of Defence 1973b). Yet the first wave of SALT agreements between 1969-1972 clearly applied to USAF involvement in the operation and was in fact widely considered by MoD officials who waited to find out if the SALT agreement would have an impact on the fate of the programme or not.

Part of the agreement made as a result of SALT was for US and Soviet governments 'Not to deploy, in the future, radars for early warning of strategic missile attack, except at locations along the periphery of its national territory; and 'Not to assume any international obligations which would conflict with this Treaty' (Ministry of Defence 1972). An operational joint Anglo-American OTHR station based in Britain was clearly out of the question. Written communications between MoD officials, however, show that they were far more optimistic about the matter, seeing the use of cover storying as 
liberating USAF from having to terminate its participation in Cobra Mist. After all, the operation was just a radio research station as far as foreign and local politicians and publics were concerned. While the decision remained up to the Americans, MoD officials hoped joint operation could continue: 'There appear to be several ways in which the U.S. could interpret their obligations... some would inhibit their continuation in the COBRA MIST project as an operational system, but others might allow it to go ahead' (Ministry of Defence 1972). One available option was to continue the programme by keeping the cover story in place:

The Objective of the COBRA MIST programme... is stated to be 'the detection of Soviet and East European aircraft movements and detection of Soviet ICBM/IRBM missile launches, including ABM launches and related activities'. The latter part of this statement falls within the area covered by the SALT Agreement. However, the UK Parliamentary and public announcements about COBRA MIST refer only to radio research. (Ministry of Defence 1972)

As another MoD official suggested, albeit in considerably more cryptic terms: "As regards SALT, "the better opinion", as the lawyers say, seems to be-both in FCO [Foreign and Commonwealth Office] and MOD - that cancellation or retention of COBRA MIST should be irrelevant' (Ministry of Defence 1973b).

In light of USAF's decision to terminate its participation in the programme and the MoD's reluctance to continue the operation without them, staging talk took the subject of coordinating an exit strategy, of scripting and rehearsing the final act in the frontstage performance of cover storying, secrecy, and deception: 
So far as Congress, Parliament and the public are concerned, the 'cover story' of COBRA MIST is that it is a joint USAF-RAF station engaged in long range radio research... If it is now decided to close down the project, a very careful explanation... will need to be agreed between the two Governments for use on both sides of the Atlantic. (Ministry of Defence 1973b)

A careful and jointly agreed upon explanation is one 'which can be made public' in both the UK and US (Ministry of Defence 1973b). Such a coordinated inter-State discourse reinstates the imagined order and coherence of Cobra Mist as a joint Anglo-American 'radio research' programme and its relationship to both American and British nationStates; a narrative no less deceptive than the original press release in August 1967, highlighting themes of rationalism, public good, control, and intra- and intergovernmental consensus and order. Whereas mentions of commotion, disagreement, error, arbitrariness, uncertainty, ad-hoc decision-making, and the very language of an 'agreed' and 'very careful explanation,' have no place except in the secret regions of the backstage.

\subsection{Mystery versus Transparency}

Finally, the matter of publics and the production of mystery. Mystery, as I use the term here, describes a state of perpetual disagreement among outside audiences over the ultimate truth a secret programme, and the lasting effect of this state of disagreement on the interpretation of future disclosures. As mentioned, USAF and MoD officials went public with Cobra Mist on 25 August 1967. At this moment, Cohra Mist faced at least three typological outcomes. One possible outcome was indifference, a hypothetical state 
in which publics and the news media take little to no interest in denouncing a secret site thereby leaving its secrecy in tact. Then there was the possibility of increased exposure. One way this could occur is by the initial 25 August 1967 press release inciting an unrelenting interest from different publics, journalists, and politicians aimed at publicizing more about the alleged radio research station at Orfordness which, succeeding. The end goal of exposure, or denunciation, is to destroy any claim to secrecy the programme might have hoped for. Of course, many details about the operation would remain unknown to outsiders, for not everything can be known and understood, but the point is that what relevant audiences do come to know is deemed sufficient to re-label it an open government programme rather than a closed one (Ku 1998). Normative assumptions about secrecy and deception in government today would seem to posit a world consisting of these two typological outcomes alone: organizations either remain secret, the result of public indifference, apathy, or acceptance; or, under heightened political pressure, become increasingly transparent. Yet neither of these possible outcomes would seem to describe the current state of Cobra Mist.

Thus, the case of Cobra Mist suggests a third possible outcome in the dynamics of organizational secrecy, resembling not secrecy or transparency, but what I am calling mystery. When MoD officials revealed the existence of the operation in August 1967, they unintentionally managed to effect a mysterious atmosphere in which publics speculate, distrust, and conflict with one another over the ultimate truth of the operation, but without ever reaching a point of agreement or exposure. For many people today, Cobra Mist remains an unexplained mystery. 
After the operation shutdown on 30 June 1973, Cobra Mist became regularly described in British newspapers as an enigmatic entity enveloped in mystery: 'Throughout its short life the Orford Ness project has be[e]n shrouded in mystery' (East Anglian Daily Times 1973b); 'The Orford establishment has been cloaked in mystery and if the layers have been loosened and parted over the past 18 months the site has remained an enigma' (East Anglian Daily Times 1973a); the 'Short and mysterious life of "Cobra Mist"' (East Anglian Daily Times 1973a). One letter to the editor published in the East Anglian Daily Times was notably clever in its description of Cobra Mist as the 'Orford Ness Monster' whose 'identity is in doubt':

Sir, - Question: What's half a mile across, hundreds of feet high, cost millions of pounds, is brand new, and doesn't work? Answer: The Orford Ness Monster... It sprawls across Orford Ness, visible for miles. The Radio Corporation of American built it. The British taxpayer paid them for it. Most of its short life it's been known as USAF Cobra Mist Radar Station. Now its identity is in doubt. In the course of one day, an officer on Orford Ness told me that the Monster belonged to the Americans, an official at the U.S. Embassy told me that this wasn't quite true, a securityconscious spokesman at the Ministry of Defence told me that it wasn't even a radar station, and the Lord Carrington told the Lords that it was a radar research establishment... (Irvine 1973)

The lack of detailed, consistent, and clarifying information provided to the press on the programme, coupled with a series of other puzzling outcomes including its almost immediate shutdown with minimal warning, intensified the operation's state of mystery. 
As Heazell (2011:241) argues, 'half-truths, deliberate and misleading falsehoods, and optimistic expectations jumbled together in a fashion that could only breed speculation.'

In spite of the recent release of thousands of declassified records in the National Archives, detailed freedom of information releases from the US Pentagon, ${ }^{10}$ and two authoritative historical analyses (Heazell 2011; Kinsey 1981), Cobra Mist is for many publics an unexplained mystery contained by the lingering presence of a 'something more.' Tireless attempts at exposure have only multiplied the number of competing and incommensurable explanations for the operation, ranging from differing theories of American intelligence use to UFOs. In any case, for those actors unsatisfied by the official details revealed on the programme, which is actually quite extensive, the ultimate truth has yet to be exposed. 'Many of the rumours of the day were never officially denied,' writes Orfordness historian, Gordon Kinsey (1981:119). By sticking to its initial revelation about Cobra Mist being a benign Anglo-American radio research station, and choosing not to officially engage with the rumours and speculations of the day, the MoD allowed a state of mystery to intensify rather than dissipate.

Cobra Mist was (and still is) alleged a range of identities by publics at the time of its operation. Chiefly among them are an early warning system against Russian missile strikes (East Anglian Daily Times 1973a, 1973b; Pincher 1969); and a "“radiocommunications" establishment built with American money' that is really 'a giant outstation of the U.S. Intelligence Service' led by the National Security Agency for the 'interception of certain kinds of secret information passing between military installations behind the Iron Curtain' (Pincher 1971). Neither theory was confirmed, denied, or disproven by USAF or the MoD. Moreover, local controversy centred around the

${ }^{10} \mathrm{http}$ ///www.cufon.org/cufon/cobramst2.htm\#top. Accessed 26 March 2015. 
potential targeting of the programme by the Soviets, putting nearby towns like Orford and Aldeburgh, Suffolk in danger, but this also never surpassed speculation, and indeed, was contingent on the initial hearsay that Cobra Mist was something more than it claimed.

Second, there were unclarified questions about cost split and total. Who was fronting the majority of the bill, the American or British government, and what was the total cost of the operation? According to Heazell (2011:245), even to this day it 'will almost certainly never be clear what the final total was,' estimates ranging from 35-55 million pounds for the US, and approximately 1.4 million pounds for the UK. Exact costs for Cobra Mist vary from one newspaper article to the next. The point being that while debated costs is generally quite a mundane source of uncertainty, in the case of Cobra Mist, it would only seem to strengthen the belief that the site was something more than the official record says it was. Under conditions of mystery, such benign details are recast as indicators of deeper truths and undiscovered lies.

Third, one encounters the rapid and poorly explained closure of the site in June 1973. As Heazell (2011:268) observes, 'The curiously indecisive explanations for the abrupt abandonment of such an ambitious and costly project inevitably lead one to wonder if there is still hitherto undisclosed information about Cobra Mist yet to be revealed.' As discussed, the official explanation obstinately clung to by the MoD was that the radio research station was no longer needed by the Americans, as they now had an equivalent research capacity available in the US, making the operation a redundant use of public funds. Yet under circumstances of mystery, such an account hardly explains the need for an almost immediate shut down of the site with little to no notice to interested 
and affected publics including the programme's employees, thus fueling the site's status as unsettled mystery.

Fourth, even as one turns to the Pentagon papers, in all of their dense and jargonladen technicality, there remains a lingering degree of confusion, speculation, and uncertainty which only makes matters more mysterious to the outside observer. In other words, even the technical reports released on Cobra Mist, usually among the most trusted of disclosures, are themselves written in a way that breeds multiple interpretations, speculation, and mystery on behalf of outside observers. For example, Fowle et al. (1979) contribute to the mystery of Cobra Mist in the title- 'The Enigma of the AN/FPS-95 OTH Radar' (my emphasis) — and the opening quotation to their report alone: 'This is as strange a maze as e'er men trod; / And there is in this business more than nature / Was ever conduct of: some oracle / Must rectify our knowledge' (Shakespeare, The Tempest). As if only an oracle could tell us what went wrong with Cobra Mist. In the body of the report, the authors describe Cobra Mist as an 'enigma which has not been resolved to this day.' Furthering speculation about the operation, Fowle et al. (1979:323) entertain the possibility that Cobra Mist was secretly jammed by pro-Soviet forces:

In the absence of any convincing conventional explanation for the clutterrelated noise, some speculated that the noise could have been generated deliberately. After all, the AN/FPS-95 was engaged in a surveillance of the Soviet Union and the Soviet-Bloc countries, a function that could have been deeply resented. Perhaps this resentment provoked countermeasures to reduce the radar's effectiveness and ultimately remove it from the scene. Admittedly, the notion seems 'far fetched'; however, it is not easily 
disposed of and remains a possible explanation for the noise.... we explore this possibility and describe how it could have been done.

While the explanation seems 'far fetched' to the authors, they seek to develop it as a reasoned explanation nonetheless, as 'it is not easily disposed of and remains a possible explanation for the noise' (Fowle et al. 1979:323; my emphasis). That a line of speculation strongly lingers despite being somewhat implausible (but must still be entertained) is an integral component of what I am calling a state of mystery.

Specifically, the explanation is far fetched because for jamming to have occurred, it would have had to be done in secret, an unconventional and altogether 'more ridiculous' strategy Fowle et al. (1979:323) call 'covert jamming.' Otherwise, Cobra Mist insiders would have recognized the excess noise for what it was, namely, a deliberate countermeasure employed by enemy forces. Covert jamming works by secretly generating a signal that permeates a target area, thus getting picked up by any High Frequency OTHR radar picking up backscatter from that same place. In this case, it was believed the jamming signal could have been generated by Soviet ships anchored in the North Sea. Crucial here is the power of the radar station, as large, High Frequency radars have much more powerful antennas and transmitters and a much larger receiving aperture, allowing them to get much stronger signal return. Whereas smaller, lower frequency radars generate a less powerful signal return, and in any case do not have the capacity to separate the target signal from clutter (so would not know they were being jammed, as this comes at the inability to filter out clutter). Apart from Cobra Mist, the covert jamming signal would thus escape 'the world at large' (Fowle et al. 1979:324). High Frequency OTHR return signals are always hidden by clutter, which comes in at a 
far greater power than the target. The key here, making the jamming covert rather than conventional, is that the enemy generated signal is such that it cannot be filtered out, as it is greater than the target return signal but considerably smaller than the clutter signals. The intelligence reading is effectively jammed, but covertly, as the falsely generated signal would evince the same qualities as excess noise from legitimate clutter leading radar technicians to the wrong conclusions:

The first reaction would be that, since the clutter return was not fully cancelled, something must be wrong with the radar. If we found the radar to be fault-free, we would blame the ionosphere. If we exonerated the ionosphere, we would blame the clutter. In the end, we would lose patience and summarily cancel the program without ever discovering the case. This is indeed covert jamming. (Fowle et al. 1979:324)

And this, the authors and former Cobra Mist officials suggest, may very well be what happened. But still, no one knows for sure.

Cobra Mist shutdown for good on in June 1973 but even this did not put an end to the mystery. The same questions were left unanswered and the mysteriousness of the programme was extended by linking it up with proximate knowledge controversies. For example, following the Rendlesham Forest incident of December 1980, a supposed UFO landing in Rendlesham forest, certain UFOlogists have sought to link the two nodes, Rendlesham Forest incident and Cobra Mist, in new and unexpected ways adding to the overall mystery of the operation (e.g., Pope, Burroughs, and Penniston 2014:149). According to one well known UFOlogist, Jenny Randles, the alleged UFO landing in Rendlesham Forest was in fact a Russian 'Cosmos' satellite which had been shot down 
by the US National Security Agency, operating a kind of secret 'death ray' from the old Cobra Mist facilities under the codename 'Cold Witness' (Heazell 2011:281). Although not everyone may adhere to the minority views of UFOlogists, their assertions about Cobra Mist are still significant insofar as they help intensify its general aura as one of mystery rather than settled and exposed transparency. Such explanations, no matter how ridiculous, become an irreducible part of the 'covert sphere' (Melley 2012).

The opening of the southern portion of Orfordness in 1995 for public visitation has also reinforced the status of the site as a space of mystery. Although the land and building Cobra Mist occupied is still restricted from public access, it is close enough to the former Atomic Weapons Research Establishment's side of the Ness, now owned by the National Trust, that Cobra Mist gets discussed at designated sections of the tour where it can be seen from afar. Public access to the lower half of Orfordness intensifies and extends the mystery of Cobra Mist in three ways.

First, by making accessible certain unaccounted for markings, objects, and structures on the site that get linked up with Cobra Mist, if only to add greater confusion and speculation to the operation rather than clarify it. In particular, there is what Heazell (2011) calls the 'unexplained ring,' an unaccounted for circular concrete structure on Orfordness, located in the distance from Cobra Mist on the side that's publicly accessible. As Heazell (2011:272) observes, 'No oral or documentary evidence has come to light to explain its purpose and it continues to be one more tantalising Orford Ness mystery.' Some believe it was a structure related to Cobra Mist, others believe it was not, both instances of what the MoD would call 'guesswork.' 
Second, there is the content and extremely peculiar philosophy of the tour, which aims to reproduce rather than destroy the political mysteriousness of Orfordness. It does this by purposively feeding disinformation to visitors, explicitly informing them that certain lies were told, but that they, the visitors, would not learn which stories were untruthful, thus allowing the site to retain its mystery. The public tour also intensifies the mystery of the programme by revealing multiple competing theories about its ultimate truth, as opposed to sticking to a single and coherent narrative. Cobra Mist is introduced by National Trust tour guides with hesitation, uncertainty, and speculation as if pinning down its true identity were an impossible work in progress. In the course of the tour, staring over at the inaccessible Cobra Mist from a distance, one learns about the possibility of pro-Soviet forces jamming the radar from ships stationed in the North Sea, about the mysterious and unaccounted for concrete ring, and a new hypothesis as well: that Cobra Mist was discussed during the SALT agreements between US and Soviet governments in the early 1970s, wherein its immediate closure could have been negotiated as the station was too powerful to be retained in the Soviet interest.

Third, the fact that Cobra Mist was excluded from National Trust ownership only seems to contribute to the re/production of the operation as a space of mystery in that it is still closed from public access, and no one really knows what is happening with the site today. Orfordness became publicly accessible up to a point. That point is the inaccessible land and remnant architecture of Cobra Mist that visitors must only observe from a distance, but never touch or enter. Until March 2011, the site was owned and operated by the BBC World Service. Today its use is unknown. According to the tour led by the National Trust, there is reason to believe that 'something is still going on at the 
mysterious station,' but who knows what. Thus, the status of the programme as a mystery remains intact to this day. This is true even after the release of official Pentagon papers, available online on the websites of UFOlogists, and an inordinate amount of recently declassified materials in the National Archives. Numerous publics are still not convinced. Something more has yet to be revealed. 


\section{Chapter: Discussion and Conclusion}

In my analysis of Cobra Mist I have sought to demonstrate the various organizational practices and consideration that underpin the backstage governmental performance of cover storying. Cover storying, like any effective government technology, is the product of intensive planning, strategizing, and brainstorming backstage. A key component of any analysis of cover storying is therefore to empirically trace the backstage work and reasoning of government actors as they prepare to go public while donning a mask that publics are imagined to find plausible and sincere. Cover storying can, in this respect, as Arendt (2001) points out in her essay on secrecy and deception in government, result in a narrative more plausible than the ultimate truth it conceals, if only because the deceivers profit from knowing in advance what an audience anticipates on the basis of a preexisting or projected definition of the situation. Implicit in every deceptive act is a world performed rather than pre-given. As the projected definition of the situation is disrupted, struggles may occur backstage as insiders dole out blame, contest existing institutional arrangements, and strategize next steps in the performance of cover storying. Once a masked operation is terminated, it must either enact a counter-image of transparency, exposing its use of the strategy of cover storying, or ride the cover story out to the bitter end, in either case managing the outbreak of controversy. Decommissioned secret and deceptive sites, where there is public interest, become the subject of historical sociological, anecdotal, and artistic scrutiny. At this point the mystery of many decommissioned sites is destroyed, their deepest and most profound secrets exposed. In other cases, the mystery lives on, intensified and expanded one speculative moment after another. Such, I have argued, has been the outcome for Cobra Mist. The final sections of 
this thesis conclude the analysis of Cobra Mist by further discussing the mergence of governmentality studies with dramaturgy as it relates to studies of secrecy and deception, and by discussing four avenues for future research on cover storying: scandal, materiality, conflict, and mystery.

\subsection{Dramaturgy and the Governmentality of Secrecy}

In his article 'Between Michel Foucault and Erving Goffman,' Ian Hacking (2004) argues that the two scholars are theoretically and methodologically complementary. Although Hacking focuses on the more archaeological phase of Foucault's work, given its influence on his own work on the production and internalization of human 'kinds,' I have argued that Hacking's general reasoning can still be applied to the genealogical phase of Foucault's thought and by extension governmentality studies. Foucaultian genealogies of government emphasize conceptual abstraction from the empirical world, thereby bracketing questions about how government plays out at the level of everyday interactions between actors. To open up these symbolic interactive moments to scrutiny, Hacking calls for additional use of the dramaturgical perspective of Goffman. In this thesis, the combination of Foucault governmentality studies, adopted as an analytic ethos dedicated to concept formation, with Goffmanian dramaturgy, used as a metaphorical toolkit for documenting symbolic interactions between actors front/backstage, has yielded an in depth and processual account of the work of Cobra Mist insiders around the problems of cover storying, as well as the unintended effects of mystery.

Yet to suggest that genealogies of government and dramaturgy can be simply combined in this way misses the crucial point, namely, that the problem is much less 
theoretical as it is methodological. Governmentality studies claims to take seriously the project of documenting the diverse rationalities and technologies at stake in different government programmes. But while producing stimulating accounts of these programmes from the perspective of official discourse, backstage talk and practice is more often than not absent from the discussion. This is a problem for two reasons.

First, because one cannot properly trace the emergence of specific governmental technologies without paying attention to how those technologies are prepared and assembled backstage. While there are plenty of genealogies of government that do this, many do not. Indeed, extending the tracing of technologies of government into the invisible world of the backstage would bring the original proposals of Rose and Miller (1992) closer to the work of Latour in actor-network theory. In the section on technologies, Rose and Miller (1992) draw a parallel between their own suggestions for the study of technologies and Latour's (e.g., 1987) careful outlining of interactive networks comprised of actors as well as non-human objects or actants. The latter, Rose and Miller argue, offers a viable model and framework for governmentality studies. While it is not feasible to 'follow the actors' in live action when researching secret sites (Best and Walters 2013), it is possible to follow them after the fact in the form of declassified archival texts. Declassified documents can also be obtained through systematic use of access to and freedom of information requests. Such records, although always partial and incomplete, can inform us of the various backstage meetings, conversations, and communications that complement the work of government officials frontstage. Here Goffman's dramaturgy is indispensible, not only for the backstage/frontstage metaphor, but for the variety of additional concepts found in 
Goffman's legacy (e.g., 1959, 1961, 1969, 1986), from staging talk to the discursive frame, that allow us to painstakingly describe everyday transactions between actors. A further difficulty concerns the notion the State as discussed by Abrams: without detailing the backstage messiness of governance in the form of specific rationalities and technologies of power, genealogies of government risk hypostatizing rather than destabilizing the idea of the State by accounting for political life in terms that are far too orderly and coherent to reflect actually existing reality (see also Curtis 1995).

Second, by restricting the analysis of government to official discourse, governmentality scholars are destined to have far more to say about truth-telling than secrecy and deception. Yet given the central place of secrecy and deception in politics and constitution of the modern State, the art of such practices should not be overlooked. On the whole, social analysts appear reluctant to take such research opportunities seriously. Perhaps this unwillingness stems from a fear that controversies and leaks are somehow not 'scientific' enough for good sociology. For one, leaks on secret sites tend to be highly politicized. Like much of the research on moral panics, sociologists tend to pay greatest attention to the strategic and 'disproportionate' processes through which politicization occurs, rather than what we can learn from the leak itself (for an impressive example to the contrary, see Bail 2015). Moreover, leaks, along with declassified archival records, access to and freedom of information requests, and other data on secret sites, are necessarily incomplete. Researching secret sites therefore requires sociologists to be comfortable with what can be quite extensive knowledge gaps.

The whole situation only becomes more complicated when we acknowledge that the incompleteness of available data is not only a consequence of available sociological 
methods, but is itself an effect of our object of analysis, sometimes even a strategic and intentional one. As Aldrich (2003:6) puts it,

Contemporary historians who explore the state are quite unique.

Nowhere else is the researcher confronted with evidence precisely managed by their subject. From astronomy to agriculture, from botany to the built environment, no investigator confronts information so deliberately preselected. Historians are what they eat and the convenient but unwholesome diet of processed food on offer in national archives has resulted in a flabby historical posture. Of course, the huge proportion of records not selected for preservation by officials are fairly unimportant and include materials such as the routine forms processed by social security offices. But within this vast programme of selection, declassification and destruction there is ample scope to massage the representation of the more secretive aspects of government.

Historians, sociologists, political scientists, and others that wish to systematically trace the workings of secrecy are thus faced with an inevitable source of uncertainty: one not only comes to 'understand' secrecy, but does so in part according to secrecy's terms. Secrecy can be grasped sociologically, but only up to a point, and that point is itself a product of the very thing we are trying to conceptualize and understand, namely, secrecy.

Yet despite any reservations sociologists might have about the ability to systematically research the secret back regions of government, there is still much insight to be garnered from an incomplete dataset. Indeed, let us recall that is not just research on political secrecy that is destined to be partial, but all sociological knowledge given the 
situated lens of the human observer. It is true that organizational leakage, declassified archival records, and the results of access to and freedom of information requests, perhaps more so than other texts, bring into focus the limits of knowledge. The nondocumenting, destructive, and elusive nature of secret government organizations means that the imagined data we need to surpass these limits is often beyond our grasp. This does not mean, however, that significant theoretical and empirical insight into the diverse forms and content of secretive and deceptive government practices cannot be achieved, as I hope the analysis of Cobra Mist shows. To bring this thesis to a close, next I offer four avenues for future research on Cobra Mist and the art of government deception by cover storying in general. These are scandal, materiality, conflict, and mystery.

\subsection{Cover Storying and Scandal}

The first avenue for future research concerns the relationship between cover storying, backstage deliberation and decision-making, and scandal-avoidance. Recall that a 'suitable cover story' for Cobra Mist officials was one that did not stray too far from the truth. The discursive frame of 'radio research,' many insiders suggested, was not technically false. To this end, Cobra Mist insiders sought to utilize what I have called the strategy of omission, or paltering, omitting crucial details in going public, but in manner that shifts the true identity of the operation in a direction that is still, by Western moral and legal standards, an intentionally misleading one. One reason for the choice of omission as a strategy over falsification was the acceptance of actors backstage that eventually secret information becomes public. Invoking a valuable metaphor from thermodynamics, Gibson (2014) deems this the 'entropic' nature of information in 
organizations: clandestine information will always at some point break free from its institutional confines and dissipate in a form that is no longer secret. Deleuze and Guattari (1988:287) reason similarly about secret information, arguing that perception and leakage may be inimical to the secret, but in any case are 'an essential part of it: something must ooze from the box, something will be perceived through the box or in the half-opened box.' The entropy of information means that while organizations can prolong the leakage of secret information, like an enclosed balloon rising in altitude, eventually any attempts at concealment will fail. In the case of Cobra Mist, impending openness, whether through leakage or by forced disclosure initiated by pressure from parliament, meant that the cover story was not to be considered solely for its narrative plausibility, but also for the level of backlash it would receive from publics and politicians once the ultimate truth was out.

In other words, cover storying is not simply about concealing truth, but doing so in a way that minimizes the possibility of future scandal. There is a substantial literature on scandal in sociology which examines the social and political conditions on which scandals erupt, the changing form of scandal in contemporary society, and the reactions and management strategies used by actors and institutions to resolve them (Adut 2009; Thompson 2000; Vaughan 1985). Deception in this sense, as Goffman (1986:102) points out in his book Frame Analysis, 'involves two elements: a moral one pertaining to the reputability of the deceiver and a strategic one pertaining to misdirectings of the dupe's perception and (consequently) his response.' This moral element of cover storying, irreducibly bound to the maintenance of the State's reputation through the avoidance of scandal (Carpenter 2010), is in much need of further research. 
For example, in future research we might ask how the imagined potential for scandal informs and constrains the work of actors backstage who, particularly when engaged in the art of deception, must index their actions according to the fine line between secret present and public future. Whereas most sociological analyses of scandal focus on scandals after they have materialized in the public sphere, much less is known about how government officials discuss, imagine, and avoid future scandals in closed door meetings by engaging in what Gibson (2012) calls 'foretalk.' In Cobra Mist, this took the form of continuously monitoring leaks as media and public reactions took form, and brainstorming strategies for scandal-avoidance such as drafting Parliamentary Q and A scripts that never went public. A behind the scenes analysis of strategies of scandalavoidance in the art of government is a much needed addition to the literature. In some ways, the recent work of Gibson (2014) and Bail (2015) fits this description already. Gibson's (2012) analysis of the imagining of possible futures during secret deliberations in the midst of the Cuban Missile Crisis is also highly relevant here.

Scandal avoidance may also help us explain why Cobra Mist insiders' anxieties about information entropy was more focused on the views and future consensus of ruling politicians in the formal political world rather than outside publics (with the rare concern for influential journalists like Chapman Pincher, who was very much an insider to the formal political world in any case; see Moran 2012). Among the host of reasons for this, including the maintenance of internal governmental relationships and rapport and the existence of hierarchical structures of accountability (in a representative democracy, the MoD is technically responsible to the political party in power, not 'the Public' or civil society), is the interconnected desire to secure political support and consensus for its 
decisions, albeit after the fact, and thereby ensure an image of government as a coherent and unified State (on this point, see Carpenter 2010). Were the UK Prime Minister's office and other office leaders unable to accept the MoD's perceived necessity to palter about the nature of Cobra Mist, a targeted scandal would be at risk of breaking out at the moment of going public with the truth. Such a scandal is likely to result in the singling out of the MoD and the Cobra Mist programme in particular, treated not as a seamlessly integrated nodes within the larger British State, but as a misbehaving agency/programme versus the State, and which must either face punishment (e.g., legal sanctions), demonstrate its innocence (e.g., persuade publics and politicians that the lie was operationally necessary), or otherwise reestablish its competency, loyalty, and deserve of State institutional trust. Future research into the relationship between secrecy, deception, and scandal in government organizations should address such questions.

\subsection{Cover Storying and Materiality}

Second, from the geography of the site to the publicly visible architecture, the art of cover storying is bound to and constituted by its physical presence in the world (Herzfeld 2009; Paglen 2010a; Perkins and Dodge 2009). Here we would do well to make better use of recent work in actor-network theory to help clarify the role of agentive objects or actants in the translation of deception into operable technologies of cover storying (e.g., Bourne 2012; Latour 2005; Law 2009; Law and Callon 1988; Mol 2002). Especially pertinent from this angle is the question of how the misbehaviour of certain actants in a network can result in leakage, publicity, and scandal (Best and Walters 2013); as well as the inter-subjective question of how actors fabricating, performing, and maintaining 
organizational cover ups do so in a manner that stems their ongoing relationship to their object counterparts (Jerolmack and Tavory 2014). The point being that while there is much to suggest that secrecy, like security (Aradau 2010), has a distinctive materiality and relationship to space, overall such themes are underdeveloped in the literature. Actornetwork theory, with its flattening of human/non-human relations and tracing of diverse 'material-semiotic' networks (Law 2009), would seem an excellent starting place for future research into material and spatial configurations of secret sites.

\subsection{Cover Storying and Conflict}

Third, while I have described how various backstage struggles around cover storying and leakage in the context of Cobra Mist emerged and their subsequent outcomes, much remains unanswered regarding the reasons for disagreement between MoD and USAF officials. In the face of leakage, MoD actors proved far more committed to the continued use of the assembled cover story than USAF officials, the latter having argued on numerous occasions that the chosen technology of cover storying should be abandoned. One argument for relinquishing the cover story from frontstage performances was that various publics, which are not stupid, by now recognize the falsity of the cover story. MoD officials insisted to the contrary, that the assembled narrative about radio research was still in tact and necessary. Without equivalent declassified archival records from the US to compare, I cannot reasonably theorize in this thesis reasons and conditions for this disjuncture. A more expansive empirical view of the Cobra Mist operation would first be necessary. Thus, while in the preceding analysis I suggested the importance of spatial and architectural proximity, the argument being that the location of Cobra Mist on British 
national territory made it a more politically sensitive programme than in the US, this connection remains speculative and in need of further empirical research.

Further, when faced with the themes of backstage tensions and conflict between government officials over State secrets and the art of deception, I believe that future research would benefit from the work of scholars like Didier Bigo $(2002,2006)$. Using Bourdieu's (e.g., 1977) theory of practice, Bigo's work traces the various conflicts and power struggles that occur between security professionals in public and backstage. He argues that inter- and intra-organizational conflict is a routine element of the work occurring in the security field and demonstrates the effects of these struggles on constructions of threat, secrecy, institutional trust, and expertise. Already sociologists of secrecy and deception have began to theorize the role of backstage competition on information leakage and the maintenance of organizational secrecy (Bail 2015; Ku 1998; Sagar 2013). Future work in this area would no doubt benefit from the work of Bigo and others who draw from Bourdieu's theory of practice to conceptualize the relationship between secrecy and organizational failure and conflict (e.g., Vaughan 1999).

\subsection{Cover Storying and Mystery}

Lastly, the section on mystery versus transparency in the foregoing analysis highlights the need for a more relational sociological rather than zero-sum understanding of the secrecy/transparency binary. Too often are the notions of secrecy and transparency conferred in sociological discourse as if they were somehow fixed categories with meaning external to the relational settings in which they are framed. The problems with this approach are now all too clear (Birchall 2011; Bratich 2006; Dean 2001; Horn 2011; 
Taussig 1999). For one, it overlooks the inherent paradox of the secrecy/transparency binary when defined in zero-sum terms. If secrecy and transparency are opposites, it is also true that secrecy and transparency are one another's condition of possibility: secrecy generates the very sense of a public it presupposes. The secret designates that which is deemed to be known, that which hasn't yet been disclosed. In doing so, it presupposes a subject that desires, discovers and knows, a subject from which nothing should be withheld' (Dean 2001:119-120).

Secrecy and transparency presuppose one another for their very existence, making the idea of the two as opposing forces self-contradictory and defeating. Moreover, for a secret to exist, it must first have a distinctively 'public' character. As Herzfeld (2009:135) observes, 'secrecy must itself be performed in a public fashion in order to be understood to exist.' Among other things, it is the materiality of Cobra Mist, an elusive building on the easternmost coast of England, which helps perform its secret character into public existence (Herzfeld 2009; Paglen 2010a).

More importantly, however, this dichotomous treatment of secrecy/transparency overlooks the often non-linear, ambiguous, and mythical ways in which secrecy and transparency acquire meaning and relate to one another in different organizational contexts (Christensen and Cornelissen 2015). The dominant cultural metaphor of secrecy/transparency as inverse counterparts is not geared to capturing those moments when the very act of making things public exposes little to nothing; when greater disclosure reveals not heightened transparency, but a confusing and conflictive state of mystery in which the ultimate truth is debated but never settled. While mystery, as I have 
used the term, is meant to face this difficulty head on, much future research into the workings of this concept is required. For example, is mystery applicable to other cases apart from Cobra Mist? Here we might consider the works of sociologists of religion, who have long had much to say about the notion of mystery in religious doctrine, in search of analogous insights applicable to other non-religious cases like Cobra Mist.

For example, Boyer (2007:89), in his article 'The Logic of Mystery,' offers an 'analytical taxonomy' of mystery based on how 'the "logic" of mystery functions' rather than how it is experienced. This shift is useful because it breaks from the otherwise phenomenological approaches that aim to describe the diverse affective experiences of mysteries that actors reflect on and internalize, but which are not easily parsed into conceptual types. Boyer posits five types of mystery. These are investigative mystery, revelational mystery, extensive mystery, facultative mystery, and dimensional mystery. For Boyer, the core distinction between investigative and revelational mystery is that investigative mystery can come to an end, its mysterious aura destroyed through the act of becoming known; whereas with revelational mystery, its mysterious aura is always present, even after the knowledge sought becomes publicly known.

A simple example of investigative mystery is the crime investigation novel wherein the protagonist pursues the ultimate truth behind what, for only the moment, remains a mystery (on this version of mystery in crime and espionage fiction, see Boltanski 2014). Eventually, the protagonist will solve the crime, and the case will no longer be shrouded in mystery. The investigative mystery is settled once and for all. By contrast, a revelational mystery stays mysterious even after the moment of revelation: 'While an investigative mystery defies reason for the moment... a revelational mystery 
defies reason in some sense even after it is... "figured out" (Boyer 2007:91). Working out of the sociology of religion, Boyer offers the example Jesus' disciples and the sharing of heavenly secrets which lingered mysteriously even after being made public: 'No one who watches the disciples in the gospel stories can think that they actually understand the mystery that Jesus says they have been "given"'(Boyer 2007:91). A revelational mystery will always be mysterious to some degree.

Perhaps another way to conceptualize the distinction between investigative and revelational mystery, although more crudely, is through the notions of secrecy versus mystery. As Boyer (2007:91) writes: 'Whereas a secret is hidden from outsiders, a mystery is hidden — period. It remains incomprehensible even to those who know it.' Secrecy and mystery in this sense are not mutually exclusive, but overlap. A mystery can start as a secret. Returning to our example of the crime investigation novel, let us imagine that by the end of the book, as readers we are provided with facts meant to clear things up but which, for whatever reason, we find ambiguous or unsatisfactory. Perhaps we distrust the novel's narrator. The protagonist claims to have solved the case, to have discovered and therefore destroyed the secret through careful reasoning and investigation; but we, as readers, are not convinced. The known secret has become a mystery which its readers, having set out believing the protagonist would succeed, cannot fully accept in its current form, making it mysterious. Here the work of Taussig (1999), drawing from Walter Benjamin, appeals to the useful distinction between 'exposure' and 'revelation.' Whereas exposure amounts to a total negation the secret, 'a revelation does justice to it' (Benjamin 1998:31); 'the just revelation... stands in juxtaposition to exposure, which, Benjamin 
warns, would only destroy the secret' (Taussig 1999:2). If exposure is the antithesis of secrecy, revelation, according to Benjamin, is only its beginning in new mysterious form.

As for empirically researching revelation and mystery, one way to approach it is through the lens of controversy. Until 'secreting' (Deleuze and Guattari 1988:287) into the public sphere generating controversy, no government secret can be mysterious. Moreover, disagreement between actors in public must also be, to an extent, revealed. To expose disagreement, sticking with Benjamin's meaning of the term, as unfounded or invalid would be to destroy it. Thus, revelation must not only do justice to the secret, keeping it alive in mysterious form, but also do justice to disagreement in that disagreement is revealed not in order to reach consensus, but to preserve the state of disagreement and therefore mystery. Actors disagree 'without ever reaching a point of clarity or "ultimate truth" (Horn 2011:119). What may well be the ultimate clarifying texts in other secret State operations no longer hold the same weight: insider documents just as often become evidence for that 'something more.' The study of mystery in knowledge controversies around government uses of secrecy and deception is sociologically significant for three reasons.

First, because following the lines, translations, and associations through which a secret government operation becomes mysterious means taking earnestly the claims of multiple actors, including those typically marginalized as 'bonkers' or insignificant to social inquiry, like popular conspiracy theorists (Birchall 2006; Fenster 1999) and other non-State 'specialists in secrecy' (Bratich 2006:494). If mystery is in part the result of an incapacity of actors to agree on the ultimate truth of a secret state operation's official claim to being, it follows that the voice of every actor, no matter how seemingly 
ridiculous, should be taken into account (cf. Latour 2005:259). Second, by studying the emergence, intensification, and extension of controversies involving mystery, we overcome the common tendency in discussions of government secrecy to assume secrecy is merely the opposite of transparency — as if secrecy simply signified ignorance, and transparency knowledge. Like Bratich's 'spectacular secrecy,' the study of mystery 'compels us to think secrecy outside of its commonsensical status as opposite a public' (Bratich 2006:494). Third, mystery brings new meaning to those numerous secret sites that are decommissioned, but retain a mysterious aura today. Closing down secret sites does not necessarily put an end to their cultural significance. As I have shown with Cobra Mist, even after the site's closure, the site remains a mystery thanks in large part to the accounts of local British newspapers, contemporary tourism narratives produced by the National Trust, and the published works of Orfordness historians. Other mysterious sites like Cobra Mist can no doubt be found and researched sociologically.

\subsection{Conclusion}

The central goal of this thesis has been to develop a conceptual framework and agenda for a sociology of secrecy and deception in government. To this end, using Abrams (1988) as a starting point for questions about the nature of State secrecy, I have turned to governmentality studies and Goffman's early work on dramaturgy in order to synthesize the conceptual tools necessary to investigate the art of cover storying in a little known US-UK secret Cold War intelligence operation called Cobra Mist. Cobra Mist has been discussed elsewhere in academic literature on the Cold War, but never with an in-depth focus on processes of cover storying or from a sociological perspective. Ultimately, it is 
hoped that the case study presented here will serve as a basis for future historical sociological research not just on Cobra Mist and social processes of cover storying, but on the many other socially organized forms of secrecy and deception that shape and pervade our everyday lives. 


\section{Appendices}

\section{Appendix A}

\section{A.1 Timeline of Events}

1966: Radio Corporation of American (RCA) wins bid for main contract for construction of Sentinel Fan (later renamed Cobra Mist), an over-the-horizon radar (OTHR) station jointly funded by the United States Air Force (USAF) and UK Ministry of Defence (MoD). Balfour Beatty Ltd. also contracted to help build site.

25 August 1967: Press statement on Sentinel Fan published in East Anglian Daily Times. Introduced as joint US-UK radio research station without mention of codename.

Mid 1967: Site construction begins. 150 employees involved in site construction.

1968: Code name changes. Sentinel Fan renamed Sentinel Mist.

1969: USAF begins voicing impatience with slow construction pace of Cobra Mist resulting in US-UK tensions. Tensions continue until site closure in 1973.

July-August 1969: Codename changes again. Sentinel Mist renamed Cobra Mist.

Early Fall 1970: Prior to site trials, investigations carried out into likelihood of radio interference with television and radio signals in surrounding regions.

November 1970: Interference with local television and radio signals accepted as likely possibility. Plans begin for second press release on possible interference.

Early 1971: Possible radio interference with nearby pacemakers raised into question. US officials set up secret research programme at Brooks Air Force Base in Texas to assess potential radio interference with pacemakers. Programme concludes that only one type of pacemaker, the 'Meditonic 5841,' susceptible to radio interference from Cobra Mist. Decision made to not publicize matter of pacemakers in press release.

26 February 1971: MoD publishes second press statement in East Anglian Daily Times on possible radio interference with no mention of pacemakers. Press release sticks with original cover story about radio research with no mention of codename.

July 1971: Site construction completed. System testing begins one week later. 
February 1972: RCA turns site over to MoD and USAF following completion of site trials. Many RCA technicians retain employment at site. Original plan to go operational in July 1972 delayed until January 1972 due to excess noise in receivers.

Early-mid 1972: Investigations into source of noise begin.

January to May 1973: Stanford Research Institute (SRI) commissioned to investigate noise, forming the US-UK Cobra Mist Scientific Assessment Committee. Committee cannot locate source of excess noise.

Early-mid June 1973: SRI committee produces final report recommending upgrades to receivers to deal with noise. USAF and $\mathrm{MoD}$ decide to terminate operation in light of recommendations.

29 June 1971: MoD confirms publicly closure of Cobra Mist.

30 June 1973: Cobra Mist terminated and RCA employees laid off with minimal notice.

3 July 1973: RCA staff stage sit-in strike after demands regarding notice of unemployment, promises of alternative employment, enhanced redundancy pay, and relocation grants unmet. Redundancy agreement from RCA accepted several days later.

1975: Cobra Mist facilities taken over by branch of the UK's Foreign and Commonwealth Office's (FCO) Communications Engineering Department to act as medium-wave broadcast transmitter.

1978: $\mathrm{FCO}$ transmitting station begins broadcasting $\mathrm{BBC}$ 's medium-wave services across Europe. Takes full charge of BBC medium-wave transmissions by September 1982.

December 1980: mysterious lights and an alleged UFO landing reported in Rendlesham Forest, Suffolk, UK. Connections later made to Cobra Mist and now FCO station.

1981: Gordon Kinsey publishes first public historical account of Cobra Mist in his book Orfordness-Secret Site.

1986: $\mathrm{BBC}$ begins operating the transmitting station for itself.

1993: MoD sells Orfordness, excluding the FCO's transmitting station, to the National Trust. Under National Trust ownership, Orfordness renamed 'Orford Ness National Nature Reserve.' Plans to open to public.

6 June 1995: Orford Ness National Nature Reserve opened to public. National Trust provides tours of site including all but FCO transmitting station, which remains off limits.

1997: FCO transmitting station purchased by Merlin Communications International Ltd as part of privatization of all $\mathrm{BBC}$ transmitting stations. Merlin Communications 
International Ltd purchased by VT Group in 2001. UK Branch of VT Group purchased by Babcock International Group in 2010.

2010: Paddy Heazell publishes second public historical account of Cobra Mist in his book Most Secret: The Hidden History of Orford Ness.

March 2011: Last BBC broadcast transmitted from station.

May 2012-Present: Final transmission broadcasted from Babcock owned transmitting station from Radio Netherlands. Station goes silent. Still owned by Babcock International Group, but no activity at site since May 2012. Building and surrounding property, privately owned, remain inaccessible to public and National Trust. The remnants of the site, visible from the publicly accessible side of Orfordness, are shown to visitors from a distance, on certain National Trust tours, where they can learn about the history of Orfordness and Cobra Mist. 


\section{References}

Abbott, Andrew. 2001. Time Matters: On Theory and Method. Chicago: University of Chicago Press.

Abrams, Philip. 1982. Historical Sociology. New York: Cornell University Press.

Abrams, Philip. 1988. 'Notes on the Difficulty of Studying the State (1977).' Journal of Historical Sociology 1(1):58-89.

Adler, Patricia A. and Peter Callero. 1987. Membership Roles in Field Research. Thousand Oaks: Sage.

Adut, Ari. 2009. On Scandal: Moral Disturbances in Society, Politics, and Art. New York: Cambridge University Press.

Aldrich, Richard J. 2003. The Hidden Hand. Woodstock: Overlook Books.

Aldrich, Richard J. (Richard James). 2010. GCHQ: The Uncensored Story of Britain's Most Secret Intelligence Agency. London: Harper Press.

Alexander, Jeffrey C. 1990. 'Culture and Political Crisis: "Watergate" and Durkheimian Sociology.' Pp. 187-224 in Durkheimian Sociology: Cultural Studies, edited by Alexander, Jeffrey C. New York: Cambridge University Press.

Alexander, Jeffrey C. and Philip Smith. 1993. 'The Discourse of American Civil Society: A New Proposal for Cultural Studies.' Theory and Society 22(2):151-207.

Aradau, Claudia. 'Security that Matters: Critical Infrastructure and Objects of Protection.' Security Dialogue 41(5):491-514.

Arendt, Hannah. 2001. Crises Of The Republic. New York: Houghton Mifflin Harcourt.

Bachrach, Peter and Morton S. Baratz. 1962. 'Two faces of power.' American Political Science Review 56(4):947-952.

Bail, Christopher A. 2015. 'The Public Life of Secrets: Deception, Disclosure, and Discursive Framing in the Policy Process.' Sociological Theory 33(2):97-124.

Baker, Keith. 1994. 'A Foucauldian French Revolution?' In Foucault and the Writing of History, edited by K. Goldstein. Cambridge: Blackwell Publishing.

Baker, Wayne E. and Robert R. Faulkner. 1993. 'The Social Organization of Conspiracy: Illegal Networks in the Heavy Electrical Equipment Industry.' American Sociological Review 58(6):837-860.

Barnes, John Arundel. 1994. A Pack of Lies: Towards a Sociology of Lying. New York: Cambridge University Press.

Bartelson, Jens. 1995. A Genealogy of Sovereignty. New York: Cambridge University Press.

Bartelson, Jens. 1998. 'Second Natures: Is the State Identical with Itself?' European Journal of International Relations 4(3):295-326.

Bartelson, Jens. 2001. The Critique of the State. New York: Cambridge University Press.

Becker, Jasper. 1996. Hungry Ghosts: China's Secret Famine. New York: Holt.

Benjamin, Walter. 1998. The Origin of German Tragic Drama. New York: Verso.

Berger, Peter L. 1963. Invitation to Sociology: A Humanistic Perspective. New York: Open Road Media.

Best, Jacqueline and William Walters. 2013. 'Translating the Sociology of Translation.' International Political Sociology 7(3):345-349.

Bevir, Mark. 2010. 'Rethinking Governmentality: Towards Genealogies of Governance.' European Journal of Social Theory 13(4):423-441. 
Bialasiewicz, Luiza, David Campbell, Stuart Campbell, Stephen Graham, Alex Jeffrey, and Alison J. Williams. 2007. 'Performing Security: The Imaginative Geographies of Current US Strategy.' Political Geography 26(4):405-422.

Bigo, Didier. 2002. 'Security and Immigration: Toward a Critique of the Governmentality of Unease.' Alternatives: Global, Local, Political 27(1):63-92.

Bigo, Didier. 2006. 'Globalized (In)Security: The Field and the Ban-Opticon." Pp. 5-49 in Illiberal Practices of Liberal Regimes: The (In) Security Games, edited by D. Bigo and A. Tsoukala. Paris: L'Harmattan.

Birchall, Claire. 2006. Knowledge Goes Pop: From Conspiracy to Gossip. New York: Berg.

Birchall, Clare. 2011. "There's Been Too Much Secrecy in This City": The False Choice between Secrecy and Transparency in US Politics.' Cultural Politics 7(1):133-56.

Bok, Sissela. 1989. Secrets: On the Ethics of Concealment and Revelation. New York: Vintage.

Bok, Sissela. 1999. Lying: Moral Choice in Public and Private Life. New York: Vintage.

Boltanski, Luc. 2014. Mysteries and Conspiracies: Detective Stories, Spy Novels and the Making of Modern Societies. Malden: Polity.

Bond Jr, Charles and Ahmet Uysal. 2007. 'On Lie Detection "Wizards." Law and Human Behavior 31(1):109-15.

Bourdieu, Pierre. 1977. Outline of a Theory of Practice. Cambridge: Cambridge University Press.

Bourne, Mike. 2012a. 'Guns Don't Kill People, Cyborgs Do: A Latourian Provocation for Transformatory Arms Control and Disarmament.' Global Change, Peace \& Security 24(1):141-63.

Boyer, Steven D. 2007. 'The Logic of Mystery.' Religious Studies 43(1):89-102.

Bratich, Jack. 2006. 'Public Secrecy and Immanent Security: A Strategic Analysis.' Cultural Studies 20(4-5):493-511.

Butler, Judith. 1990. Gender Trouble: Feminism and the Subversion of Identity. New York: Routledge.

Callero, Peter L. 2003. 'The Sociology of the Self.' Annual Review of Sociology 29:11533.

Campbell, David. 1992. Writing Security: United States Foreign Policy and the Politics of Identity. Minneapolis: University of Minnesota Press.

Canetti, Elias. 1978. Crowds and Power. New York: Continuum.

Carpenter, Daniel. 2012. Reputation and Power: Organizational Image and Pharmaceutical Regulation at the FDA. New Jersey: Princeton University Press.

Chambers, Simone. 2004. 'Behind Closed Doors: Publicity, Secrecy, and the Quality of Deliberation.' Journal of Political Philosophy 12(4):389-410.

Christensen, Lars Thoger and Joep Cornelissen. 2015. 'Organizational Transparency as Myth and Metaphor.' European Journal of Social Theory 18(2):132-149.

Clayman, Steven E. and Ann Reisner. 1998. 'Gatekeeping in action: Editorial Conferences and Assessments of Newsworthiness.' American Sociological Review 63(2):178-199.

Colwell, Chaunsey. 1997. 'Deleuze and Foucault: Series, Event, Genealogy.' Theory \& Event 1(2):n.p. 
Compton-Lilly, Catherine. 2013. 'Case Studies.' Pp. 54-65 in Reviewing Qualitative Research in the Social Sciences, edited by A. Trainor and E. Graue. New York: Routledge.

Coser, Lewis A. 1963. 'The Dysfunctions of Military Secrecy.' Social Problems 11(1) $13-22$.

Costas, Jana and Christopher Grey. 2014. 'Bringing Secrecy into the Open: Towards a Theorization of the Social Processes of Organizational Secrecy.' Organization Studies Online First.

Curtis, Bruce. 1995. 'Taking the State Back Out: Rose and Miller on Political Power.' The British Journal of Sociology 46(4):575-589.

Curtis, Bruce. 2004. 'Reading Reflexively: The 2003 Porter Lecture.' Journal of Historical Sociology 17(2-3):240-264.

Davidson, Arnold Ira. 1997. Foucault and His Interlocutors. Chicago: University of Chicago Press.

Davis, Sophia. 2008. 'Cultural Geographies in Practice Military Landscapes and Secret Science: The Case of Orford Ness.' Cultural Geographies 15(1):143-149.

Dean, Jodi. 2001. 'Publicity's Secret.' Political Theory 29(5):624-650.

Dean, Mitchell. 2010. Governmentality: Power and Rule in Modern Society. Thousand Oaks: Sage.

Deleuze, Gilles. 1992. 'Postscript on the Societies of Control.' October 59:3-7.

Deleuze, Gilles and Félix Guattari. 1988. A Thousand Plateaus: Capitalism and Schizophrenia. Minneapolis: University of Minnesota Press.

East Anglian Daily Times. 1967. 'Orfordness Site for Radio Station.' East Anglian Daily Times, August 25. Ipswich: Suffolk Public Records Office.

East Anglian Daily Times. 1973a. 'No Early Warning.' East Anglian Daily Times, June 30. Ipswich: Suffolk Public Records Office.

East Anglian Daily Times. 1973b. 'Scientists Protest-MP "Staggered"; Fury over U.S. Closure of Suffolk Secret Base; Short and Mysterious Life of 'Cobra Mist."' East Anglian Daily Times, June 30. Ipswich: Suffolk Public Records Office.

Ekman, Paul. 2009. Telling Lies: Clues to Deceit in the Marketplace, Politics, and Marriage. New York: W. W. Norton \& Company.

Elias, Norbert. 1978. What is Sociology? New York: Columbia University Press.

Ellsberg, Daniel. 2003. Secrets: A Memoir of Vietnam and the Pentagon Papers. New York: Penguin.

Ellsberg, Daniel. 2010. 'Secrecy and National Security Whistleblowing.' Social Research 77(3):773-804.

Fenster, Mark. 1999. Conspiracy Theories: Secrecy and Power in American Culture. Minneapolis: University of Minnesota Press.

Flintham, Matthew. 2012. 'The Military-Pastoral Complex: Contemporary Representations of Militarism in the Landscape.' Tate Online Research Papers (17).

Flint, Ray. 2005. 'Cobra Mist (Orfordness).' Retrieved January 22, 2015 (http://web.archive.org/web/20080704074415/http://www.users.zetnet.co.uk/Ray. Flint/cobra/cm.htm).

Flynn, Kathryn. 2006. 'Covert disclosures: Unauthorized Leaking, Public Officials and the Public Sphere.' Journalism Studies 7(2):256-273. 
Flyvbjerg, Bent. 2001. Making Social Science Matter: Why Social Inquiry Fails and How It Can Succeed Again. Cambridge: Cambridge University Press.

Foucault, Michel. 1972. Archaeology of Knowledge. New York: Routledge.

Foucault, Michel. 1977. Discipline and Punish: The Birth of the Prison. New York: Vintage Books.

Foucault, Michel. 1980. 'Two Lectures, Lecture One: 7 January 1976.' Pp. 79-108 in Power/Knowledge, edited by C. Gordon. New York: Pantheon Press.

Foucault, Michel. 1994. Birth of the Clinic, The: An Archaeology of Medical Perception. New York: Vintage.

Foucault, Michel. 2009. Security, Territory, Population: Lectures at the Collège de France 1977-1978, edited by M. Senellart, F. Ewald, and A. Fontana. New York: St Martins Press.

Foucault, Michel. 2012. The History of Sexuality: An Introduction. Toronto: Random House.

Fowle, Evert, E. Key, R. Bodei, and R. Sear. 1979. The Enigma of the AN/FPS-95 OTH Radar. Bedford, Massachusetts: The MITRE Corporation. Retrieved June 27, 2015 (http://www.hpcc.ecs.soton.ac.uk/ dan/talks/DarkSideOfTheMoon/FPS95_enigma_complete3.pdf).

Fridman, Daniel. 2014. 'Resisting the Lure of the Paycheck: Freedom and Dependence in Financial Self-Help.' Foucault Studies 18:90-112.

Galison, Peter. 2004. 'Removing Knowledge.' Critical Inquiry 31(1):229-243.

Galison, Peter. 2010. 'Secrecy in Three Acts.' Social Research: An International Quarterly 77(3):941-974.

Garland, David. 1997. "Governmentality" and the Problem of Crime: Foucault, Criminology, Sociology.' Theoretical Criminology 1(2):173-214.

Gibson, David R. 2014. 'Enduring Illusions The Social Organization of Secrecy and Deception.' Sociological Theory 32(4):283-306.

Giddens, Anthony. 1981. A Contemporary Critique of Historical Materialism. California: University of California Press.

Gill, Peter. 2006. 'Not Just Joining the Dots But Crossing the Borders and Bridging the Voids: Constructing Security Networks after 11 September 2001.'Policing and Society 16(1):27-49.

Glaeser, Andreas. 2011. Political Epistemics: The Secret Police, the Opposition, and the End of East German Socialism. Chicago: University of Chicago Press.

Glenney IV, William. 2009. 'Military Deception in the Information Age.' Pp. 254-74 in Deception: From Ancient Empires to Internet Dating, edited by B. Harrington. Stanford: Stanford University Press.

Goffman, Erving. 1959. The Presentation of Self in Everyday Life. New York: Anchor Books.

Goffman, Erving. 1961. Asylums: Essays on the Social Situation of Mental Patients and Other Inmates. New Jersey: Transaction Publishers.

Goffman, Erving. 1969. Strategic Interaction. Pennsylvania: University of Pennsylvania Press.

Goffman, Erving. 1986. Frame Analysis: An Essay on the Organization of Experience. Boston: Northeastern University Press. 
Gross, Neil. 2009. Richard Rorty: The Making of an American Philosopher. Chicago: University of Chicago Press.

Habermas, Jürgen. 1991. The Structural Transformation of the Public Sphere: An Inquiry Into a Category of Bourgeois Society. Massachusetts: MIT Press.

Hacking, Ian. 2004. 'Between Michel Foucault and Erving Goffman: Between Discourse in the Abstract and Face-to-Face Interaction.' Economy and Society 33(3):277302.

Haraway, Donna. 1988. 'Situated Knowledges: The Science Question in Feminism and the Privilege of Partial Perspective.' Feminist Studies 14(3):575-99.

Harrington, Brooke, ed. 2009. Deception: From Ancient Empires to Internet Dating. California: Stanford University Press.

Hay, Colin. 2014. "Neither Real nor Fictitious but 'as If Real'? A Political Ontology of the State." The British Journal of Sociology 65(3):459-80.

Hazelrigg, Lawrence E. 1969. "A Reexamination of Simmel's 'The Secret and the Secret Society': Nine Propositions." Social Forces 47(3):323-30.

Heazell, Paddy. 2011. Most Secret: The Hidden History of Orford Ness. The History Press.

Hennessy, Peter. 2012. "The Less Secret State." History Today, October. Retrieved January 29, 2015 (http://www.historytoday.com/peter-hennessy/less-secret-state).

Herzfeld, Michael. 2009. 'The Performance of Secrecy: Domesticity and Privacy in Public Spaces.' Semiotica 175:135-162.

Horn, Eva. 2003. 'Knowing the Enemy: The Epistemology of Secret Intelligence.' Grey Room (11):59-85.

Horn, Eva. 2011. 'Logics of Political Secrecy.' Theory, Culture \& Society 28(7-8):10322.

Irvine, A. J. 1973. 'Orford Ness Monster.' East Anglian Daily Times, June 3. Ipswich: Suffolk Public Records Office.

Jerolmack, Colin and Iddo Tavory. 2014. 'Molds and Totems Nonhumans and the Constitution of the Social Self.' Sociological Theory 32(1):64-77.

Jessop, Bob. 1990. State Theory: Putting the Capitalist State in Its Place. Penn State Press.

Kinsey, Gordon. 1981. Orfordness--Secret Site: A History of the Establishment 19151980. Suffolk: Terence Dalton Limited.

$\mathrm{Ku}$, Agnes S. 1998. 'Boundary Politics in the Public Sphere: Openness, Secrecy, and Leak.' Sociological Theory 16(2):172-92.

Laclau, Ernesto and Chantal Mouffe. 2001. Hegemony and Socialist Strategy: Towards a Radical Democratic Politics. New York: Verso.

Larner, Wendy and William Walters, eds. 2004. Global Governmentality: Governing International Spaces. New York: Routledge.

Latour, Bruno. 1987. Science in Action: How to Follow Scientists and Engineers through Society. Cambridge: Harvard University Press.

Latour, Bruno. 2005. Reassembling the Social: An Introduction to Actor-NetworkTheory. New York: Oxford University Press.

Latour, Bruno. 2013. An Inquiry into Modes of Existence: An Anthropology of the Moderns. Cambridge: Harvard University Press. 
Law, John. 2009. 'Actor Network Theory and Material Semiotics.' Pp. 145-58 in The New Blackwell Companion to Social Theory, edited by T. B. Malden: Blackwell Publishing.

Law, John and Michel Callon. 1988. 'Engineering and Sociology in a Military Aircraft Project: A Network Analysis of Technological Change.' Social Problems 35(3):284-97.

Law, John and John Urry. 2004. 'Enacting the Social.' Economy and Society 33(3):390410.

Littrell, W. Boyd. 1973. 'Vagueness, Social Structure, and Social Research in Law.' Social Problems 21(1):38-52.

Lowry, Ritchie P. 1971. 'Toward a Sociology of Secrecy and Security Systems.' Social Problems 19:437.

Lukes, Steven. 1974. Power: A Radical View. Macmillan: London.

Lutz, Catherine and Geoffrey M. White. 1986. 'The Anthropology of Emotions.' Annual Review of Anthropology 15(1):405-36.

Machiavelli, Niccolò. 1998. The Prince. Chicago: University of Chicago Press.

Manley, Andrew, Catherin Palmer, and Martin Roderick. 2012. 'Disciplinary Power, the Oligopticon and Rhizomatic Surveillance in Elite Sports Academies.' Surveillance \& Society. 10(3/4):303-19.

Marion, Jean-Luc. 2002. In Excess: Studies of Saturated Phenomena. Bronx: Fordham University Press.

Marx, Gary T. and Glenn W. Muschert. 2009. 'Simmel on Secrecy: A Legacy and Inheritance for the Sociology of Information.' Pp. 217-33 in Soziologie als Möglichkeit [The Possibility of Sociology: 100 Years of Georg Simmel's Investigations into the Forms of Social Organization], edited by C. Rol and C. Papilloud. Wiesbaden: VS Verlag für Sozialwissenschaften.

Masco, Joseph. 2002. 'Lie Detectors: On Secrets and Hypersecurity in Los Alamos.' Public Culture 14(3):441-467.

Mearsheimer, John J. 2011. Why Leaders Lie: The Truth about Lying in International Politics. New York: Oxford University Press.

Melley, Timothy. 2012. The Covert Sphere: Secrecy, Fiction, and the National Security State. New York: Cornell University Press.

Merton, Robert K. 1940. 'Bureaucratic Structure and Personality.' Social Forces 18(4):560-568.

Ministry of Defence. 1966. 'United States-United Kingdom Cooperation in System 441A.' T 225/4385. United Kingdom: National Archives.

Ministry of Defence. 1967. 'Joint Radio Research Station.' AIR 12/12210. United Kingdom: National Archives.

Ministry of Defence. 1968a. 'Letter to A.M. Palliser Esq., CMG. from A.R. Dobson, April 9.' PREM 13/2001. United Kingdom: National Archives.

Ministry of Defence. 1968b. 'Orfordness.' AIR 20/12210. London: National Archives.

Ministry of Defence. 1968c. 'SENTINEL FAN and the Daily Mail.' DEFE 31/16. United Kingdom: National Archives.

Ministry of Defence. 1968d. 'Sentinel Fan--Breach of Security.' DEFE 31/16. United Kingdom: National Archives. 
Ministry of Defence. 1968e. 'Sentinel Fan--Breach of Security in Press Articles?' DEFE 31/16. United Kingdom: National Archives.

Ministry of Defence. 1968f. 'Sentinel Fan--Breach of Security in Press Articles.' DEFE 31/16. United Kingdom: National Archives.

Ministry of Defence. 1971a. 'Cobra Mist.' AIR 2/18799. United Kingdom: National Archives.

Ministry of Defence. 1971b. 'Cobra Mist.' AIR 2/18764. United Kingdom: National Archives.

Ministry of Defence. 1971c. 'Cobra Mist: Breach of Cover Story.' AIR 20/12210. United Kingdom: National Archives.

Ministry of Defence. 1971d. 'Cobra Mist: Breach of Cover Story.' AIR 20/12471. United Kingdom: National Archives.

Ministry of Defence. 1971e. 'Cobra Mist Security Classification.' AIR 20/12471. United Kingdom: National Archives.

Ministry of Defence. 1971f. 'Project Backscratch.' AIR 20/12471. United Kingdom: National Archives.

Ministry of Defence. 1972. 'Cobra Mist. Future Policy Following the Salt Agreement.' AIR 20/12471. United Kingdom: National Archives.

Ministry of Defence. 1973a. 'Cobra Mist.' AIR 2/18797. United Kingdom: National Archives.

Ministry of Defence. 1973b. 'Cobra Mist.' AIR 2/19001. United Kingdom: National Archives.

Ministry of Defence. 1973c. The Report of the US-UK Cobra Mist Scientific Assessment Committee Part 1. Ministry of Defence. DEFE 19/100. United Kingdom: National Archives.

Mitchell, Timothy. 1991. 'The Limits of the State: Beyond Statist Approaches and Their Critics.' The American Political Science Review 85(1):77-96.

Mol, Annemarie. 2002. The Body Multiple: Ontology in Medical Practice. Durham: Duke University Press.

Moran, Christopher. 2012. Classified: Secrecy and the State in Modern Britain. Cambridge: Cambridge University Press.

Morselli, Carlo and Cynthia Giguere. 2006. 'Legitimate Strengths in Criminal Networks.' Crime, Law and Social Change 45(3):185-200.

Moynihan, Daniel Patrick. 1998. Secrecy: The American Experience. New Haven: Yale University Press.

Negrine, Ralph. 2008. The Transformation of Political Communication: Continuities and Changes in Media and Politics. New York: Palgrave Macmillan.

Neocleous, Mark. 2002. "Privacy, Secrecy, Idiocy." Social Research 69(1):85-110.

Nietzsche, Friedrich. 1997. Nietzsche: Untimely Meditations. Cambridge: Cambridge University Press.

Nietzsche, Friedrich. 2011. The Will to Power. New York: Knopf Doubleday Publishing Group.

Orwell, George. 1949. Nineteen Eighty-Four. London: Secker and Warburg.

Paglen, Trevor. 2010a. 'Goatsucker: Toward a Spatial Theory of State Secrecy.' Environment and Planning D: Society and Space 28(5):759-771. 
Paglen, Trevor. 2010b. I Could Tell You But Then You Would Have to Be Destroyed By Me: Emblems from the Pentagon's Black World. Brooklyn: Melville House.

Passoth, Jan-Hendrik and Nicholas J. Rowland. 2010. 'Actor-Network State Integrating Actor-Network Theory and State Theory.' International Sociology 25(6):818841.

Perkins, Chris and Martin Dodge. 2009. 'Satellite Imagery and the Spectacle of Secret Spaces.' Geoforum 40(4):546-560.

Piché, Justin. 2012. 'Access the State of Imprisonment in Canada: Information Barriers and Negotiation Strategies.' Pp. 234-59 in Brokering Access: Power, Politics, and Freedom of Information Process in Canada, edited by M. Larsen and K. Walby. UBC Press.

Pincher, Chapman. 1969. 'A British Base for Those Spies in the Sky?' Daily Express, May 9. London: British Library Archives.

Pincher, Chapman. 1971. “'CIA in Britain” Row.' Daily Express, June 1. London: British Library Archives.

Pozen, David E. 2009. 'Deep Secrecy.' Stanford Law Review 62(2):257-399.

Prior, Lindsay. 2008. 'Repositioning Documents in Social Research.' Sociology 42(5):821-836.

Rappert, Brian. 2012. 'States of Ignorance: The Unmaking and Remaking of Death Tolls.' Economy and Society 41(1):42-63.

Reich, Zvi. 'The Anatomy of Leaks Tracing the Path of Unauthorized Disclosure in the Israeli Press.' Journalism 9(5):555-581.

Rigney, Daniel. 1979. 'Secrecy and Social Cohesion.' Society 16(4):52-55.

Roberts, Simon. 2008. 'D-Notices - UK's Defence Self Censorship System.' Retrieved June 10, 2015 (http://www.defenceviewpoints.co.uk/articles-and-analysis/dnotices-uk-s-defence-self-censorship-system).

Rosanvallon, Pierre. 2008. Counter-Democracy: Politics in an Age of Distrust. Cambridge: Cambridge University Press.

Rose, Nikolas. 1999. Powers of Freedom: Reframing Political Thought. Cambridge: Cambridge University Press.

Rose, Nikolas and Peter Miller. 1992. 'Political Power beyond the State: Problematics of Government.' The British Journal of Sociology 43(2):173-205.

Rourke, Francis E. 1957. 'Secrecy in American Bureaucracy.' Political Science Quarterly 540-564.

Russell, James A. and José Miguel Fernández-Dols. 1997. The Psychology of Facial Expression. Cambridge: Cambridge University Press.

Ryan, Dan. 2006. 'Getting the Word Out: Notes on the Social Organization of Notification.' Sociological Theory 24(3):228-254.

Saar, Martin. 2002. 'Genealogy and Subjectivity.' European Journal of Philosophy 10(2):231-45.

Sagar, Rahul. 2013. Secrets and Leaks: The Dilemma of State Secrecy. New Jersey: Princeton University Press.

Sawyer, R. Keith. 2002. 'A Discourse on Discourse: An Archeological History of an Intellectual Concept.' Cultural studies 16(3):433-456.

Schudson, Michael. 1993. Watergate in American Memory: How We Remember, Forget, and Reconstruct the Past. New York: BasicBooks. 
Shauer, Frederick and Richard Zeckhauser. 2009. 'Paltering.' Pp. 38-54 in Deception: From Ancient Empires to Internet Dating, edited by B. Harrington. Stanford: Stanford University Press.

Shils, Edward. 1996. The Torment of Secrecy: The Background and Consequences of American Security Policies. Chicago: Ivan R. Dee, Inc.

Silver, Alexander et al. 2010. 'Top 10 Weird Government Secrets.' Time. Retrieved 22 June 2015 (http://content.time.com/time/specials/packages/completelist/0,29569,2 008962,00.html).

Simmel, Georg. 1906. 'The Sociology of Secrecy and of Secret Societies.' The American Journal of Sociology 11(4):441-498.

Sjoberg, Gideon and Paula Jean Miller. 1973. 'Social Research on Bureaucracy: Limitations and Opportunities.' Social Problems 21(1):129-143.

Stake, Robert E. 1995. The Art of Case Study Research. Thousand Oaks: Sage.

Star, Susan Leigh and James R. Griesemer. 1989. 'Institutional Ecology, "Translations" and Boundary Objects: Amateurs and Professionals in Berkeley's Museum of Vertebrate Zoology, 1907-39.' Social Studies of Science 19(3):387-420.

Tamboukou, Maria. 1999. 'Writing Genealogies: An Exploration of Foucault's Strategies for Doing Research.' Discourse: Studies in the Cultural Politics of Education 20(2):201-217.

Taussig, Michael T. 1999. Defacement: Public Secrecy and the Labor of the Negative. Stanford: Stanford University Press.

Tefft, Stanton K. 1980. Secrecy, A Cross-Cultural Perspective. New York: Human Sciences Press.

Thomason, J. F. 2003. 'Development of Over-the-Horizon Radar in the United States.' Pp. 599-601 in Radar Conference, 2003. Proceedings of the International.

Thompson, Dennis F. 1999. 'Democratic Secrecy.' Political Science Quarterly 114(2):181-93.

Thompson, John B. 2000. Political Scandal: Power and Visibility in the Media Age. Malden: Polity.

Timmermans, Stefan and Iddo Tavory. 2012. 'Theory Construction in Qualitative Research: From Grounded Theory to Abductive Analysis.' Sociological Theory 30(3):167-186.

Tonkiss, Cleare. 2004. 'Analysing Text and Speech: Content and Discourse Analysis.' Pp. 85-98 in Researching Society and Culture, edited by C. Seale. Thousand Oaks: Sage.

Tsoukas, Haridimos and Christian Knudsen. 2005. 'Introduction: The Need for MetaTheoretical Reflection in Organization Theory.' Pp. 1-38 in The Oxford Handbook of Organization Theory, edited by H. Tsoukas and C. Knudsen. New York: Oxford University Press.

United States Air Force. 1971. 'Cobra Mist Security Classification.' AIR 20/12471. United Kingdom: National Archives.

Urry, John. 2007. Mobilities. Malden: Polity.

Valverde, Mariana. 2006. 'The Sociology of Law as a "Means Against Struggle Itself.", Social \& Legal Studies 15(4):591-97.

Vaughan, Diane. 1985. Controlling Unlawful Organizational Behavior: Social Structure and Corporate Misconduct. Chicago: University of Chicago Press. 
Vaughan, Diane. 1999. 'The Dark Side of Organizations: Mistake, Misconduct, and Disaster.' Annual Review of Sociology:271-305.

Vincent, David. 1998. The Culture of Secrecy: Britain, 1832-1998. Oxford University Press Oxford.

Wagner, Roy. 1984. 'Ritual as Communication: Order, Meaning, and Secrecy in Melanesian Initiation Rites.' Annual Review of Anthropology 13:143-55.

Walby, Kevin. 2012. Touching Encounters: Sex, Work, and Male-for-Male Internet Escorting. Chicago: University of Chicago Press.

Walby, Kevin and Mike Larsen. 2012. 'Access to Information and Freedom of Information Requests Neglected Means of Data Production in the Social Sciences.' Qualitative Inquiry 18(1):31-42.

Walsh, John and Steven High. 1999. 'Re-thinking the Concept of "Community".' Social History / Histoire Sociale 32(64):255-274

Walters, William. 2009. 'Anti-Political Economy: Cartographies of "Illegal Immigration" and the Displacement of the Economy.' Pp. 113-38 in Cultural Political Economy, edited by J. Best and M. Paterson. London: Routledge.

Walters, William. 2012. Governmentality: Critical Encounters. New York: Routledge.

Walters, William. 2014a. 'Drone Strikes, Dingpolitik and beyond: Furthering the Debate on Materiality and Security.' Security Dialogue 45(2):101-118.

Walters, William. 2014b. 'Parrhēsia Today: Drone Strikes, Fearless Speech and the Contentious Politics of Security.' Global Society 28(3):277-299.

Weber, Cynthia. 1998. 'Performative States.' Millennium-Journal of International Studies 27(1):77-95.

Weber, Max. 1946. From Max Weber: Essays in Sociology, Translated, Edited, and with an Introduction by H. H. Gerth and C. Wright Mills. New York: Oxford University Press.

Weiskopf, Richard and Hugh Willmott. 2013. 'Ethics as Critical Practice: The "Pentagon Papers," Deciding Responsibly, Truth-Telling, and the Unsettling of Organizational Morality.' Organization Studies 34(4):469-493.

Wilsnack, Richard W. 1980. 'Information Control: A Conceptual Framework for Sociological Analysis.' Journal of Contemporary Ethnography 8(4):467-499.

Woodward, Rachel. 2004. Military Geographies. Malden: Blackwell Publishing.

Zaret, David. 1996. 'Petitions and the 'Invention' of Public Opinion in the English Revolution.' American Journal of Sociology 101(6):1497-1555.

Zerubavel, Eviatar. 2006. The Elephant in the Room: Silence and Denial in Everyday Life. New York: Oxford University Press. 